NUREG/CR-6324

UCRL-ID-120056

\title{
Quality Assurance for Gamma Knives
}

Manuscript Completed: August 1995

Date Published: September 1995

Prepared by

E. D. Jones, W. W. Banks, L. E. Fischer

Lawrence Livermore National Laboratory

7000 East Avenue

Livermore, CA 94550

\section{Prepared for}

Division of Industrial and Medical Nuclear Safety

Office of Nuclear Material Safety and Safeguards

U.S. Nuclear Regulatory Commission

Washington, DC 20555-0001

NRC Job Code L1938 


\section{Disclaimer}

This document was prepared as an account of work sponsored by an agency of the United States Government. Neither the United States Government nor the University of California, nor any of their employees, makes any warranty, express or implied, or assumes any legal liability or responsibility for the accuracy, completeness, or usefulness of any information, apparatus, product, or process disclosed, or represents that its use would not infringe privately owned rights. Reference herein to any specific commercial product, process, or service by trade name, trademark, manufacturer, or otherwise, does not necessarily constitute or imply its endorsement, recommendation, or favoring by the United States Government or the University of California. The views and opinions of authors expressed herein do not necessarily state or reflect those of the United States Government or the University of California and shall not be used for advertising or product endorsement purposes.

This work was supported by the United States Nuclear Regulatory commission under a Memorandum of Understanding with the United States Department of Energy, and performed under the auspices of the U.S. Department of Energy by Lawrence Livermore National Laboratory under Contract W-7405-Eng-48. 


\section{DISCLAIMER}

Portions of this document may be illegible in electronic image products. Images are produced from the best available original document. 


\begin{abstract}
This report describes and summarizes the results of a quality assurance (QA) study of the Gamma Knife, a nuclear medical device used for the gamma irradiation of intracranial lesions. The study's focus was on the physical aspects of QA and did not address issues that are essentially medical, such as patient selection or prescription of dose. A risk-based QA assessment approach was used. In this report, sample programs for quality control and assurance are included.

The use of the Gamma Knife was found to conform to existing standards and guidelines concerning radiation safety and quality control of external beam therapies (shielding, safety reviews, radiation surveys, interlock systems, exposure monitoring, good medical physics practices, etc.) and to be compliant with NRC teletherapy regulations. There are, however, current practices for the Gamma Knife not covered by existing, formalized regulations, standards, or guidelines. These practices have been adopted by Gamma Knife users and continue to be developed with further experience. Some of these have appeared in publications or presentations and are slowly finding their way into recommendations of professional organizations.
\end{abstract}


$\left[\quad-{ }^{\prime}+\ldots\right.$ 


\section{TABLE OF CONTENTS}

Executive Summary .......................................................................................................................... vii

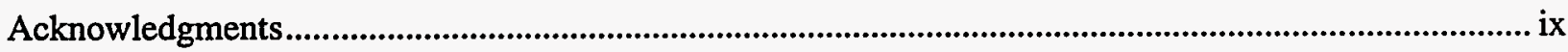

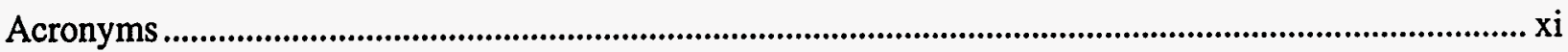

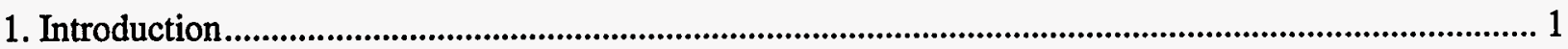

1.1 Background and Objectives ............................................................................................................. 1

1.2 Scope and Organization of Document ................................................................................... 1

2. Review of Relevant Regulations, ......................................................................................................... 5

3. Quality Assurance Assessment Process ............................................................................................. 9

4. Device Registration and Acceptance Testing …………….....................................................................13

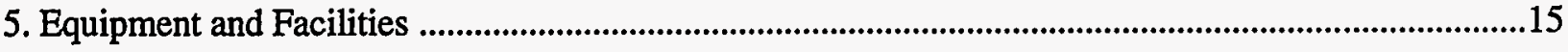

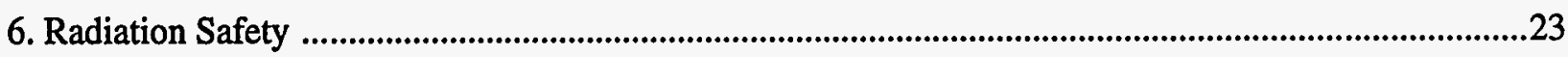

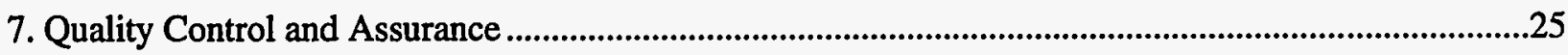

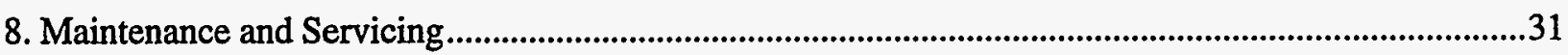

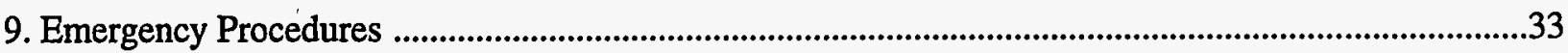

10. Computerized Treatment Planning System ........................................................................................35

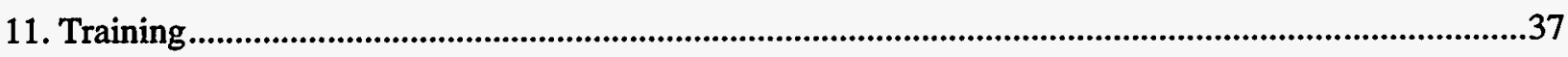

12. Summary of Regulatory Issues ................................................................................................

Bibliography .................................................................................................................................4

Appendix 'A: A Review of Relevant Regulations, Standards, and Guidelines ............................................53

Appendix B: Facilities and Equipment ...........................................................................................65

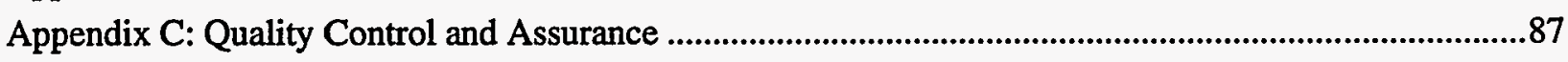

Appendix D: Examples of Written Emergency Procedures ................................................................... 121

Appendix E: Sample Facility Training Program ........................................................................................ 129

\section{FIGURES}

Figure 1-1. Steps in the quality assurance study...........................................................................2

Figure 3-1. Row diagram of major Gamma Knife treatment and quality assurance activities. ..................10

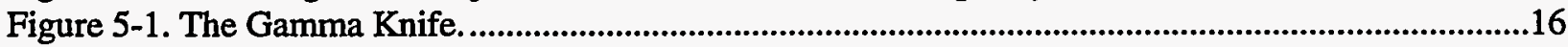

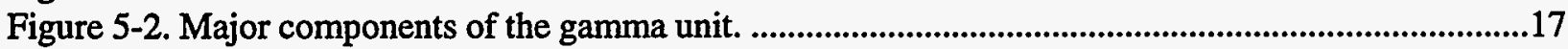

Figure 5-3. Major components of the radiation unit...................................................................................18

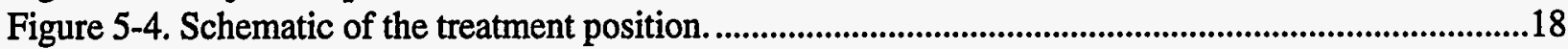

Figure 5-5. A typical Gamma Knife suite or treatment facility................................................................19

\section{TABLES}

Table 7-1. Quality control of Leksell Gamma Units compared to Cobalt-60 Teletherapy Units. ...............26

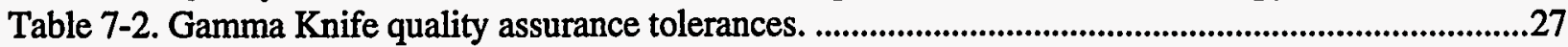

Table 7-3. Failure modes associated with the use of the Gamma Knife. ..............................................28 



\section{EXECUTIVE SUMMARY}

\section{Introduction}

This report describes and summarizes the results of a quality assurance (QA) study of a nuclear medical device, the Gamma Knife*, used for therapeutic irradiation of intracranial lesions. The work was performed by Lawrence Livermore National Laboratory for the U.S. Nuclear Regulatory Commission (NRC). The study's focus was on the QA of the physical aspects of the device, such as mechanical and electrical components, radiation dosimetry, and safety features. Medical QA issues, like patient selection or prescription of dose, were not addressed.

External beam radiation therapy has evolved to the development of the Gamma Knife, a gamma (cobalt$60)$ stereotactic radiosurgery device. Stereotactic radiosurgery is the use of external radiation in conjunction with a stereotactic guidance device to very precisely deliver a dose to intracranial tissue volumes. The Gamma Knife is a relatively new gamma therapy device, which was commercially introduced into the U.S. for medical treatments in 1987. Current NRC regulations address procedures for conventional cobalt- 60 teletherapy devices, but do not necessarily address appropriate or comparable procedures for the Gamma Knife. The NRC thus required a quality assurance study of the Gamma Knife to aid in updating teletherapy regulations to include aspects of Gamma Knife-type devices.

\section{Quality Assurance Assessment Approach}

The objectives of this study were to 1) review and analyze current regulations, consensus standards, and guidelines relevant to the safe use of the Gamma Knife-type devices, 2) identify quality assurance factors for Gamma Knife-type systems and components involved in safety, and 3) compare the findings to current NRC regulations and guidelines to identify any overlaps, gaps, or conflicts among existing regulations and current practices.

Five steps were used in the quality assurance assessment process:

1. A quality assurance study protocol was developed in conjunction with a review of relevant regulations, standards, and guidelines from regulatory and professional organizations.

2. The Gamma Knife facilities, equipment, functions, and operations were examined.

3. Quality assurance practices and procedures were identified.

4. Current Gamma Knife practices were compared to existing regulations and standards.

5. Findings were summarized.

Before beginning a quality assurance assessment of the Gamma Knife, device-relevant regulations, standards, and guidelines were reviewed. These included NRC teletherapy regulations and voluntary or consensus standards and guidelines produced by professional or medical organizations. Based on preliminary background research on Gamma Knife-type devices, a quality assurance study protocol was developed. The general areas covered by the protocol included:

- General information on standards or guidelines

- General quality assurance information

- Quality control

- Service and maintenance

\footnotetext{
* The Gamma Knife is a registered trademark of Elekta Instruments, Inc.
} 
- Computerized treatment planning system

- General and risk-related information

A multi-discipline team of physicians and medical physicists with expertise in teletherapy, and scientists and engineers with extensive knowledge of QA and safety analyses developed a data collection plan, based on the QA protocol, for examining Gamma Knife facilities, equipment, functions, and operations.

The collected data were used by the project team to identify quality assurance practices and procedures. These included device functional and acceptance tests; QA procedures for gamma unit physics; dosimetry and safety measures; pre-therapy performance checkouts; abnormal events during gamma unit operations; emergency procedures; and maintenance and servicing. The observations were verified, refined, and validated by Gamma Knife experts. The products of the analysis were quality assurance factors for systems and components involved in safety and data on important QA elements and their tolerances.

The last step of the QA assessment was to compare the QA practices and procedures to existing NRC regulations and consensus standards and guidelines.

\section{Conclusions and Recommendations}

It was found that the use of the Gamma Knife conforms to existing standards and guidelines concerning radiation safety and quality control of external beam therapies and complies with NRC teletherapy regulations.

Key findings for the quality assurance of the use of Gamma Knives are summarized in this report under these topics:

- Device registration and acceptance testing

- Equipment and facilities

- Radiation safety

- Quality control and assurance

- Maintenance and servicing

- Emergency procedures

- Computerized treatment planning system

- Training

There are, however, some current practices for the Gamma Knife not covered by existing, formalized regulations, standards, or guidelines. These practices have been adopted by Gamma Knife users and continue to be developed with further experience. Some of these have appeared in publications or presentations and are slowly finding their way into recommendations of professional societies.

The results of this study suggest several model quality assurance practices and procedures. Examples of these are contained in the main text along with sample QA protocols in the appendices. Also contained in the report are specific suggested changes to current NRC teletherapy regulations and guidelines to address specific QA issues concerning the Gamma Knife. 


\section{ACKNOWLEDGMENTS}

This work was sponsored by the U.S. Nuclear Regulatory Commission, Office of Nuclear Material Safety and Safeguards, Division of Industrial and Medical Nuclear Safety. The Technical Monitor was Dr.

Patricia Rathbun who made significant contributions to the project team's efforts with her insights, ideas, experience, guidance, and management skills.

Several professional people provided help, support, and cooperation in the conduct of this project. Elekta Instruments, in particular, Richard Grome, Hans Sundquist, and Martin Knotts, extended extraordinary time and effort in cooperating with this project. Our primary consultants, Dr. David Larson and Dr. John Lyman, were technically excellent and refreshingly candid in their comments and suggestions. We would also like to thank the Radiation Oncology staff at the University of California, San Francisco, especially Dr. Lynn Verhey and Dr. Vernon Smith, for responding to our questions and arranging visits to their Gamma Knife facility. Other selected Gamma Knife users whose experiences were invaluable to our study included Dr. Brian Copcutt, Dr. Harold Berk, Dr. L. Dade Lunsford, Dr. Ladislau Steiner, Dr. Andrew Wu, and Ann Maitz. George Simion and James Tortorelli, from INEL, were helpful in sharing quality assurance information and experiences with brachytherapy remote afterloaders. 
$\ldots \ldots \ldots-\ldots \ldots \ldots$ 


\section{ACRONYMS}

\begin{tabular}{|c|c|}
\hline AANS & American Association of Neurosurgeons \\
\hline AAPM & American Association of Physicists in Medicine \\
\hline ACR & American College of Radiology \\
\hline ANSI & American National Standards Institute \\
\hline ASTRO & American Society of Therapy, Radiology, and Oncology \\
\hline AVMs & Arteriovenous Malformations \\
\hline $\mathrm{CT}$ & Computed Tomography \\
\hline CTPS & Computerized Treatment Planning System \\
\hline FDA & Food and Drug Administration \\
\hline HIMA & Health Industry Manufacturers Association \\
\hline HPA & Hospital Physicists Association \\
\hline HRA & Human Reliability Analysis \\
\hline IAEA & International Atomic Energy Agency \\
\hline ICRP & International Commission on Radiological Protection \\
\hline ICRP & International Commission on Radiological Protection \\
\hline ICRU & International Commission on Radiation Units and Measurement \\
\hline IEC & International Electrotechnical Commission \\
\hline INEL & Idaho National Engineering Laboratory \\
\hline IPSM & Institute of Physical Sciences in Medicine \\
\hline ISRS & International Stereotactic Radiosurgery Society \\
\hline LLNL & Lawrence Livermore National Laboratory \\
\hline MRI & Magnetic Resonance Imaging \\
\hline NCRP & National Council on Radiation Protection and Measurement \\
\hline NEMA & National Electrical Manufacturers Association \\
\hline NIST & National Institute of Standards and Technology \\
\hline NMSS & NRC Office of Nuclear Material Safety and Safeguards \\
\hline NRC & Nuclear Regulatory Commission \\
\hline PMA & Pre-Market Approval \\
\hline PRA & Probabilistic Risk Analysis \\
\hline
\end{tabular}


Quality Assurance for Gamma Knives

QC

Quality Control

QM

Quality Management

RSC

Radiation Safety Committee

UCLA University of California at Los Angeles

UCSF

University of California at San Francisco 


\section{INTRODUCTION}

\subsection{Background and Objectives}

This report describes and summarizes the results of a quality assurance (QA) study of a nuclear medical device, the Gamma Knife*, used for the gamma irradiation of intracranial lesions. The study's focus was on the physical aspects of QA and did not attempt to address issues that are essentially medical, such as patient selection or prescription of dose. While it is recognized that physical and medical quality assurance are intertwined, this study only examined physical aspects of QA in a narrow sense.

Radiation therapy has become one of the major methods of treatment in the management of cancer and other tumorous diseases. The objective of conventional radiation therapy using a teletherapy sealed source is to deliver a precisely measured dose of radiation to a defined tissue volume. External beam radiation therapy has evolved to the development of the Gamma Knife, a gamma (cobalt-60) stereotactic radiosurgery device. Stereotactic radiosurgery is the use of external radiation in conjunction with a stereotactic guidance device to very precisely deliver a dose to intracranial tissue volumes, such as brain tumors and arteriovenous malformations. Gamma Knife radiosurgery involves closed-skull, single-treatment session irradiation of a lesion by 201 stationary cobalt- 60 sources ( 6600 Curies) geometrically arranged to converge into a dose volume. The Gamma Knife is a relatively new gamma therapy device, which was commercially introduced into the U.S. for medical treatments in 1987.

The U. S. Nuclear Regulatory Commission (NRC) has the authority to regulate the medical use of nuclear byproduct material-or radiation from byproduct material-to protect the health and safety of patients, while recognizing that physicians have the primary responsibility for the protection of their patients. Current NRC regulations-Title 10 of the Code of Federal

* The Gamma Knife is a registered trademark of Elekta Instruments, Inc.
Regulations, Part 35 (10 CFR Part 35)-address procedures for conventional cobalt- 60 teletherapy devices (Subpart I), but do not necessarily address appropriate or comparable procedures for the Gamma Knife. Also, reports received by the NRC indicate there are some cases of teletherapy misadministrations with other cobalt- 60 devices that have resulted from equipment malfunctions or human errors in treatment planning, dose calculations, and measurements. It is reasonable to project that comparable events may occur with Gamma Knives. The NRC thus required a quality assurance study of the Gamma Knife to potentially aid the updating of teletherapy regulations to include aspects of Gamma Knifetype devices.

The NRC Office of Nuclear Material Safety and Safeguards (NMSS) instructed the Fission Energy and Systems Safety Program of Lawrence Livermore National Laboratory (LLNL) to examine quality assurance practices and procedures for the Gamma Knife. LLNL's objectives were to 1) review and analyze current regulations, standards, and guidelines relevant to the safe use of Gamma Knife-type devices, and 2) identify quality assurance factors for Gamma Knife-type systems and components involved in safety. This is a report on LLNL's findings regarding the physical QA of the Gamma Knife.

\subsection{Scope and Organization of Document}

This document describes the results of a quality assurance assessment of the use of the Gamma Knife. The assessment focused on the physical (mechanical and electrical), radiation dosimetry, and safety features of the device. Quality assurance issues regarding medical practices and judgments were not addressed.

The steps in the quality assurance study are illustrated in Figure 1-1. Before beginning a quality assurance assessment of the Gamma 
Section 1. Introduction

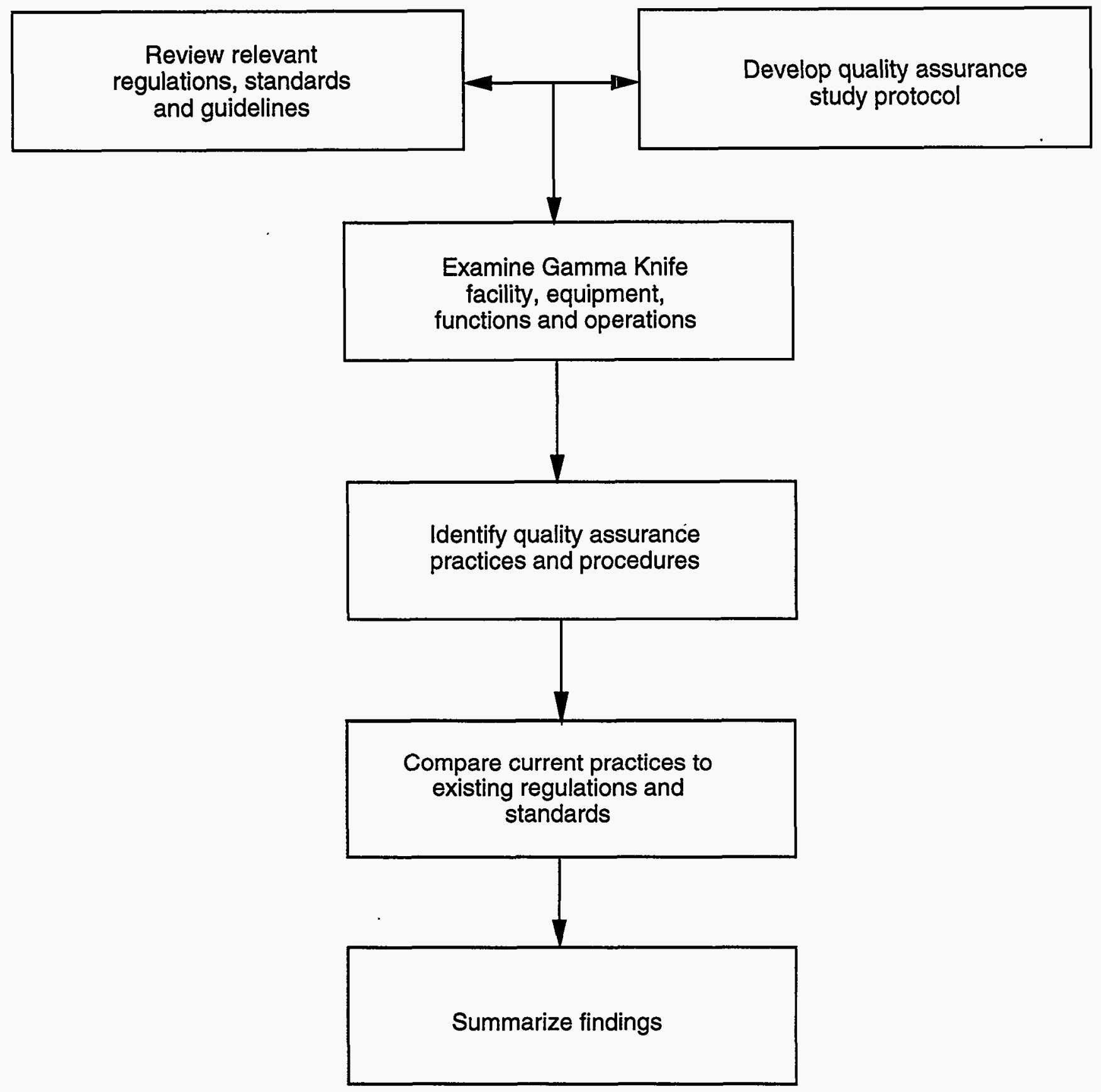

Figure 1-1. Steps in the quality assurance study. 
Knife, device-relevant regulations, standards, and guidelines were reviewed. These included NRC teletherapy regulations and voluntary or consensus standards and guidelines produced by professional or medical organizations. Based on preliminary background research on Gamma Knife-type devices, a quality assurance study protocol was developed. This protocol listed issues and questions to be addressed during the review of relevant regulations, standards, and guidelines and during the QA assessment process. The general areas covered by the protocol included quality control (QC) and QA practices and procedures, device maintenance and servicing, QA of the computerized treatment planning system (CTPS), and miscellaneous riskrelated information.

The design of the Gamma Knife makes it a relatively simple mechanical machine with very few moving parts. But in using the device, great care must be taken by the Gamma Knife medical team to plan and administer the correct dose and treatment to the patient.

Limited data exists concerning safety component performance for this relatively new device. Most operational information resides in the experience base of the manufacturers and users. As such, the project team primarily based the quality assurance assessment on facility visits, interviews with the manufacturer and users, and observations of patient treatments.

In the QA assessment process, Gamma Knife facilities and equipment were examined, along with the functions and operations of the Gamma Knife system during treatments. Based on these studies, the QA project team postulated a set of current quality assurance practices and procedures associated with the use of the Gamma Knife. These observations were verified, refined, and validated by Gamma Knife experts. The QA measures were then compared to existing NRC regulations and consensus standards and guidelines to identify the overlaps and any gaps or conflicts among existing regulations and current practices. The findings of the QA study are summarized in this report.

Section 2 discusses the review of relevant regulations, standards, and guidelines from professional and standard-setting organizations, including the QA study protocol. The quality assurance assessment process is outlined in Section 3. Section 4 describes the device registration and acceptance testing. Facilities and equipment descriptions are contained in Section 5. Radiation safety is addressed in Section 6.

Reviews of quality assurance/control, maintenance, and emergency procedures are addressed in Sections 7, 8, and 9, respectively. QA aspects of the computerized treatment planning system are summarized in Section 10. Training issues are described in Section 11. Finally, specific issues regarding the perceived mis-matches between existing 10 CFR Part 35 regulations and current Gamma Knife practices are summarized in Section 12. A Bibliography of documents reviewed during this study is attached. In Appendix A, QA recommendations and guidelines, not necessarily specific to the Gamma Knife, from medical or standard-setting organizations are compared-in a matrix format-to the NRC's regulations in $10 \mathrm{CFR}$ Part 35 to display any gaps or overlaps. Other Appendices contain more detailed information on the Gamma Knife and sample protocols supporting quality assurance. 
$\begin{array}{ccccccc}- & & \end{array}$ 


\section{REVIEW OF RELEVANT REGULATIONS, STANDARDS, AND GUIDELINES}

The first phase of the QA study was to collect information regarding current regulations, standards, and guidelines relevant to radiation therapy devices, like the Gamma Knife, from the $\mathrm{NRC}$ and other regulatory, medical, and standardsetting organizations.

Nuclear byproduct material, or radiation therefrom, is regulated by either federal or state laws. The Food and Drug Administration (FDA) provides market approval for cobalt- 60 teletherapy units based on substantiated safety and effectiveness of the units. The FDA approves devices for sale and, prior to the passage of the Safe Medical Devices Act of 1990, monitored device use and performance through required manufacturer reports of safety-relevant incidents. There is now a medical device reporting requirement for users to notify the FDA directly about device malfunctions or abnormalities.

Twenty-eight states, known as Agreement States, have entered into an agreement with the NRC to regulate the use of byproduct material (as authorized by section 274 of the Atomic Energy Act). These States issue licenses and currently regulate about 4,000 institutions, e.g., hospitals, clinics, or physicians in private practice, while the NRC has about 2,000 byproduct licensees. The Agreement States' regulations for byproduct material are comparable to those of the NRC.

The NRC regulates the use of byproduct material in medicine by licensing and regulating institutions that use such material in diagnostic or therapeutic applications. The NRC issues regulatory requirements through the Code of Federal Regulations and by licensee conditions that authorize and control the use of byproduct material. The NRC also provides guidance regarding its regulatory requirements by means of Regulatory Guides and Policy and Guidance Directives to the NRC staff. This system of rules, policies, and guidance implements the NRC's general policy (Federal Register, Vol. 44, p. 8242, February 9, 1979 (44 FR 8242)) of providing regulations necessary for the radiation safety of workers and the general public. The NRC tries to minimize intrusion into medical judgments affecting patients and into other areas traditionally considered to be a part of the practice of medicine. NRC regulations are predicated on the assumption that properly trained and adequately informed physicians will make decisions that are in the best interest of their patients.

The NRC's regulations are published in Title 10 of the Code of Federal Regulations (10 CFR). Part 20 contains the standards for protection against radiation, while Part 35 deals specifically with the medical use of byproduct material. Subpart I Teletherapy of $10 \mathrm{CFR}$ Part 35 contains specific regulations for conventional cobalt- 60 teletherapy facilities. Some of the quality control and calibration requirements for teletherapy facilities may not be appropriate for the external beam therapy technology of the Gamma Knife.

The NRC distinguishes between the unavoidable risks attendant in purposefully prescribed and properly performed clinical procedures and the unacceptable risks of improper or careless use. In 1991, the NRC amended 10 CFR Part 35 to require implementation of a quality management program-known as the Quality Management (QM) Rule (10 CFR Parts 35.2 and 35.32)-to provide confidence that radiation will be administered as directed by an authorized user. Regulatory language specific to the Gamma Knife is contained in the QM rule.

NRC Regulatory guides are issued, after a formal review and comment process, to assist institutions in meeting the requirements of the regulations. The guides provide additional information and suggested procedures and programs: they do not require compliance. For instance, Regulatory Guide 8.33, "Quality Management Program" provides guidance to licensees and applicants for developing policies and procedures to establish their $\mathrm{QM}$ program required by the QM rule, including suggested policies and procedures for gamma stereotactic radiosurgery. 
The NRC regulates the radiation safety of patients where justified by the risk to patients and where voluntary standards, or compliance with such standards, is inadequate (44 FR 8242). Voluntary or consensus standards are produced by professional or medical organizations. Many of the quality assurance and radiation safety voluntary standards concerning other external beam therapeutic procedures are relevant to the use of the Gamma Knife.

To collect and review information from the regulatory and consensus organizations, LLNL developed a comprehensive survey protocol of QA issues. The primary QA or safety areas covered were:

\subsection{General information on standards or guidelines}

2.0 General quality assurance information

3.0 Quality control

4.0 Service and maintenance

5.0 Computerized Treatment Planning System (CTPS)

6.0 General and risk-related information

A complete listing of the protocol topics are provided in the Appendix A matrices. The topics were determined and linked, in part, to existing NRC teletherapy and safety regulations and guidelines such as:

- 10 CFR Parts 35 and 20

- Regulatory Guide 10.8, Revision 2, "Guide for the Preparation of Applications for Medical Use Programs"

- Regulatory Guide 8.33, “Quality Management Program"

- Draft Regulatory Guide FC 414-4, "Guide for the Preparation of Applications for Licenses in Medical Teletherapy Programs"

- Regulatory Guide 8.18, "Information Relevant to Ensuring That Occupational Radiation Exposures at Medical Institutions Will Be As Low As Reasonably Achievable"

- Regulatory Guide 8.23, "Radiation Safety Surveys at Medical Institutions"
QA topics not linked to NRC regulations and guidelines were included in the protocol and were based on the project team's background research on radiation therapy devices and experience in QA assessments. This was particularly true in the areas of maintenance and Computerized Treatment Planning Systems (CTPS).

At the direction of the NRC, the following organizations were contacted:

- American National Standards Institute (ANSI)

- Food and Drug Administration (FDA)

- American College of Radiology (ACR)

- American Association of Physicists in Medicine (AAPM)

- Hospital Physicists Association (HPA)

- National Council on Radiation Protection and Measurement (NCRP)

- International Commission on Radiological Protection (ICRP)

- Institute of Physical Sciences in Medicine (IPSM)

- International Atómic Energy Agency (IAEA)

- American Society of Therapy, Radiology, and Oncology (ASTRO)

- National Institute of Standards and Technology (NIST)

- International Electrotechnical Commission (IEC)

The protocol provided a structured approach to information collection, analysis, and reporting. Information was obtained from the standardsetting organizations by telephone interviews, inperson interviews, and collection of pertinent documents. The protocol provided a means to compare recommendations among organizations as well as with $\mathrm{NRC}$ regulations and guidelines.

The protocol results indicate that limited regulatory and guideline information exists specific to the Gamma Knife. NRC's QM Rule (10 CFR Parts 35.2 and 35.32) and Regulatory Guide 8.33 were the only documents containing a reference to the Gamma Knife. However, many of 
the QA and radiation safety issues concerning other external beam therapeutic procedures are relevant, if only tangential, to the use of the Gamma Knife. This is especially true in the area of radiation safety, shielding, safety reviews, radiation surveys, interlock systems, exposure monitoring, and good medical physics practices. In Appendix A, the most pertinent documents are summarily described and compared-in a matrix format-to the NRC's regulations in 10 CFR Part 35 to show any information gaps or overlaps. A listing of all documents reviewed in this study is in the Bibliography.

In reviewing the standard-setting organizations, it was found that standards and guidelines specific to the Gamma Knife have been and are being developed, first and foremost, by the user community. The impetus for quality assurance comes first from oversight by the manufacturer. QA procedures are typically encoded in the user manuals and take the form of acceptance tests, dosimetry methods, treatment procedures, maintenance schedules, emergency procedures, etc.

There is an annual Gamma Knife users meeting which includes quality assurance issues among the medical presentations. The user information is formalized through publications and, more recently, through professional organizations. The International Stereotactic Radiosurgery Society
(ISRS) and the American Association of Neurosurgeons (AANS) are considering the establishment of committees to provide recommendations for the use of Gamma Knives. Also, the American Association of Physicists in Medicine (AAPM) Radiation Therapy Committee has several active task groups that could include information about the Gamma Knife in their reports in preparation. These include Task Group 40, Quality. Assurance in Radiation Oncology (this report will supersede the recommendations of AAPM Report 13 (AAPM 1984)); Task Group 42, Stereotactic Radiosurgery; and Task Group 50, Standards for 3D Radiation Treatment Planning Systems.

Basically, it was found that the use of the Gamma Knife conforms to existing standards and guidelines concerning radiation safety and quality control of external beam therapies (shielding, safety reviews, radiation surveys, interlock systems, exposure monitoring, good medical physics practices, etc.) and complies with NRC teletherapy regulations. There are, however, current practices for the Gamma Knife not covered by existing, formalized regulations, standards, or guidelines. These practices have been adopted by Gamma Knife users and continue to be developed with further experience. Some of these have appeared in publications or presentations and are slowly finding their way into recommendations of professional societies. 
-
- 


\section{QUALITY ASSURANCE ASSESSMENT PROCESS}

The steps in the quality assurance study are illustrated in Figure 1-1. The study protocol developed in the preliminary phase of this study provided a framework for the QA assessment of the Gamma Knife, and a basis for comparison of current practices to $\mathrm{NRC}$ regulations. A detailed listing of the protocol topics and their linkages to 10 CFR Part 35 sections and other organizations' regulations, standards, and guidelines are provided in Appendix A.

Given the protocol, the first step in the QA assessment process was to examine and understand the Gamma Knife facility, equipment, functions and operations.

A multi-discipline team made up of physicians and medical physicists with expertise in teletherapy; risk assessment experts; and scientists and engineers with extensive knowledge of QA and safety analyses, was organized to gather information. A data collection plan, based on the QA protocol, was formulated and included background research, visits to the manufacturer and Gamma Knife facilities.

Background research on the Gamma Knife involved documents and user manuals provided by Elekta, and literature searches. The user manuals and literature searches contained descriptions of the Gamma Knife components, cautionary notes with regard to safety, and stepby-step descriptions of how to operate the Gamma Knife and perform treatments. While most of the published literature on the Gamma Knife concerns medical issues, there were some articles on radiation safety and quality assurance.

Elekta made presentations to LLNL and NRC personnel on the design and use of the Gamma Knife, its manufacturing process, and the loading of the cobalt- 60 sources. The presentations provided a sound theoretical understanding of how the Gamma Knife systems work; potential hazards or safety concerns; quality assurance, maintenance, and emergency procedures; and tasks in the treatment process.

The project team went on a two-day site visit to a Gamma Knife facility, with the Gamma Knife's lead design engineer and the facility's medical physicist present. This afforded an opportunity to inspect the Gamma Knife and ask questions. A mock acceptance test procedure and routine calibrations and checks were performed, and the medical physicist walked through the treatment procedure, noting all the checks he performs to ensure accuracy in the treatment. This experience helped the team understand what system sequences were pertinent to potential risks, the relative importance of hazards and failure modes, and the QA tasks in the treatment procedure. On the second day, a Gamma Knife patient treatment was observed, from imaging and lesion localization to treatment planning, and patient positioning and treatment. This permitted a verification and validation of what was learned the day before.

Figure 3-1 shows the relationship of Gamma Knife treatment and quality assurance activities. Only QA activities associated with the Gamma Knife facility were examined. The project team did not investigate $Q A$ practices in imaging facilities (CT, MRI, angiography) nor in neurosurgical suites.

During the course of the project, the team visited and observed patient treatments at about half (five sites) of the then-existing Gamma Knife facilities (new facilities are steadily being established). These empirical experiences helped to refine the identification of quality assurance elements.

The University of California at San Francisco (UCSF) Medical Center had recently acquired a Gamma Knife. Thus, there was a nearby Gamma Knife on which to perform further investigations, and learn from UCSF's experience with the use of the Gamma Knife. 


\section{Gamma Knife Treatment Process}

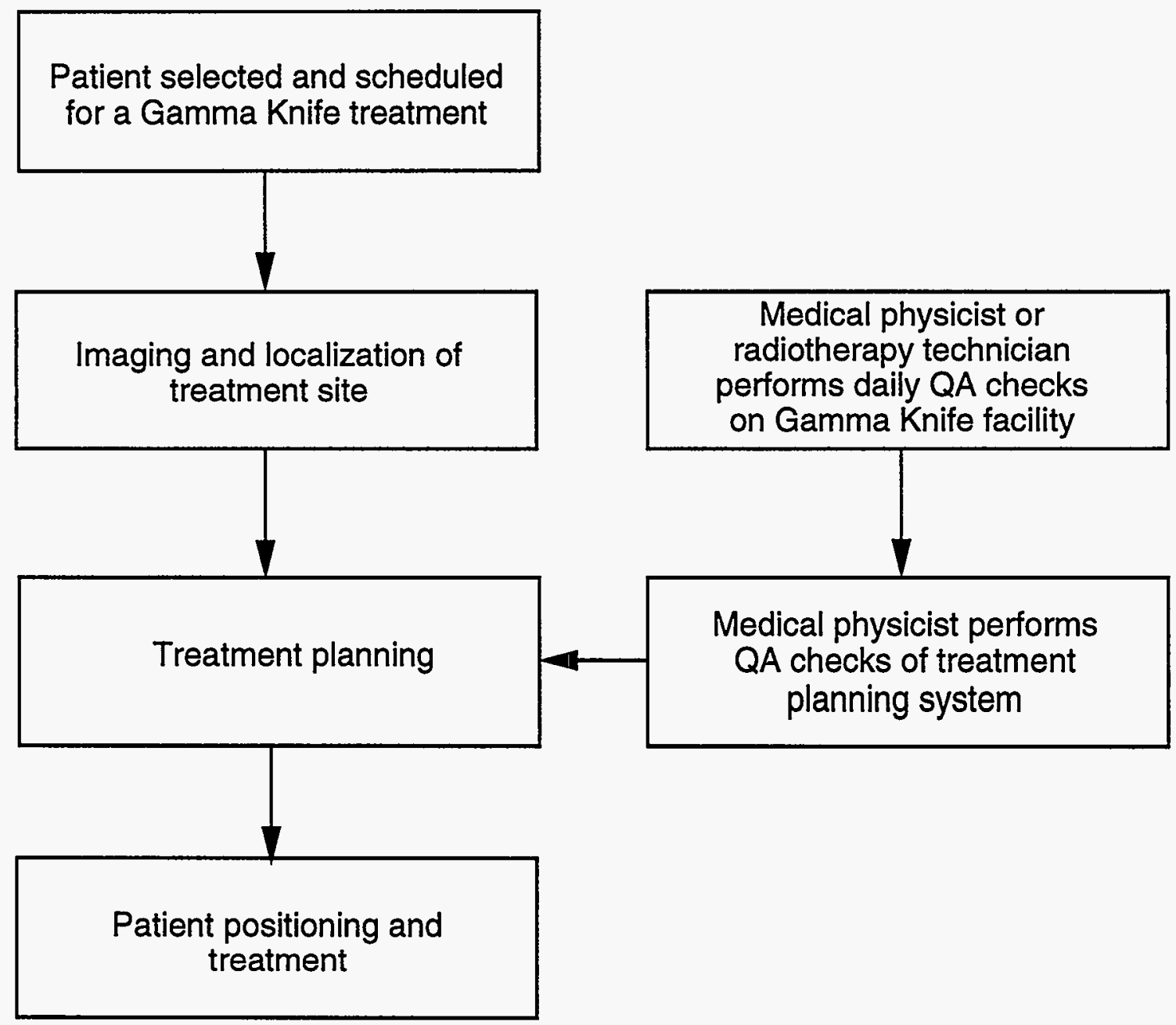

Figure 3-1. Row diagram of major Gamma Knife treatment and quality assurance activities.

The next step in the QA assessment process was to postulate a set of quality assurance issues and identify QA practices intended to meet those issues. The types of hazards encountered in the use of the Gamma Knife included:

- Ionizing radiation to the patient during the treatment cycle, the practitioner during normal operating and emergency conditions, and the public;

- Hydraulic pressure in containers and components under rapid pressure changes;
- Electrical inadvertent activation and deactivation, and electrical component and power source failures; and

- Mechanical operations of the gamma unit.

The project team developed the following preliminary list of processes or sequences pertinent to these hazards and QA issues associated with the use of the Gamma Knife:

- Device functional and acceptance tests;

- Quality assurance procedures for gamma unit physics;

- Dosimetry and safety measures; 
- Pre-therapy performance checkouts;

- Abnormal events during gamma unit operation;

- Emergency procedures; and

- Maintenance and servicing.

These observations were then verified, refined, and validated by Gamma Knife experts. The products of this interactive analysis were the identification of quality assurance factors for Gamma Knife systems and components involved in safety and data on important quality assurance elements and their tolerances.

The next step of the QA assessment was to compare the QA practices and procedures to existing NRC regulations and consensus standards and guidelines to identify overlaps, gaps, or conflicts among existing regulations and current Gamma Knife practices.
As a result of this assessment process, key topics for the quality assurance of the use of Gamma Knives were found to be:

- Device registration and acceptance testing;

- Equipment and facilities;

- Radiation safety;

- Quality control and assurance;

- Maintenance and servicing;

- Emergency procedures;

- Computerized treatment planning system; and

- Training

Findings of the QA assessment for each of these topics is summarized in the remaining sections of the report. Section 12 contains a final summary of regulatory issues versus current Gamma Knife practices. 


\section{DEVICE REGISTRATION AND ACCEPTANCE TESTING}

The Leksell Gamma Unit or Gamma Knife is registered in the State of Georgia, an NRC Agreement State. Service is licensed by the State of Georgia to Elekta Instruments, Inc. for 1) installation, relocation, and removal of the Leksell Gamma Units from treatment rooms, and 2) maintenance, repair, and operation testing of the Leksell Gamma Unit.

The Gamma Knife has market approval from the Food and Drug Administration (FDA) via the 510(k) Premarket Notification process (FDA 904158). Cobalt-60 teletherapy units are classified as Class II devices and are controlled by substantiation of safety and effectiveness. This substantiation can be provided by a justification of "substantial equivalence" to existing devices. The content format for such a justification is not specified. In fact, the device does not even have to be built and operating to receive $510(\mathrm{k})$ approval, if the FDA finds the manufacturer's information about the device satisfactory. This is not true for Class III devices which require pre-market approval (PMA) and demonstrated safety and effectiveness with clinical trials.

The FDA approves devices for sale and, prior to the passage of the Safe Medical Devices Act of 1990 , monitored device use and performance through required manufacturer reports of safetyrelevant incidents. There is now a medical device reporting requirement for users to notify the FDA directly about any device malfunctions or abnormalities.

The FDA has guidelines for good manufacturing practices (FDA 91-4179). The manufacturer is also required to maintain a file on the history and performance of the device, and the FDA is required to inspect manufacturers of approved devices once every two years. Trade societies such as the National Electrical Manufacturers Association (NEMA) and the Health Industry Manufacturers Association (HIMA) also have good manufacturing practices guidelines.

As part of the quality assurance process, a visit was made to the manufacturer's facilities. This visit was very important, since this is the only place to see certain aspects of the equipment and certain points of the quality assurance program, such as:

- Inspection of the radiation unit while unloaded of cobalt- 60

- The manufacturing process including quality assurance and control

- The beam channel accuracy test

- Focal point measurements

- Function test performed at the factory

- The handling of Gamma Knife information with Elekta

- Individuals responsible for the development and design of the Gamma Knife, including the loading and testing of the computerized dose planning system

The manufacturing practices are essential to the safe operation of the Gamma Knife. They determine and fix, for the life of the machine, the possible limits of accuracy and precision for radiosurgical incisions.

The Gamma Knife manufacturer employs quality checks for materials, fabrication, and functionality (without gamma sources) before shipping the device to a user facility. The materials protocol includes review of quality declarations by the suppliers; inspection of materials composition; and tests for defects. Elekta has a policy of always having two suppliers for its components, and the quality of components delivered is carefully checked. Components are tracked by gamma unit number, so that any failure can be traced back to the supplier.

The fabrication protocol includes measurements of helmet fittings and beam channel and collimator fittings. The final collimator quality, beam channel accuracy tests, and focal point measurements ensure that the 201 gamma beams focus within a $0.3 \mathrm{~mm}$ diameter of the mechanical center of the device. Measurements are also made 
to ensure the accuracy of tools and devices that will be utilized by facilities for quality control and assurance checks.

The manufacturer tests the device's mechanical and electric functions for correct operation and safety. These test are performed without gamma sources in the radiation unit. The modes for which such tests are made include the treatment positioning procedure, user supervision of device operations, and safety procedures.

The treatment positioning procedure is simulated to ensure that the safety timers, console indicators, and helmet microswitches are set and working properly. In the supervision functions, the behaviors of the unit during a power failure or hydraulic failure are checked. The unit is also tested for proper performance when the user intervenes in the treatment cycle, by invoking the emergency interrupt or treatment stop functions. The emergency procedures are carried out to ensure that the device responds appropriately. Also, the unit's safety interlock systems are checked. Finally, the gamma unit is inspected to ensure all components, tools, and spare parts are present and in good shape.

After the Gamma Knife is installed (with gamma sources) at a facility, acceptance tests are performed. These tests include function, radiophysical, medical, and general tests. Manufacturer-supplied documentation includes leak test results and activities of the cobalt -60 sources; quality assurance declarations on materials; and results of the fabrication measurement protocols.

The function tests include treatment positioning; treatment safety timers, interrupts, and interlocks; and emergency procedures. Dummy runs are performed to check the mechanical and electrical installations. The radiophysical tests involve measuring the radiation dose rate, the spatial absorbed dose distribution, the focus point, and radiation protection from leakage and scattered radiation in compliance with NCRP 102. The medical and general tests simulate device operation with checks of various components and safety features. These include simulated power, hydraulic, and mechanical failures; treatment intervention by the user; simulated use of the stereotactic instrument and dose planning system; and simulated treatments. Part of the final acceptance test is the performance by the authorized user of calibrations and safety checks that will also be performed during the lifecycle of the device. During these tests, users are taught about the critical components of the Gamma Knife in various operating and emergency modes. 


\section{EQUIPMENT AND FACILITIES}

The Gamma Knife is a gamma radiation device designed to perform stereotactic radiosurgery of the brain. Dr. Lars Leksell, a neurosurgeon at the Karolinska Institute in Stockholm, Sweden, first proposed the use of external radiation beams with the guidance of a stereotactic frame to precisely locate and treat surgically inaccessible lesions within the brain (Leksell 1971). Leksell's early work used proton beams, a linear accelerator, and a cobalt unit. The first Gamma Knife (using 179 cobalt-60 sources) was installed at Karolinska in 1968. It was designed for the treatment of functional neurosurgical symptoms. A second unit was designed in the early 1970 s to produce a spherical radiation dose for treatment of tumors and Arteriovenous Malformations (AVMs). The unit that was designed for and used by the Karolinska Institute in 1968 was donated to the University of California at Los Angeles (UCLA) in 1981, entering the United States as a research unit on a broad byproduct license. In the 1980 s, the third and fourth gamma units, which had 201 cobalt- 60 sources, were installed in Buenos Aires, Argentina, and Sheffield, England, respectively. The fifth Gamma Knife was the first 201 cobalt60 source unit in the U.S. and was installed at the University of Pittsburgh Medical Center in 1987 (Maitz et al. 1990, Lunsford et al. 1989). To date, there are approximately 15 Gamma Knives installed in the U.S., and more than 7000 U.S. patients have undergone radiosurgical treatments with Gamma Knives.

The U.S. Gamma Knife model consists of a radiation unit, four interchangeable collimator helmets, a patient treatment table, a hydraulic system, a control console, and a treatment planning computer system. The Gamma Knife is pictured in Figure 5-1, and its major components are illustrated in Figures 5-2 through 5-4. The radiation unit has 201 cobalt- 60 sources that are arranged in a large, heavily shielded sphere $(18,000 \mathrm{~kg}$ ) (see Figure 5-3 and 5-4). Radiation from each cobalt -60 source is collimated into narrow beams that converge at the center of the sphere. A movable external collimator device or helmet is advanced hydraulically to align with the fixed internal collimators inside the sphere. The combined collimators cause the irradiation beams to converge at the center of the sphere. The crosssectional diameter of the beams at the focal point can be varied by changing the size of the circular apertures of the collimators in the helmet. In addition, any of the removable collimators can be replaced with an occlusive plug to prevent irradiation of the lens or critical structures near the target. For each helmet, a pair of trunnions serves as a fixation point for the stereotactic frame, which in turn is attached by four pins to the outer surface of the patient's skull. General technical specifications of the Gamma Knife are included in Appendix B.

The cumulative radiation from 201 beams results in a concentrated radiation dose at the center of the sphere (with a rapid exponential dose falloff in all directions from the center) while sparing tissue along the 201 individual beam entry paths. In other words, a high level of radiation is delivered in the precise center of the sphere, and a very low dose of radiation is delivered to regions away from the center. The concentrated dose or beam profile occupies a volume in three-dimensional space. Each isodose line, determined as a percentage of the total dose, defines an isodose volume. In a Gamma Knife treatment, the patient's head, held in the stereotactic head frame, is positioned so that the center of an intracranial target volume is at the beam focal point. Ideally, a radiation isodose volume should superimpose on the three-dimensional volume of the intracranial lesion. The total dose delivered to the external contour target volume depends on the activity of the cobalt- 60 sources, the isodose line that conforms to the lesion contour, and the length of time the patient's head remains positioned in the gamma unit. 


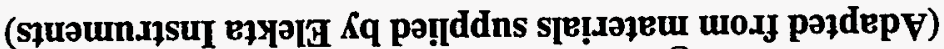

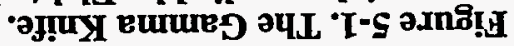

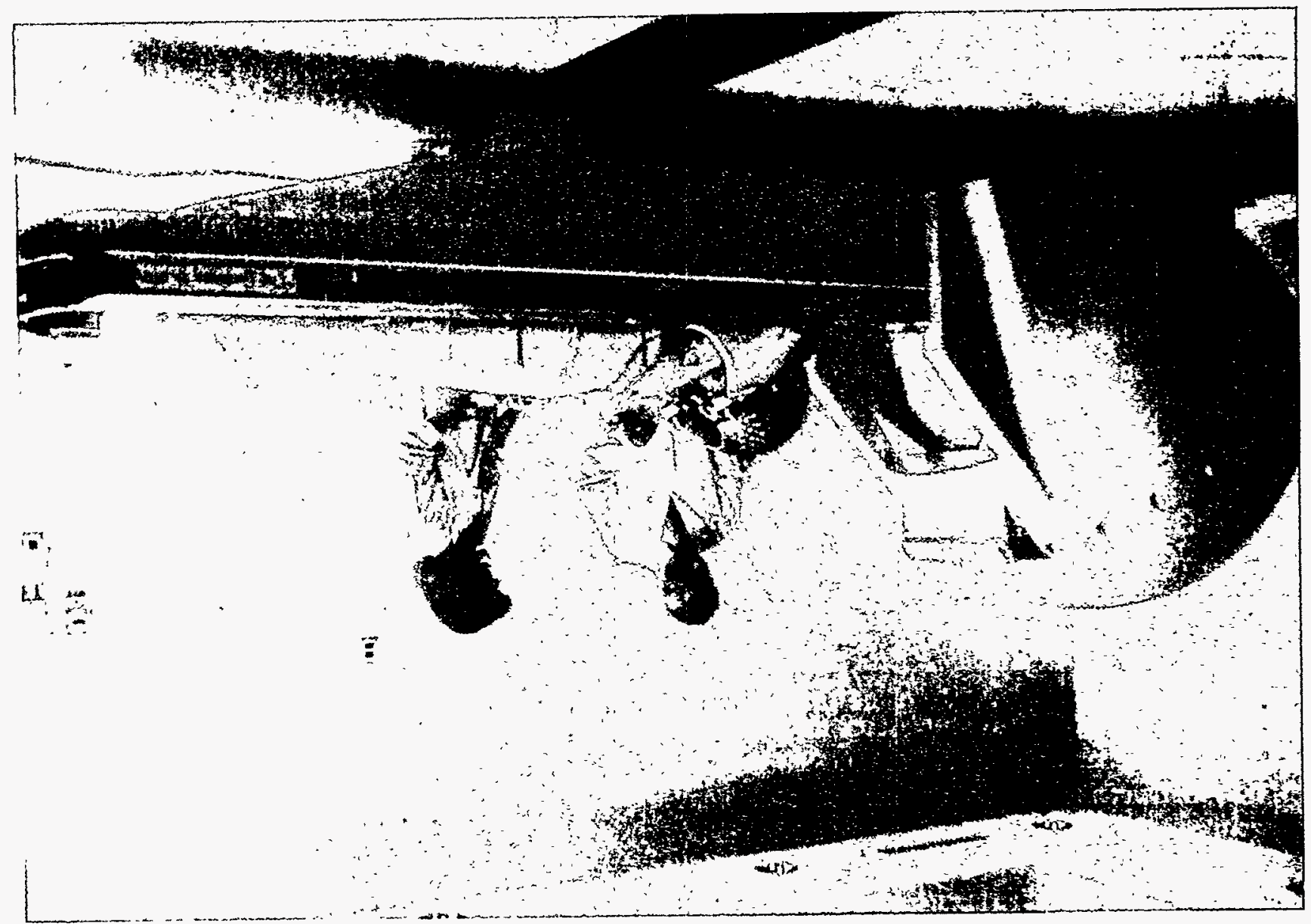

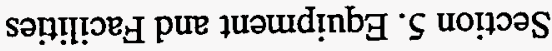




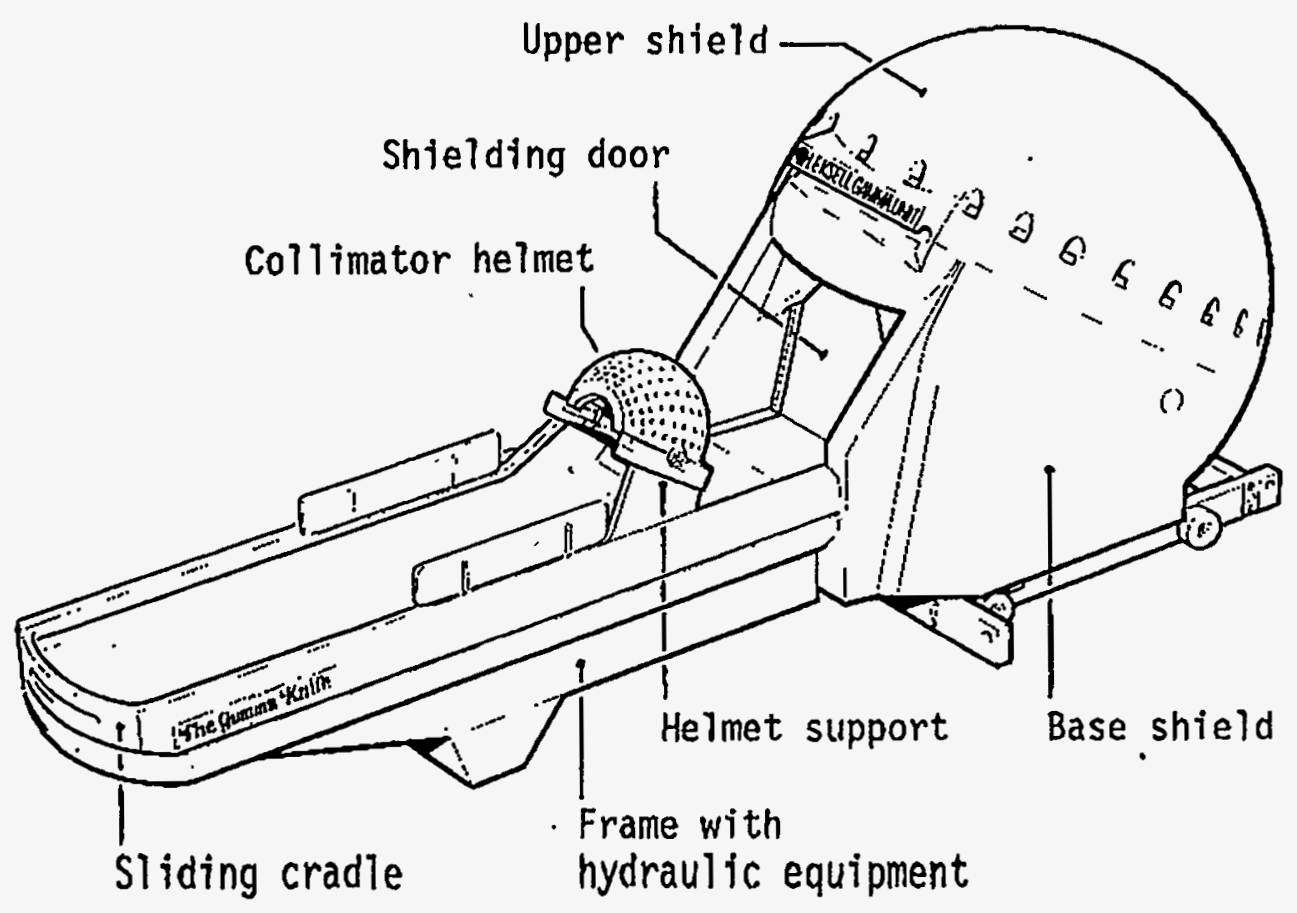

Fig. 3. The gamma unit with operating table

Figure 5-2. Major components of the gamma unit. (Adapted from materials supplied by Elekta Instruments) 


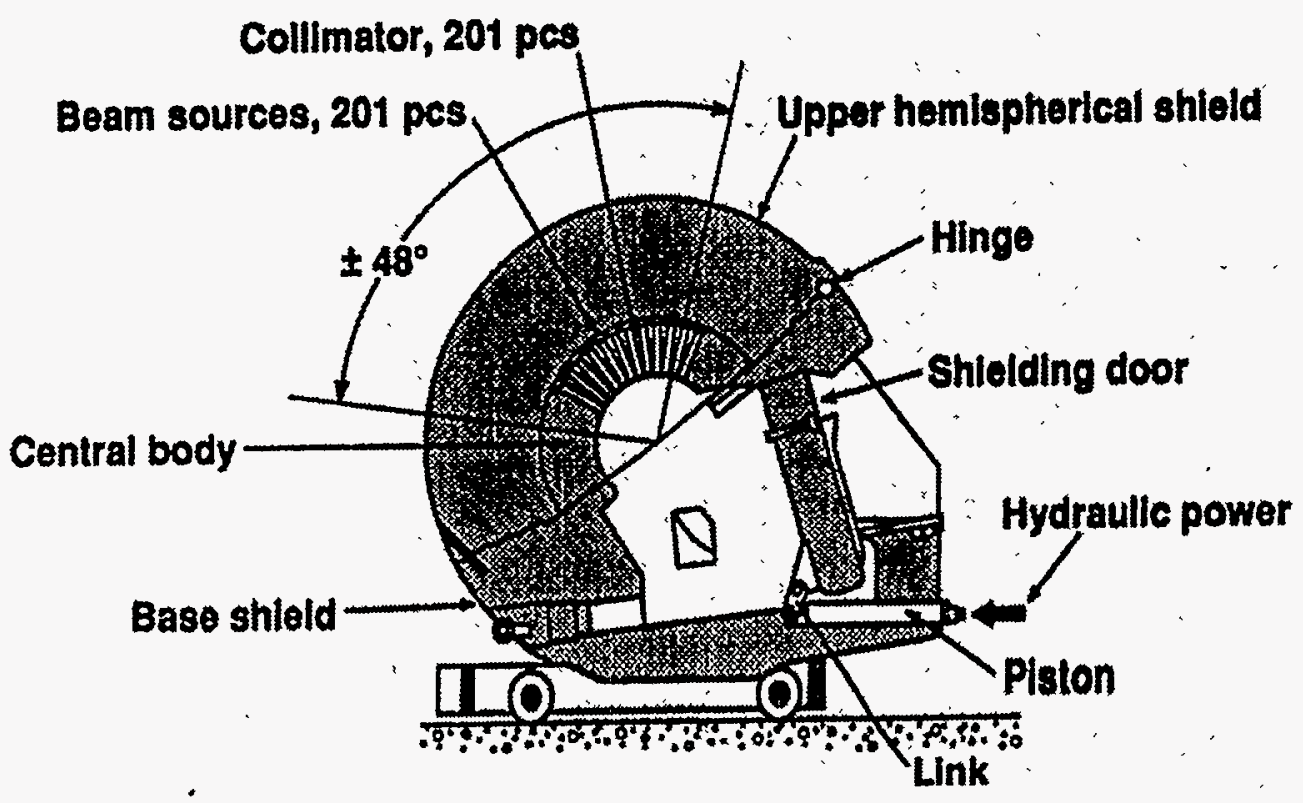

Figure 5-3. Major components of the radiation unit. (Adapted from materials supplied by Elekta Instruments)

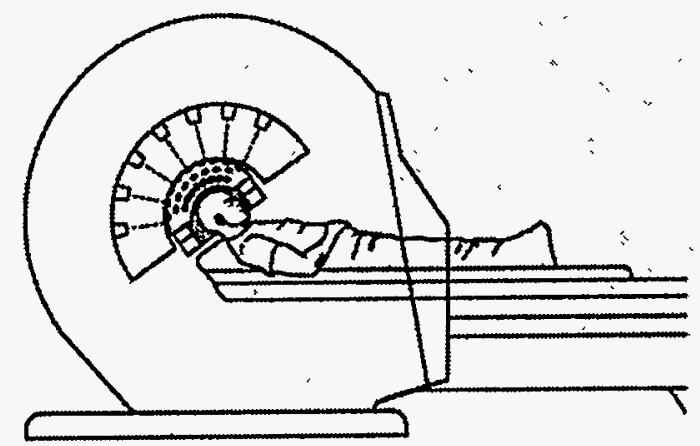

Figure 5-4. Schematic of the treatment position. (Adapted from materials supplied by Elekta Instruments) 


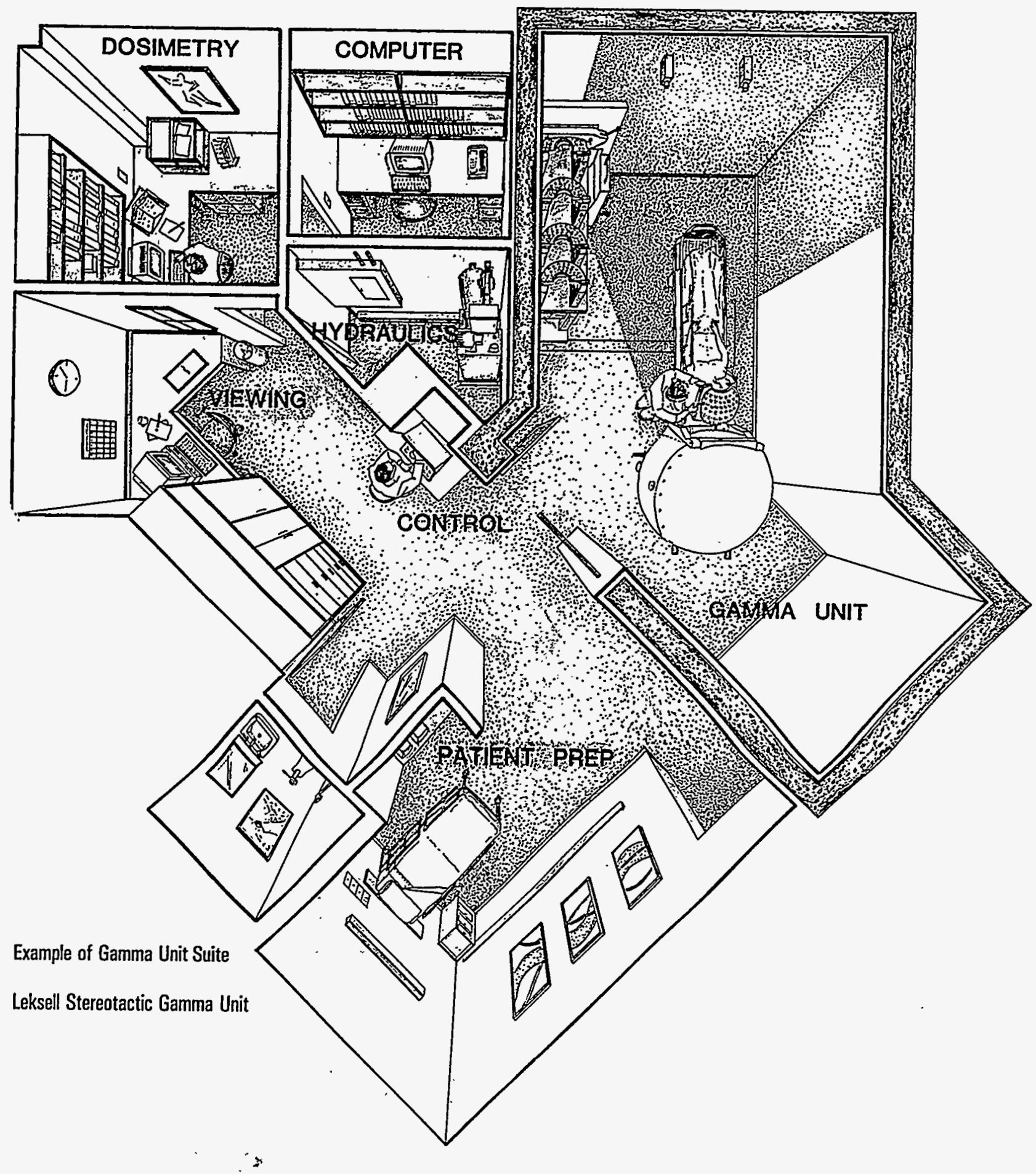

Figure 5-5. A typical Gamma Knife suite or treatment facility. (Adapted from materials provided by Elekta Instruments) 
A typical Gamma Knife facility or suite (Figure 55) consists of a treatment room, hydraulic room, control console, treatment planning area, patient preparation area, medical physics area, a bathroom, and storage. A Gamma Knife suite is a dedicated facility and is used only for Gamma Knife source loadings and treatments. Facility site planning criteria are contained in Appendix B. The gamma unit is isolated in a shielded treatment room with a shielded door interlock system. The room shielding is designed to meet NRC requirements for teletherapy units (Maitz et al. 1990). Recommendations in Report 49 of the National Committee on Radiation Protection and Measurements (NCRP 1976) are used as guidelines. Exposure rates are limited to $2 \mathrm{mR} / \mathrm{hr}$ in both controlled and non-controlled areas. Normal operations constitute a maximum workload of two patients per day, five days per week. The control console is usually placed just outside the treatment room door to provide easy access to the treatment room and the hydraulic room. The control console is equipped with two separate event counters as well as treatment control and interrupt push-button switches. A television monitor is connected to cameras within the treatment room and a microphone system for two-way verbal communication with the patient is included.

The Gamma Knife treatment process utilizes resources and facilities under the control of different hospital departments. Gamma Knife medical teams consist of a neurosurgeon, radiation oncologist, medical physicist, and a radiotherapy technician or a registered nurse. The team is usually a dedicated team, with authorized substitutions when necessary. Some facilities have more than one team.

Attachment of the stereotactic frame to the patient's skull is performed by the neurosurgeon. Radiological images are taken in the CT, MRI, and angiography facilities. The Gamma Knife facility itself may be under the control of neurosurgery or radiation oncology or both. Personnel from medical physics perform quality assurance on the gamma unit and the treatment planning equipment. In consultation with the
NRC, it was decided that organizational reliability issues were beyond the scope of the study.

It was observed that the treatment process steps used by different facilities were very similar. The Gamma Knife treatment procedure is well-defined and includes a series of steps that have to be done in the correct order. The treatment process consists of three phases: imaging and localization of lesion; treatment planning; and patient positioning and treatment.

A single treatment may include several Gamma Knife "shots." Each shot corresponds to a set of patient positioning, dose profile, and time parameters. The shot parameters are selected during the treatment planning process so that their superposition or aggregated effects meet the desired treatment plan of the medical team.

Stereotactic radiosurgery begins with the patient's head fixed in a Leksell stereotactic frame system. This is applied to the patient, under local anesthesia, via a four-pin fixation. Once affixed, the frame remains in place as a reference coordinate system until treatment is completed.

Depending on the type of disease to be treated, various diagnostic imaging techniques can be used for localization. Computed Tomography (CT) or Magnetic Resonance Imaging (MRD) are used for tumors. For AVMs, the most common disorder treated with radiosurgery, a set of orthogonal angiographic images of the brain is taken. The stereotactic frame's rectilinear fiducial coordinate system is realized on the images, from which three-dimensional coordinates and magnification factors of the target lesion's position are determined.

Based on the size, shape, and location of the target lesion as seen on the localization images, the coordinates of each proposed radiation shot or isocenter at the target contributing to the treatment are determined. Multiple shots are often needed in a single treatment to irradiate lesions either too large to cover with a single shot or sufficiently irregular in shape to require a combination of various-sized isocenters. The proposed shots, i.e., the coordinates, collimator sizes, gamma angles (defined as the angle of the 
patient's head with respect to the frame), and required dose are entered into the computerized treatment planning system that is provided with the gamma unit. The computer system can calculate and display the composite isodose distribution for all three principal axes. In treatment planning, the computer-generated isodose contour plots are superimposed upon the imaging study on which the target volume has been defined, until selected dose contours are aligned with the boundary of the lesion (Flickinger et al. 1990, Flickinger et al. 1990a, Wu et al. 1990). In practice, final shot parameters are selected only after several iterations of proposed treatment plans.

An important issue in radiosurgery, beyond determining the dose that is given to the target, is determining the dose that can be tolerated by the brain tissue surrounding the lesion. Given a dose chosen by the physicians for a treatment plan, the computer calculates the time that the target volume must remain in the focal point of the gamma unit in order to deliver the desired amount of radiation.

After all these calculations have been made, the patient is placed in one of four collimator helmets. The choice of collimator helmet depends on the size and configuration of the lesion to be treated. The previously determined stereotactic coordinates are then set on the Leksell frame by means of side bars and a trunnion. These settings are checked by members of the Gamma-Knife team.
The patient lays on a treatment table during treatment with the stereotactic frame attached by trunnions to the collimating helmet. A hydraulic system controls the opening and closing of the steel shielding door of the radiation unit and the movement of the treatment table in and out of the unit. In the event of a power or hydraulic failure, a hydraulic fluid reservoir provides sufficient pressure to release the treatment table so that it exits the radiation unit and closes the shielding door.

All personnel leave the patient in the treatment room and engage the door interlock. The treatment procedure begins by setting the counters on the console and pushing a button. The radiation unit shielding door opens as the table holding the patient and external collimator helmet is advanced hydraulically into the unit. When the collimator helmet is aligned with the internal collimator, the radiation treatment commences. After the prescribed amount of time has elapsed, the collimator helmet and the patient are automatically withdrawn from the unit and the shielded door closes. If additional shots are required by the treatment plan, then the coordinates, collimators, and counters are reset, and the treatment process is repeated. All shots are usually given in a single treatment session.

Treatment times can be as short as 5 to 15 minutes in a Gamma Knife with new cobalt- 60 sources, but can be much longer in an older unit after the sources have decayed over time. 


\section{RADIATION SAFETY}

As per the Gamma Knife device registry, the amount of leakage radiation through the radiation unit source housing conforms to NCRP 33 recommendations. (NCRP 33 has now been superseded by NCRP 102.) These include recommendations for the 'Beam-Off' position where the exposure rates at 1 meter from the source average $2 \mathrm{mr} / \mathrm{hr}$ with a maximum of 10 $\mathrm{mr} / \mathrm{hr}$. NCRP 33 recommends that leakage radiation measured one meter from the source shall not exceed 0.1 percent of the useful beam rate when the beam is in the 'On' position, except for the collimator zone. The Leksell Gamma Unit is an internal beam unit with stationary sources, so there is no external primary beam. Elekta states there is lower scattered radiation than is associated with conventional external beam teletherapy equipment. Primary transmitted radiation in the 'Beam-On' position is the same as for the 'Beam-Off' position.

The level of scattered and leakage radiation, when the radiation unit shielding door is open and the couch is either in (1) a treatment position without a patient or (2) in the withdrawn position, is measured in a plane one meter above and parallel to the floor with an appropriate monitor. For typical results of such measurements, see Maitz et al. 1990.

In the revised $10 \mathrm{CFR} 20$, public and occupational dose limits are specified. Guidance is provided in
NRC Regulatory Guide 8.34, "Monitoring Criteria and Methods to Calculate Occupational Doses," on the methods to be used for determining the dose equivalents.

The amount of radioactive material from the sources collected from wipe tests must not exceed 0.05 microcuries. In compliance with NCRP 33 paragraph 4.2.2.c, the wipe test for the Gamma Knife involves a smear test of the convex surface of a previously exposed collimating helmet; or a wipe of the radiation unit's seams and shielding door. The wipe sample is placed in a tube for a $\mathrm{NaI}$ counter. The test is usually performed semiannually.

An electrical door interlock (10 CFR Parts 35.615 and 35.636) separates the Gamma Knife medical team from the patient in the shielded treatment room. Each entrance is equipped with a beam condition light, as is the Gamma Knife console, and a permanent radiation monitor is installed in the treatment room. The patient in the Gamma Knife treatment room is continuously observed during treatment (as is required by 10 CFR Part $35.615(\mathrm{e})$ ) via remote video monitors.

Personnel radiation exposure must conform to the requirements of 10 CFR 20,19,35.20(c), as well as periodic radiation surveys ( $10 \mathrm{CFR}$ Parts $35.641,35.643$, and 35.620). 
$--\ldots$ 


\section{QUALITY CONTROL AND ASSURANCE}

Dosimetry of the Gamma Knife typically involves the use of an ion chamber, diodes, TLDs, and films centered within the Gamma Knife phantom (Wu 1990 and 1992, Berk and Agarwal 1991). The combination of these measurements provides the dose rate and dose profiles, and confirms the centralized location of the focal point. The measurements may also be used to check the accuracy of the treatment planning system (Maitz et al. 1992). The Gamma Knife medical physicists that were part of this study used the AAPM Task Group 21 (AAPM 1983, Huq and Nath 1991) dosimetry calibration protocol and used sources traceable to NIST standards.

Calibration measurements of cobalt- 60 teletherapy units (10 CFR Part 35.632) are compared to practices for the Gamma Knife in Table 7-1. (See Section 12 for a further discussion of the mismatches.)

Examples of calibration and quality assurance protocols are presented in Appendix C. Some of the more important quality assurance elements and their tolerances are listed in Table 7-2. The quality assurance elements are designed to check the dosimetry and physics parameters that affect the accuracy of dose delivery or to maintain safety and compliance with $10 \mathrm{CFR}$ Part 35 . The tolerances associated with these elements were based on documented and anecdotal information from Gamma Knife facilities. Each facility visited had records on the quality assurance activities and calibration data. The tolerances varied slightly among facilities depending on who performed the checks and what methods were used. The data could have been tabulated and continually updated in such a way as to provide a basis for statistical quality control of the dosimetry and physics parameters. However, only a few facilities had committed the resources to such an effort.

These physical quality assurance activities are comparable to those for other radiation therapies, and the tolerances are well within those expected for radiotherapy (e.g., AAPM 1984, Suntharalingam and Johansson 1988, Starkschall and Horton 1991).

Specific Gamma Knife dosimetry, quality assurance, and the accuracy of stereotactic radiosurgery are contained in the report of AAPM Task Group 42, Stereotactic Radiosurgery.

Safety-critical abnormal events or component failure modes, associated with either the operation of the gamma unit or with facility systems and functions, are listed in Table 7-3.

These events were selected because they could lead to undesired radiation exposures of either patients or personnel. The events were determined by asking Elekta personnel and Gamma Knife users what sort of events had occurred in the past or what events they were concerned about happening in the future. Also, several event scenarios were proposed, based on the project team's investigations, that were thought to be possible. The project team verified these event scenarios via discussions with the manufacturer and users. 
Table 7-1. Quality control of Leksell Gamma Units compared to Cobalt-60 Teletherapy Units.

\begin{tabular}{|c|c|}
\hline cobalt-60 Teletherapy Units & Leksell Gamma Units \\
\hline Calibrate prior to first medical use & Same \\
\hline $\begin{array}{l}\text { Calibrate prior to medical use whenever the spot- } \\
\text { check measurements indicate that the output } \\
\text { differs by more than } 5 \% \text { from the output } \\
\text { obtained at the last full calibration, corrected for } \\
\text { radioactive decay }\end{array}$ & Same \\
\hline $\begin{array}{l}\text { The output should be within } 3 \% \text { for the range of } \\
\text { field sizes and for the distance or range of } \\
\text { distances in medical use }\end{array}$ & $\begin{array}{l}\text { The calibration output is defined to be the output } \\
\text { at the center of a 16-centimeter diameter sphere of } \\
\text { water equivalent material. This determination is } \\
\text { only done for the } 18 \text {-millimeter collimator using a } \\
\text { calibrated mini-ionization chamber }\end{array}$ \\
\hline $\begin{array}{l}\text { Check the coincidence of the radiation field and } \\
\text { the field indicated by the light beam localizing } \\
\text { device }\end{array}$ & $\begin{array}{l}\text { This requirement is not applicable to the Leksell } \\
\text { Gamma Unit }\end{array}$ \\
\hline $\begin{array}{l}\text { Check the uniformity of the radiation field and } \\
\text { its dependence on the orientation of the useful } \\
\text { beam }\end{array}$ & $\begin{array}{l}\text { This requirement is not applicable to the Leksell } \\
\text { Gamma Unit }\end{array}$ \\
\hline $\begin{array}{l}\text { Check timer constancy and linearity over the } \\
\text { range of use and the on-off error }\end{array}$ & Same \\
\hline $\begin{array}{l}\text { Check the accuracy of all distance measuring and } \\
\text { localization devices in medical use }\end{array}$ & $\begin{array}{l}\text { This requirement is not applicable to the Leksell } \\
\text { Gamma Unit }\end{array}$ \\
\hline
\end{tabular}


Table 7-2. Gamma Knife quality assurance tolerances.

\begin{tabular}{|c|c|c|}
\hline QA Element & Frequency & Tolerance \\
\hline Timer accuracy & Monthly & $\leq 2 \mathrm{sec}$ \\
\hline Timer linearity & Monthly & $\leq 2 \% ;$ Correl. $=0.999$ \\
\hline On-off error & Monthly & $-(0.03-0.05) \mathrm{min}$ \\
\hline Radiation output & Monthly & $\leq 2 \%$ \\
\hline $\begin{array}{l}\text { Anticipated output } \\
\text { vs. measured }\end{array}$ & Monthly & $\leq(2-3) \%$ \\
\hline $\begin{array}{l}\text { Computer output } \\
\text { vs. measured }\end{array}$ & Monthly & $\leq(2-4) \%$ \\
\hline Dose profiles & Annual & $\pm 1 \mathrm{~mm}$ on $50 \%$ line \\
\hline $\begin{array}{l}\text { Radiation/mechanical } \\
\text { isocenter coincidence }\end{array}$ & Annual & $\pm(0.3-0.4) \mathrm{mm}$ \\
\hline Trunnion centricity & Monthly & $\pm(0.2-0.5) \mathrm{mm}$ \\
\hline Collimator factors & Annual & $\leq(2-5) \%$ \\
\hline Helmet microswitch test & Monthly & $\pm 0.1 \mathrm{~mm}$ of trip point \\
\hline Couch movement time & Monthly & $\begin{array}{l} \pm 10 \text { sec. from initial } \\
\text { calibration }\end{array}$ \\
\hline Radiation monitors & Daily & $\leq 10 \%$ of annual calibration \\
\hline Door interlock & Daily & $\leq 0.5 \mathrm{~cm}$ of trip position \\
\hline Leak tests & Semi-annual & $<0.005 \mathrm{mCi}$ \\
\hline
\end{tabular}


Section 7. Quality Control and Assurance

Table 7-3. Failure modes associated with the use of the Gamma Knife.

Radiation unit shielding door fails to close fully

Treatment table halts in transit

Helmet microswitches malfunction

Treatment intervention by personnel

Emergency procedures invoked

Treatment door interlock interrupted while unit shielding door still open

Treatment door interlock fails

Counters/timers fail

Motion safety timers fail

Status lights fail

Console operating buttons fail

Inadvertent activation of operating modes

Audio/visual communication failures

Radiation monitors inaccurate/inoperable

Emergency stops not operable

Emergency release rod fails to work

Personnel cannot pull out treatment couch in an emergency

Electrical component failures

Emergency power not available

No emergency lights or monitors

Hydraulic component failures

Hydraulic fluid depressurization 
The occurrence of some of these events is potentially mitigated by periodic checks of Gamma Knife features to ensure safety and to maintain compliance with NRC regulations' $(\mathrm{Wu}$ 1992, Berk and Agarwal 1991). On the day of and before a treatment, the Gamma Knife systems within the treatment facility are checked by the medical physicist, radiotherapy technician, or both. These daily checks augment monthly, semiannual, and annual quality assurance activities (see Table 7-2 and Appendix C). Typical daily quality assurance activities consist of:

1. A visual inspection of the hydraulic room, console area, and treatment room. These are to ensure all necessary equipment is present. Hydraulic fluid on the floor may indicate a leak that can lead to underpressurization of the gamma unit.

2. The gamma unit power is turned on as are the video monitors.

3. With an active survey meter in hand, a radiation check source is taken into the treatment room and placed on the radiation monitors to verify in-room flashing. While in the room, the unit is inspected and verified safe for treatment. The shielding cover at the rear of the helmet is opened, thereby breaking a safety interlock and simulating a condition for no treatment.

4. The treatment room is exited and it is verified that no one is in the treatment room. Then, at the control console, several checks are made. These include verification of the alarm of the remote radiation monitor; setting and resetting of counters; lamp tests; verification of "cover open" light and an attempt at treatment start which should fail, since a safety interlock was interrupted in Step 3.

5. The treatment room is re-entered to close the rear helmet shielding cover (connecting a safety interlock) and to remove the radiation check source.

6. The treatment room is exited and verified empty of personnel. The counters are set (usually to a minute) and the treatment cycle initiated. With the treatment couch in motion, the emergency interrupt button is pushed to verify the couch freezes in place until the interrupt is released and the treatment cycle is continued. When the unit is in the treatment position, the "treatment yes" light should be on. The treatment stop button then is tested to verify that the treatment terminates and the couch is withdrawn to a safe position.

7. The treatment door interlock system is tested by opening the door and trying to initiate treatment.

8. Finally, the counters are set for a short treatment and a proper treatment cycle and completion (without interruption) is verified.

9. The proper functions of the communication and visual systems are verified.

10. Also the daily quality assurance protocol for the computerized treatment planning system Kula is run and verified (see Section 9).

Two microswitches are located at the base surface of the collimating helmet. Their engagement indicates the proper positioning of the helmet for a treatment to commence. To test the sensitivity of the two microswitches, a procedure is conducted using a special tool provided by the manufacturer to simulate docking in the central body. The microswitch gap can not be greater than 0.1 millimeter for treatment. The test is performed daily at some sites but monthly at others. Couch movement time is the interval during which the patient may be exposed to radiation upon movement to and from the treatment position. Upon pushing the treatment start button, an internal timer starts. If the helmet microswitches have not been properly engaged within the timer period (typically set between 90 and 120 seconds) the couch is automatically withdrawn. The test is performed monthly.

Records of the QA measurements and checks are kept on forms or by checklists in a file or in logbooks. The records are periodically reviewed by a medical physicist to ensure completeness and accuracy. Any feature malfunction is to be immediately brought to the attention of a Gamma Knife physicist.

With respect to physical QA, there were some inter-departmental issues. In the Gamma Knife treatment process, there are usually several departments involved: neurosurgery, radiology, radiation oncology, and medical physics. Each department is responsible for different physical aspects of QA for the Gamma Knife treatment process and system. However, there was not 
always good quality control on the transfer of information among departments. This can be critical, for instance, in the case of an AVM treatment if angiography films are transferred without a complete understanding of their orientations.

This highlights the importance of the role of the medical physicist in the Gamma Knife treatment process. The physicist is involved in every aspect of the treatment process, and may be the only individual who understands all the QA/QC issues of each departmental function with regards to the Gamma Knife treatment process. For instance, it appeared that there was not a universal understanding among the authorized users of the Gamma Knife timing sequences associated with various faults. This is partly because usually only the physicist is present for the device installation commissioning and acceptance tests, while the physicians are learning how to treat patients.

In the area of the physical aspects of the delivery of daily radiation treatments (Suntharalingam and Johansson 1988), uncertainties exist in the absorbed dose distributions that are measured and calculated. Unlike other therapeutic beam devices, the Gamma Knife's mechanical stability and dose profiles are constant over time. A number of physical parameters, each having some error, contribute to the uncertainty in the threedimensional dose distribution within the brain. Uncertainties in treatment planning and set-up also influence the accuracy with which the required dose can be delivered to the prescribed target volume. These errors, which are both dosimetric and spatial, are a combined effect of both systematic and random errors. The Gamma Knife practitioners believe they can deliver a dose with an accuracy of $0.5 \mathrm{~mm}$ (compared to $2.5 \mathrm{~mm}$ for a linear accelerator). It is clear that the errors introduced in imaging; lesion definition and localization; treatment planning; and patient setup dominate any random or systematic mechanical errors of the Gamma Knife.

An aid to continuous quality improvement can be the use of checklists for the Gamma Knife procedures. Checklists could play an important role for new team members to learn about the Gamma Knife. Such documents would help to ensure that critical information is transferred to new users. Experienced users may not use the checklists at all times, but they could review them from time to time to check their performance and update the checklists with improved procedures. The checklists can also be used to correct potential errors or to detect deviations from the written directive.

The facilities' safety precautions follow the 10 CFR Part 20 regulations. Safety instruction procedures followed the JCAHO guidelines for diagnostic and radiation therapy devices. Safety instruments were facility-dedicated. Facility radiation surveys are typically performed every year and the portable radiation monitor is calibrated once a year. Exposure monitoring procedures conform to the hospital's radiotherapy guidelines and to 10 CFR Part 19 requirements. Patient cases are typically reviewed every couple of weeks. 


\section{MAINTENANCE AND SERVICING}

Most, if not all, of the maintenance and servicing of Gamma Knife units is provided by the manufacturer. Elekta Instruments recommends maintenance calls on each device at least every six months and are available in the case of emergencies. The maintenance contracts do not, however, include support of the Kula computerized treatment planning software. These are handled under separate hardware and software contracts.

Preventative maintenance is performed to ensure proper functioning of the gamma unit, including its safety features. The maintenance involves general cleaning and checks; hydraulic system checks; electrical and mechanical checks; and functional tests and checks. General cleaning and checks of the patient couch, operating table, radiation unit, helmet hoist, and control console are carried out. Hydraulic system inspections are made on the hydraulic unit (pump and valves), piping and hoses, and hydraulic cylinders. The electrical and mechanical maintenance involves the patient couch, the control console, the system relay panel, the audio-visual systems, and the collimating helmets. Functional tests and checks are performed on the system by making dummy runs and testing the safety systems (interlocks, fail-safes, treatment interrupts, safety timers, etc.). If necessary, the audio-visual system and helmet hoist are also adjusted.

Elekta Instruments keeps all maintenance records and documents pertaining to the devices' manufacturing tolerances, $\mathrm{QC}$ checks and measurements, and performance records.

Elekta also provides notices and device alerts to all of the Gamma Knife users. When there is a problem, Elekta is called and other users are notified by Elekta when deemed appropriate by Elekta.

One area that could be improved is the dissemination of non-emergency and non-safety related information with the Gamma Knife. These changes in hardware and software are particularly important for training purposes. Facilities need to know about any changes in order to update their training practices. Also, training facilities may have older equipment or software and need to be aware of any upgrades that the users they are training may have at their facility. 
$\ldots+\ldots+\ldots$ 
Section 9. Emergency Procedures

\section{EMERGENCY PROCEDURES}

The treatment cycle is monitored from the console area by means of the remote audio and monitors and indications on the control console. The stoptreatment cycle is automatically initiated 1 ) if the couch has not reached the treatment position within 80 seconds after treatment starts, 2) if correct contact between the helmet and the central body is not confirmed (by the helmet microswitches) within two seconds after full movement of the couch into the radiation unit, or 3) the treatment room door interlock is broken.

Emergency procedures may be invoked if the patient is in difficulty, the machine is not performing adequately, or there is an electrical or a hydraulic failure. The layout of the facility, the emergency procedures, and training exercises are designed to extract the patient from the gamma unit in less than two minutes.

If a power failure occurs during irradiation (about $50 \%$ of the facilities have emergency power), the couch will be removed automatically out of the radiation unit (because microswitches have to be activated for the treatment to proceed). The unit shielding door is then closed by manually shifting the shielding door closure lever on the hydraulic unit in the hydraulic room. Without recent training, the user may not readily identify which lever to shift since there are two very similar and closely positioned levers. The wrong lever releases the reserve pressure from the hydraulic system reservoir. This can be precluded by removing the wrong lever. Closing of the shielding door is prevented by an interlock until the couch is fully removed.

If hydraulic pump failure occurs during treatment, there is enough reserve pressure to complete the treatment cycle. If there is not enough reserve pressure, the operator enters the hydraulic room and re-establishes pressure with the auxiliary hand pump. If the hydraulic failure is due to an electrical failure that affects the couch microswitches, the operator must also shift the radiation unit shielding door closure lever on the hydraulic unit after the patient couch has exited to its outer position and before the door can be closed by means of the hand pump. Again, shifting the wrong (reservoir release) lever will increase the need for hand pumping. Hand pumping is a lengthy process, requiring about 300 cycles to close the shielding door. Also, the hand pumping may not generate enough positive pressure to close the door if there is a failure in the hydraulic system.

If there is not sufficient reserve pressure during treatment, the stop treatment cycle is automatically initiated. The pressure level when the hydraulic pump is activated during the start treatment is sufficient to complete the stop treatment cycle. In the event reserve pressure is not sufficient at any time during the treatment cycle and the pump fails to restore sufficient hydraulic reserve pressure within one minute, the stop treatment cycle is automatically initiated.

A primary interest of the physicians in the case of an emergency is to remove the patient from the treatment room as soon as possible, even though the unit shielding door may still be open. The manual removal of the patient is effected by entering the treatment room, pulling the pressure release handle at the end of the couch, having two people retract the couch, and removing the patient from the helmet fixation trunnions. This procedure is designed and practiced to occur within two minutes.

If the couch gets stuck in the radiation unit and it is not possible to withdraw it with hydraulic hand pumping or manual retraction, the patient must be brought out manually from the high-level radiation area, by loosening the bolt locking one or both head fixation trunnions with a special, long Allen key and pulling out the patient. When the couch is in the treatment position and is ordered out (either by end of treatment or treatment stop), it must have left the treatment position within five seconds or an alarm will be activated.

The prescription is marked to signify a successful completion of a shot. Care must be taken to mark the correct successfully completed shot. Also, it is 
a good idea to re-inspect the coordinate settings after the shot to see if they have slipped.

There are some interesting issues concerning these prescribed emergency procedures. First, the written procedures, always present during the visits, are long and detailed. Examples of written emergency procedures are shown in Appendix D. Second, the design and labeling of the hydraulic unit release valves can be confusing without the removal of one of the handles. Third, the hand pumping takes a relatively long time. Lastly, it appeared that some Gamma Knife staff were not adept at the emergency procedures. Emergency procedures were practiced every six months at some facilities, while the manufacturer recommends they be practiced every 30 days. In any case, there seems to be a need to upgrade emergency preparedness by using practice drills in various scenarios.

An alternative is to simplify the emergency procedures. One way this can be accomplished is to just turn off the console key. This will shut down the unit and the treatment table will slide out from the radiation unit since it is now free to respond to the pull of gravity. The shielding door will not be completely closed, but personnel can quickly enter the treatment room and extract the patient.
These approaches represent a trade-off in radiation exposure to the patient and staff. In the prescribed emergency procedure, the patient is exposed to scattered radiation while being slowly hand-pumped out of danger, while the staff remains safe. In the alternative approach, the staff risks radiation exposure, but the patient is recovered much more quickly.

In either approach', the patient may remain stuck in the radiation unit and the long Allen key must be employed. Staff typically practice with the Allen key while the treatment table is extracted from the radiation unit, the shielding door is closed, and the helmet is in clear view. In this case, the key is relatively easy to use. The emergency procedures were performed by members of the project team on an unloaded Gamma Knife at the manufacturer's plant. When the helmet is inside the radiation unit, it is difficult to use the Allen key. The Allen screws to be engaged in the helmet cannot be seen from the outside of the radiation unit looking in. It is advised that the facility staff utilize a screen that prevents a clear view of the Allen screws in the helmet when they practice using the long key. 


\section{COMPUTERIZED TREATMENT PLANNING SYSTEM}

General recommendations for computerized treatment planning systems can be found in ICRU 42 (ICRU 1987) and in more detail in a recent report on the commissioning and QA of CTPS (Van Dyke et al. 1993). Detailed procedures for testing treatment planning systems have been described in the literature (e.g., Masterson et al. 1991, Jacky and White 1990, Shui et al. 1992). It is recognized that QA for CTPS is an evolving subject (e.g., AAPM 1993); the AAPM Radiation Therapy Committee Task Group 50 is developing standards for 3D radiation treatment planning systems, and Task Group 4 of the Administrative Committee is considering quality assurance in medical computer systems. The FDA has a reviewer guidance (FDA 1991) for computer controlled medical devices, but this guidance is not for software development, QA, or testing. The ACR is also planning a major effort in - establishing QA standards for CTPS.

The Gamma Knife Kula CTPS QA checks are limited. The treatment planning equipment consists of a dose planning computer and software called Kula, a plotter for printing isodose plots, and film digitizing equipment. Some sites also have separate and supplementary software to perform target volume calculations.

Treatment day checks of the planning equipment are made by the medical physicist or radiotherapy technician or both. A computer point dose calculation is made to check the current dose rate from the computer with a table generated manually using yearly and monthly calibration data and the decay law. The plotter integrity is checked (given that the computer dose calculation is accurate) by plotting a simple computer isodose curve calculation and comparing it to a standard profile of the same calculation. The digitizer accuracy and linearity is evaluated by making some simple geometric determinations from imaging films using the digitizer and comparing the results to manual determinations of the same geometric measures. There should be independent verifications of each of these checks.
The Gamma Knife comes with a custom treatment planning computer program named Kula. Kula runs on a dedicated VAX computer, i.e., the computer is used to run Kula and no other software. The treatment planning system is kept in the Gamma Knife suite. Access to the code is controlled by use of a password, and the correct date must be entered to initiate the program. The correct date is required to ensure the use of the current dose rate of the cobalt- 60 sources. Also, if the correct date is entered and the program doesn't respond positively, there may be a problem with the computer clock or the program.

A patient data file must be created to perform treatment planning. The patient data file will eventually contain all pertinent information required to generate a treatment plan or prescription. This information includes patient name, patient identification number, skull measurements, gamma angle, dose matrix parameters and calculation mode, and shot parameters (coordinates, time weightings, collimators, plug patterns, and total dose). Only one patient file can be open at a time. If a patient file is closed, it can only be opened by typing the exact name in the data file. If there is more than one file for that exact patient name, then the latest created file will be opened by default. So, to have more than one file accessible for each patient requires a different patient name for that patient on each file. This practice is not encouraged. Kula has a menu that allows the user to check any contents of the data file at any time during treatment planning. This provides an opportunity to verify data and inputs and recover from any errors. The patient files are stored chronologically. The users should be cognizant that computer disk space may become limited after several patients, if there is no deletion or external storage of patient files.

Typical checks on the program, as mentioned above, are to run dose calculations that can be checked manually against standards. Kula has two modes for calculating dose profiles. The cut-andmodify method is an approximation algorithm 
Section 10. Computerized Treatment Planning System

which interpolates between intervals in the dose matrix. The exact calculation mode runs slower than the cut-and-modify mode. There can be a difference in the dose calculation between the two modes by as much as $7 \%$, depending on the size of the dose matrix. The dose algorithm in Kula has an idiosyncrasy that can cause a calculational blow up for lesions near the skull boundary.
Software reliability is a significant issue in dose calculation: software errors can have very serious consequences to several patients. This project was not scoped to analyze the software reliability of Kula. 


\section{TRAINING}

Training in the use of the Gamma Knife is accomplished by apprenticeship and on-the-job training. The manufacturer contracts with experienced Gamma Knife users to train new users. The neurosurgeons or radiation oncologists usually spend at least a couple of weeks at a Gamma Knife facility learning about the use of the Gamma Knife and participating in treatments. The medical physicists often go to a different site than the physicians and will spend approximately one week at one facility and one week at a second facility. Elekta has a physician and physicist present for the first few treatments in a new facility with new users.

At the time of this study, there were no training time requirements: the physicians and physicist could decide to end their training at any time. There was no documented list of training topics nor a syllabus to ensure knowledge of all critical steps in the procedures for preparation, planning, and delivery of treatment. There was no record, certification, or validation of adequate knowledge of routine and emergency procedures.

There were no special requirements for Gamma Knife authorized users other than those specified in 10 CFR Part 35. Also, there was little evidence of refresher training. In essence, there was no known degree of content validity, predictive validity, measured learning, or training effectiveness.

A sample facility training program for new personnel learning about the Gamma Knife and its operation is contained in Appendix E. Refresher training for facility personnel usually coincides with annual radiation safety training.

Based on conversations with Elekta Instruments and the Gamma Knife users, it is expected that training will become more standardized and validated. 


\section{SUMMARY OF REGULATORY ISSUES AND CURRENT PRACTICES}

This section summarizes specific issues about existing NRC teletherapy regulations compared to current practices in the use of the Gamma Knife.

\section{CFR Part 35}

\subsection{Definitions - Misadministration}

The definition for a misadministration is characterized by a lower threshold for gamma stereotactic radiosurgery than for teletherapy consisting of greater than four fractions. The definitions for recordable events that apply to gamma stereotactic radiosurgery also apply to teletherapy.

\section{Defining the 'wrong treatment site' for} radiosurgery is problematical, since it is not clear how far off the isodose pattern needs to be before the event is a misadministration. "Position" errors are of two types. The correct isodose volume can be at the wrong coordinates, or the wrong isodose volume can be delivered to the correct coordinates, or both the isodose volume and coordinates are incorrect. There needs to be a misadministration threshold for a spatial or volume setup error. It might be expressed as a percentage of the lesion volume. It should also account for the inherent inaccuracies in stereotactic radiosurgery, which may range from a fraction of a millimeter to a few millimeters.

The current practice of Gamma Knife users is to treat errors on a case-by-case basis as they relate to wrong treatment site. An acceptable definition of misadministration in stereotactic radiosurgery due to irradiation of a 'wrong treatment site' should require participation of the stereotactic radiosurgery community, perhaps via the ISRS, AAPM, AANS, or ASTRO.

\subsection{Definitions - Written directive}

The information in the written directive for gamma stereotactic radiosurgery should include the radiation exposure time for each target point in addition to the target coordinates, collimator size, plug pattern, and total dose.

\subsection{Requirements for possession of sealed sources}

Section (c) on leak testing should include instructions on how to perform leak tests on the Gamma Knife where the source encapsulation is not accessible. The current practice conforms to NCRP 102 (see Section 6). It involves a wipe test on a collimating helmet after it has been placed and removed from the treatment position. The seams of the radiation unit, including those around the shielding door, are also wipe tested.

\subsection{Safety instruction}

The Gamma Knife project has identified a need and suggestions for simpler written safety and emergency procedures (see Section 9). A simple emergency procedure is to just turn off the console key or push an emergency-off button, if the treatment cycle is interrupted. This will shut down the unit and the treatment table will slide out from the radiation unit. The shielding door will not be completely closed, but personnel can quickly enter the treatment room and extract the patient. This procedure entails a trade-off in radiation exposure from the patient to the staff. In the manufacturer-prescribed emergency procedure, the patient is exposed to scattered radiation while being slowly hand-pumped out of danger, while the staff remains safe. In the simple procedure, the staff risks radiation exposure, but the patient is recovered much more quickly.

There is also a need for frequent, regularly scheduled emergency procedures refresher training or staff drills, since such procedures are rarely invoked. A specific suggestion to make the emergency training more realistic is to employ a template to screen the view of the practitioner when trying to use the long Allen key to release the fixed trunnions from the helmet.

\subsection{Full calibration measurements}

Section (b) needs to be re-written to accurately reflect the full calibration procedures currently employed for the Gamma Knife. 
Instead of 35.632 (b)(1), the current Gamma Knife practice is to define the calibration output as the output at the center of a 16-centimeter sphere of water-equivalent material. This determination is only done for the 18 -millimeter collimator using a calibrated (AAPM protocol) mini-ionization chamber. The accuracy of such a measurement is about $2 \%$ or less.

Provision 35.632 (b)(2) is not applicable to the Leksell Gamma Unit, since there is no need for a light beam localizing device: the radiation convergence point is fixed at the center of the radiation unit (within $0.5 \mathrm{~mm}$ ).

Condition 35.632 (b)(3), uniformity of the radiation field, is not applicable to the Gamma $\mathrm{Knife}$. The isodose profile is checked annually, by using film dosimetry, to verify that the profile remains within $1 \mathrm{~mm}$ on the $50 \%$ line of the theoretically correct profile for that gamma unit.

35.632 (b)(6) is not applicable to the Leksell Gamma Unit. No distance measuring and localization devices for medical use are required, since the sources and the radiation focal point are fixed.

\subsection{Periodic spot-checks}

Paragraph (a) on output spot-checks should be revised to accurately reflect the Gamma Knife system. Conditions 35.634 (a) (3), light beam localizing device, and (4), distance measuring and localization devices, are not applicable to the Leksell Gamma Unit, since the sources and their focal point are fixed. Also, monthly output checks -35.634 (a)—on the Gamma Knife are not needed once it has been established that the output obeys a cobalt- 60 decay law, again since the sources and focal point are stationary. For instance, it may be necessary to have monthly output checks for only the first six months after source installation and then only every quarter or semi-annually in addition to the full calibration measurements.

Paragraph (d) on monthly equipment safety spotchecks should include a monthly check on the helmet microswitches.

\subsection{Training for teletherapy}

The issue of training and re-training on the Gamma Knife needs to be fully considered (refer to Section 11). There is a need for a consistent, measured, and validated training program for physicians and technicians. This will require training topics, documents, or a record to demonstrate that a trainee has sufficient knowledge of the routine and emergency procedures required for the safe operation of the Gamma Knife. It may also require certification from the Gamma Knife user community. Refresher training should also be codified. Elekta Instruments has expressed an interest in standardizing training for Gamma Knife users.

Written procedures or checklists for Gamma Knife treatments can aid training and improve quality assurance. Users can review the protocols to check their performance and upgrade with improved practices. The checklists can also be used to avoid errors of omission. Teletherapy and linear accelerator practitioners use checklists as standard procedures.

The NRC authorized users (with a couple of exceptions) are medical physicists and radiation oncologists. However, the majority of Gamma Knives are controlled or dominated by neurosurgeons. The NRC needs to decide whether authorized neurosurgeons should be on the Gamma Knife licenses and what the training requirements should be for an authorized neurosurgeon. There is precedent for this, with a couple of neurosurgeons qualified, on facility licenses, as authorized users. Members of the stereotactic radiosurgery community-perhaps through the ISRS or AANS-may help NRC develop SRS authorization standards for neurosurgeons.

\section{Regulatory Guide 10.8-Guide for the Preparation of Applications for Medical Use Programs and Draft Regulatory Guide FC-414-Guide for the Preparation of Applications for Licenses for Medical Teletherapy Programs}

Model procedures that licensed applicants may use to plan radiation safety programs should be written to specifically address the Gamma Knife 
system and facilities. These should include a model training and retraining program (see Section 11 and Appendix E); model procedures for leak-testing the Gamma Knife (see Section 6); model emergency or abnormal event procedures (see Section 9); and model treatment planning and treatment procedures or checklists, if deemed appropriate.

\section{Regulatory Guide 8.33-Quality Management Program}

This regulatory guide provides guidance to licensees and applicants for developing policies and procedures for the Quality Management (QM) Program of 10 CFR Part 35 (35.2 and 35.32). The guide does not restrict or limit the licensee from using other guidance that may be equally useful in developing a QM program, for example, from voluntary standards setting organizations.

Section C. 4 of Regulatory Guide 8.33 addresses suggested policies and procedures for gamma stereotactic radiosurgery.

\section{Section C.4.3}

The guidance in this section states:

The licensee should establish a procedure to have the neurosurgeon, the oncology physician, and the radiation therapy physicist date and sign a plan of treatment that includes, for each target point, the coordinates, the plug pattern, the collimator size, the exposure time, the . target dose, and the total dose before administering treatment.

In the current practices with the Gamma Knife, only two people typically sign the plan of treatment or written directive. The QM Program regulations require that the written directive be dated and signed by an unauthorized user prior to administration of radiation. Most of the authorized users at Gamma Knife facilities are the medical physicists and radiation oncologists. The neurosurgeons are typically not authorized, since they do not meet the training requirements (10 CFR Part 960) for teletherapy authorized users.

The terms "target point" and "target dose" used in this section are not common terms in usage with the Gamma Knife. Presumably, target point refers to each planned "shot" of the treatment plan and not points in the dose matrix used to calculate the dose distributions. Also, the treatment planning software does not produce a (target) dose for each shot or target point, but rather a set of isodose curves and a total dose for the aggregation of all shots in the treatment plan.

\section{Section C.4.6}

The language in this section is:

The licensee should establish a procedure to check computer-generated dose calculations by examining the computer printout to verify that correct data for the patient were used in the calculations.

This needs to be re-written to accurately reflect how computer-generated dose profiles are verified for correct patient and appropriate treatment approach, i.e., via contour overlays. The words "computer printout" should be replaced by "dose profiles, treatment plan, or prescription."

\section{Section C.4.7}

The guidance of this section states:

The licensee should establish a procedure to check that the computer-generated dose calculations were correctly input to the gamma stereotactic radiosurgery unit.

This is inaccurate about how dosage to the patient is determined with the Gamma Knife unit. The computer generated dose calculations take the form of a treatment plan or prescription for a series of shots with the gamma stereotactic radiosurgery unit. The prescribed dose is delivered to the patient by correctly setting the necessary parameters for each shot; which include the Gamma Knife $x-, y-$, and $z$-coordinates, the gamma angle, the collimator size, the plug pattern (if any), and target exposure time.

\section{Section C.4.9}

The regulatory position of this section says:

If the authorized use determines that delaying treatments in order to perform the checks of the dose calculations (see 
Regulatory Positions 4.6 and 4.7) would jeopardize the patient's health because of the emergent nature of the patient's medical condition, the checks of the calculations should be performed within two working days of the treatment.

This precautionary position is irrelevant for the Gamma Knife. Gamma Knife treatments are not emergency treatments. The treatment process requires such planning that there would never be the case where the dose calculations couldn't be checked (except in negligence) before treatment. This section should be stricken.

\section{Section C.4.11}

The language in this section is:

The licensee should establish procedures to perform periodic review of the gamma stereotactic radiosurgery QM program. Guidance on periodic reviews is provided in Regulatory Position 6. A QM program review is required by $10 \mathrm{CFR}$ Part

$$
\text { 35.32(b). }
$$

Based on the facilities visited during this study, Gamma Knife treatments are reviewed usually within two weeks of treatment. There is, on average, 170 treatments per facility per year. It was noted (see Section 7) that the sort of system data kept on the Gamma Knife could lend to statistical quality control procedures. 


\section{BIBLIOGRAPHY}

\section{American Association of Physicists in Medicine (AAPM)}

Comprehensive QA for Radiation Oncology. Report of AAPM Radiation Therapy Committee Task Group \#40, August 1993.

Benedetto, Anthony R., H. K. Huang, and Don P. Ragan, eds. Computers in Medical Physics. Medical Physics Monograph No. 17. Vermont: American Institute of Physics, 1990.

Fullerton, Gary D., David T. Kopp, Robert G. Waggener, Edward W. Webster, eds. Biological Risks of Medical Irradiations. Medical Physics Monograph No. 5. New York: American Institute of Physics, 1980.

Huq, Saiful and Ravinder Nath. "Comparison of IAEA 1987 and AAPM 1983 Protocols for Dosimetry Calibration of Radiotherapy Beams." Medical Physics 18 No. 1 (1991): 2635 .

Kereiakes, James G., ed. Radiation Oncology Physics. Medical Physics Monograph No. 15. New York: American Institute of Physics, 1987.

Paliwal, Bhudatt R., John F. Fowler, Donald E. Herbert, Timothy J. Kinsella, and Colin G. Orton, eds. Prediction of Response in Radiation Therapy: Part I-The Physical and Biological Basis. Proceedings of the AAPM Symposium "Third International Conference on Dose, Time and Fractionation" held in Madison, Wisconsin, 14-17 September, 1988.

Physical Aspects of Quality Assurance in Radiation Therapy. Report Series No. 13, Radiation Therapy Committee Task Group \#24, with contribution from Task Group \#22, 1984.
"A Protocol for the Determination of Absorbed Dose from High-Energy Photon and Electron Beams." Task Group \#21, Radiation Therapy Committee, American Association of Physicists in Medicine. Medical Physics 10 (6), 1983: 741-771.

Quality Assurance for Remote Afterloaders, Remote Afterloading Systems Task Group \#41, Glenn P. Glasgow, Chairman.

Forthcoming.

Quality Assurance of Clinical Treatment Planning. Report of Task Group \#53 of the Radiation Therapy Committee, American Association of Physicists in Medicine, 1993. Forthcoming.

Quality Assurance Radiotherapy Equipment. Proceedings of an AAPM Symposium held in Kansas City, Missouri, June 4-5, 1982.

Radiotherapy Safety. AAPM Proceedings Series No. 4.

Rotating Scintillation Camera Spect Acceptance Testing and Quality Control. Report Series No. 22, Nuclear Medicine Committee Task Group, 1987.

Scintillation Camera Acceptance Testing \& Performance Evaluation. Report Series No. 6, Nuclear Medicine Committee, 1980.

Specification of Brachytherapy Source Strength. Report Series No. 21, Radiation Therapy Committee Task Group \#32, 1987.

Stereotactic Radiosurgery, Radiation Therapy Committee Task Group \#42. Forthcoming.

Thomadsen, Bruce, ed. Radiotherapy Safety. The Proceedings of a short course at the University of Wisconsin 25-26 March 1982. New York: AAPM, 1984. 
Wright, Ann E. and Arthur L. Boyer, eds. Advances in Radiation Therapy Treatment Planning. Medical Physics Monograph No. 9. New York: American Institute of Physics, 1983.

American College of Medical Physics (ACMP)

Horton, John L. and George Starkschall, eds. Quality Assurance in Radiotherapy Physics. Proceedings of an American College of Medical Physics Symposium, May 1991. Wisconsin: Medical Physics Publishing, 1991.

Proactive Certification Program Inspector's Manual, 1988 Edition.

Radiation Control and Quality Assurance in Radiation Oncology-A Suggested Protocol, ACMP Report No. 2, 1986.

\section{American College of Radiology (ACR)}

ACR Standards for Monitoring and Evaluation in Departments of Diagnostic Radiology and Nuclear Medicine, (Rev. 3), 1990.

Brickner, Theodore J., M.D. "Carcinoma of the Cervix." Pattems of Care Study Newsletter 1 (1990-91): 1-9.

Practice Accreditation Program in Radiation Oncology, January 1989.

Practice Survey Guide, January 1989.

Quality Assurance Program in Radiation Oncology, February 1989.

Svensson, Goran K., Physical Aspects of Quality Assurance, prepared for the Committee on Quality Assurance in Radiation Oncology, 6 April 1990.

\section{American National Standards Institute (ANSI)}

Guide for Administrative practices in Radiation Monitoring, N13.2, 1969.

Standard for the Specification of Portable X or Gamma Radiation Survey Instruments, N13.4, 1971.
Radiation Protection Instrumentation Test and Calibration, N323, 1978.

Integrity and Test Specifications for Selected Brachytherapy Sources, N44.1, 1973.

Standard for Leak-Testing Radioactive Brachytherapy Sources, N44.2, 1973.

Guidelines for Maintaining Cobalt-60 and Cesium-137 Teletherapy Equipment,N449, 1974.

Procedures for Periodic Inspection of Cobalt-60 and Cesium-137 Teletherapy Equipment, N449.1, 1978.

\section{American Society for Therapeutic Radiology and Oncology (ASTRO)}

The official journal of ASTRO is the International Journal of Radiation Oncology, Biology, Physics, published monthly by Pergamon Press. ASTRO, as a scientific organization for members of the radiation oncology and medical physics community, has no task groups or committees looking at standards or specifications. The journal publishes scientific papers which include papers on the Gamma Knife and remote afterloaders from time to time. Any official positions of the Society would be published in the journal.

\section{British Standards Institution (BSI)}

Medical Electrical Equipment: Part 1. General Requirements for Safety, 1 August 1990.

Medical Electrical Equipment: Section 2.1 Specification for Medical Electron Accelerators in the Range $1 \mathrm{MeV}$ to $50 \mathrm{MeV}$. January 1989.

Medical Electrical Equipment: Section 2.11 Specification for Gamma Beam Therapy Equipment Supplement 1. Revised and Additional Text. January 1989.

Medical Electrical Equipment: Section 2.11 Specification for Gamma Beam Therapy Equipment. January 1989. 
Medical Electrical Equipment: Section 2.17 Specification for Remote-Controlled Automatically-Driven Gamma-Ray Afterloading Equipment. 1 December 1990.

Medical Electrical Equipment: Section 2.9 Specification for Dosimeters Used in Radiotherapy with Electrically-Connected Radiation Detectors. January 1988.

Recommendation for Data on Shielding from Ionizing Radiation: Part 1. Shielding from Gamma Radiation. January 1966.

Recommendation for Data on Shielding from Ionizing Radiation: Part 2. Shielding from XRadiation. January 1972.

Specification: Sealed Radioactive Sources. January 1976.

\section{College of American Pathologists (CAP)}

"Nuclear Medicine-Section VII." In Inspector's Manual (1989), Commission on Laboratory Accreditation, 1990.

\section{Food and Drug Administration (FDA)}

Application of the Medical Device GMPS to Computerized Devices and Manufacturing Processes, Medical Device GMP Guidance for FDA Investigators. Office of Compliance and Surveillance, November 1990.

Availability and Use of Standard Medical Device Reporting Forms. Letter to Manufacturers and Importers of Medical Devices from Stewart Crumpler, Director, Division of Management Information, 28 August 1991.

Barnett, Mark H. The Biological Effects of Ionizing Radiation: An Overview. HEW Publication FDA 77-8004, October 1976.

A Basic Quality Assurance Program for Small Diagnostic Radiology Facilities. HHS Publication FDA 83-8218, September 1983.

Checklist for Establishing a Diagnostic Radiology Quality Assurance Program. HHS Publication FDA 83-8219, September 1983.
"Clinical Investigators: Chapter 48-Bioresearch Monitoring-Human Drugs." In FDA Compliance Program Guidance Manual, 1 September 1991.

Device Recalls: A Study of Quality Problems. Office of Compliance and Guidance, Compliance Guidance Series, HHS Publication FDA 90-4235, 1 January 1990.

Device User Facility Reporting Sections of the Safe Medical Devices Act of 1990. Public Law 101-629, Center for Devices and Radiological Health, January 1990.

"Enforcement of the Medical Device Reporting (MDR) Regulation." In Compliance Program Guidance Manual,. Program No. 7382.011, issue date 13 February 1989.

Fiscal Year 1991 Accomplishments. Office of Training and Assistance, January 1991.

Highlights of the Safe Medical Devices Act of 1990 (Public Law 101-629). May 1991.

Highlights of the Safe Medical Devices Act of 1990. HHS Publication FDA 91-4243, August 1991.

How to Order Publications. Division of Small Manufacturers Assistance (DSMA), 15 May 1991.

Imaging Ability of Collimators in Nuclear Medicine. HHS Publication FDA 79-8077, December 1978.

Initial Registration of Device Establishment. Department of Health and Human Services, FDA Form No. 2891, January 1991.

"Inspection of Medical Device Manufacturers." In Compliance Program Guidance Manual. Program No. 7382.830 , issue date January 1989.

Instructions for Sampling and Reviewing Records Kept in Manufacturer's Device Complaint Files. FDA Program 7382.830 Attachment B, October 1985. 
An Introduction to Medical Device Regulations. HHS Publication FDA 87-4222.

Joint CDRH and State Quality Assurance Surveys in Nuclear Medicine: Phase 2Radiopharmaceuticals. HHS Publication FDA 86-8266, August 1986.

"Medical and Radiological Device Monitoring and Quality Conformance." In Compliance Program Guidance Manual. January 1, 1989.

Medical Device Establishment Registration: Information and Instructions. HHS Publication FDA 87-4199, May 1987.

Medical Device Facility User Reporting INTERIM GUIDANCE. FDA Department of Health and Human Services, November 1991.

Medical Device GMP Guidance for FDA Investigators. HHS Publication FDA 84-4191, April 1987.

Medical Device Good Manufacturing Practices Manual. HHS Publication FDA 91-4179, January 1991.

"Medical Device Premarket Approval and Postmarket Inspections." In Food and Drug Administration Compliance Program Guidance Manual. Program No. 7383.001, issue date 28 December 1990.

Medical Device Problem Reporting and the Health Care Profession. HHS Publication FDA 85-4196, January 1985.

"Medical Device Problem Reporting." In FDA Compliance Program Guidance Manual. Program No. 7382.010, issue date October 1989.

Medical Device Reporting. Cover Letter from Dept. of Health \& Human Services, January 1991.

Medical Device Reporting. Cover Letter from Dept. of Health \& Human Services, 27 March 1985.
Medical Device Reporting Questions and Answers. Center for Devices and Radiological Health (DRH) Compliance Guidance Series, HHS Publication FDA 88-4226, February 1988.

National Archives. Department of Health, Education, and Welfare, Food and Drug Administration. "Medical Devices: Reorganization, Republication and Recodification." Federal Register, Vol. 41, No. 31, Friday, 13 February 1976.

"Part 820-Good Manufacturing Practice for Medical Devices: General." Reprint of CFR Part 820, July 1978.

Premarket Approval (PMA) Manual Supplement. HHS Publication FDA 91-4245, August 1, 1991.

Premarket Notification: 501(k), Regulatory Requirements for Medical Devices. HHS Publication FDA 90-4158, August 1990.

Preproduction Quality Assurance Planning: Recommendations for Medical Device Manufacturers. HHS Publication FDA 904236, September 1989.

Radiographic Film Processing Quality Assurance: A Self-Teaching Workbook. HHS Publication FDA 81-8146, January 1981.

Regulatory Requirements for Medical Devices: a Workshop Manual. HHS Publication FDA 894165, May 1989.

Reviewer Guidance for Computer Controlled Medical Devices Undergoing 510(k) Review. Office of Device Evaluation, Center for Devices and Radiological Health, January 1991.

Safe Medical Devices Act of 1990. Public Law 101-629, Center for Devices and Radiological Health (DRH), 28 November 1990.

A Summary of the Device Use Reporting Requirements of the Safe Medical Devices Act of 1990. Public Law 101-629, 15 March 1991. 
Two-Track GMP Inspection Strategy. FDA Program 7382.830 Attachment A, October 1985.

U.S. Congress. House. Committee on Energy and Commerce. Safe Medical Devices Act of 1990. 101st Cong., 2d sess., 1990. H. Report 101808.

Workshop Manual for Computer-Interfaced Scintillation Camera Quality Assurance. HHS Publication FDA 86-8268, September 1986.

Workshop Manual for Quality Control of Scintillation Cameras in Nuclear Medicine. HEW Publication FDA 76-8039, May 1976.

\section{Health Care Financing Administration (HCFA)}

Interpretive Guidelines and Survey ProceduresHospitals, Appendix A. January 1986.

Institute of Physical Sciences in Medicine (IPSM)

Dosimetry and Clinical Uses of Afterloading Systems. IPSM Report No. 45, 1986.

Radiation Protection in Radiotherapy. IPSM Report No. 46, 1986.

\section{International Atomic Energy Association (IAEA)}

Basic Safety Standards for Radiation Protection, Safety Series No. 9.

Physical Aspects of Radioisotope Brachytherapy, Tech. Report Series No. 75.

Manual of Dosimetry in Radiotherapy, Tech. Report Series No. 110.

Handbook on Calibration of Radiation Protection Monitoring, Tech. Report Series No. 133.

Measurement of Short-Range Radiations, Tech. Report Series No. 150.

Absorbed Dose Determination in Photon and Electron Beams, Tech. Report Series No. 277.
The Joint Commission on Accreditation of Healthcare Organizations (JCAHO)

Accreditation Manual for Hospitals, Volume I: Standards. January 1991.

Guide to Quality Assurance. January 1988.

Hospital Accreditation Program: Scoring Guidelines. Monitoring \& Evaluation Standards. July 1990.

"Nuclear Medicine Services (NM)." In Accreditation Manual for Hospitals. 1990.

"Radiation Oncology Services (RA)." In Accreditation Manual for Hospitals. 1990.

M.D. Anderson Cancer Center

Quality Assurance Plan. Department of Clinical Radiotherapy 1988.

National Cancer Institute (NCI)

Criteria for Radiation Oncology in Multidisciplinary Cancer Management. 1981.

\section{National Council on Radiation Protection and} Measurements (NCRP)

Dosimetry of X-Ray and Gamma-Ray Beams for Radiation Therapy in the Energy Range $10 \mathrm{keV}$ to $50 \mathrm{MeV}$. NCRP Report No. 69, Washington, D.C., 15 December 1981.

A Handbook of Radioactivity Measurements Procedures, 2nd ed. NCRP Report No. 58, 1978.

Implementation of the Principle of As Low As Reasonably Achievable (ALARA) for Medical and Dental Personnel. NCRP Report No. 107, 1990.

Instrumentation and Monitoring Methods for Radiation Protection. NCRP Report No. 57, Washington, D.C., 1 May 1978. 
Medical X-Ray, Electron Beam and Gamma-Ray Protection for Energies up to $50 \mathrm{MeV}$ : Equipment Design, Performance, and Use. NCRP Report No. 102, Bethesda, MD, 30 June 1989.

Misadministration of Radioactive By-Product Material in Medicine-Scientific Background. National Council on Radiation Protection and Measurements, NCRP Commentary No. 7 , Bethesda, MD, 11 July 1991.

Operational Radiation Safety-Training. NCRP Report No. 71, Bethesda, MD, 15 March 1983.

Protection Against Radiation from Brachytherapy Sources. NCRP Report No. 40, Washington, D.C., 1 December 1971.

Radiation Protection for Medical and Allied Health Personnel. NCRP Report No. 105, Bethesda, MD, 30 October 1989.

Recommendations on Limits for Exposure to Ionizing Radiation. NCRP Report No. 91, 1987.

Safe Handling of Radioactive Materials. NCRP Report No. 30, Washington, D.C., 9 March 1964.

Specification of Gamma-Ray Brachytherapy Sources. NCRP Report No. 41, Washington, D.C., 1 April 1974.

Structural Shielding Design and Evaluation for Medical Use of X Rays and Gamma Rays of Energies up to $10 \mathrm{MeV}$. NCRP Report No. 49, Bethesda, MD, 15 July 1991.

\section{National Institute of Standards and Technology (NIST)}

"Calibration of Opthalmic Applicators at NIST: A Revised Approach." Medical Physics 18 (4), 1991.

"Measurement of Absorbed Doses near Metal and Dental Material Interfaces Irradiated by X-and Gamma-ray Beams." Reprint from Phys. Med. Biol., 35 (3), 1990.
"Metal-polysiloxane Shields for Radiation Therapy of Maxillo-facial Tumors." Reprint from Medical Physics 18 (2), 1991.

The Need for Brachytherapy Source Calibration in the United States. Presented at the ICRM International Symposium on Radionuclide Metrology and its Applications, Madrid, May 1991.

"Novel Radiation Dosimetry Systems." Reprint of the Proceedings from High Dose Dosimetry for Radiation Processing.

"Radiation Survey Instruments and Calibrations." NIST Workshop Proceedings, Gaithersburg, MD, 10-12 July 1984.

"Sensitometry of the Response of a New Radiochromic Film Dosimeter to Gamma Radiation and Electron Beams." Reprint from Nuclear Instruments and Methods in Physics Research A302, 1991.

\section{Society of Nuclear Medicine (SNM)}

Quality Assurance Resource Manual for Nuclear Medicine. 1990.

\section{U.S. Nuclear Regulatory Commission (NRC)}

Brodsky, A. Principles and Practices for Keeping Occupational Radiation Exposures at Medical Institutions as Low as Reasonably Achievable. NUREG-0267 Revision 1, 30 August 1982.

"Guide for the Preparation of Applications for Medical Use Programs." Regulatory Guide 10.8 .

"Guide for the Preparation of Applications for Licenses in Medical Teletherapy Programs." Draft Regulatory Guide FC 414-4.

"Quality Management Program." Regulatory Guide 8.33.

"Information Relevant to Ensuring that Occupational Radiation Exposures at Medical Institutions will be as Low as Reasonably Achievable." Regulatory Guide 8.18. 
Piner, E. and B. Smith. Analysis of Selected Incidents. Internal NRC Report, 11 May 1990.

"Proposed QA Rule and Reporting Requirements." Meeting Proceedings from the NRC Meeting with AAPM, ACMP, ACR, AES, and ASTRO, Reston, VA, 15 December 1990

"Quality Assurance in the Medical Use of Biproduct Material Survey for Licensees." Prepared by the Science Applications International Corporation, McLean, VA, 30 January 1991.

"Quality Assurance in the Medical Use of Biproduct Material Task 1 and Task 3." Prepared by the Science Applications International Corporation, McLean, VA, for the NRC. NRC-FIN-L1290-0, 29 March 1991.

"Radiation Safety Surveys at Medical . Institutions." Regulatory Guide 8.23.

"Risk Assessment: A Survey of Characteristics, Applications, and Methods Used by Federal Agencies for Engineered Systems." U. S. Nuclear Regulatory Commission, November 1992.

Shalek, Robert J. (instructor). "Verification Measurements on Cobalt- 60 Irradiators: A Short Course for Inspectors of the Nuclear Regulatory Commission," Houston, TX, 19-21 April 1978.

"Unauthorized Service on Teletherapy Units by Nonlicensed Maintenance Personnel." Office of Inspection and Enforcement, Information Notice No. 87-18, 8 April 1987.

\section{Additional Sources}

NOTE: Int. J. Radiation Oncology Biol. Phys. is an abbreviation for International Journal of Radiation Oncology, Biology, and Physics, the official journal of ASTRO, published monthly by Pergamon Press.
Andreo, Pedro. "Uncertainties in Dosimetric Data and Beam Calibration." Presented at the 17th International Congress of Radiology, Paris, 14 July, 1989. Int. J. Radiation Oncology Biol. Phys. 19 (1990): 1233-1247.

Banks, W. W. and E.D. Jones. "Project Implementation Plan, Quality Assurance for Gamma Knives." UCRL-ID-110116, Lawrence Livermore National Laboratory, March 1992.

Banks, W. W., E. D. Jones, and P. A. Rathbun. "Risk and Dose Assessment Methods in Gamma Knife Q.A." Transactions of the Twentieth Water Reactor Safety Information Meeting, NUREG/CP-0125. Bethesda, MD, October 1992.

Berk, Harold W. and Suresh K. Agarwal. "Quality Assurance of Leksell Gamma Units." Stereotactic and Functional Neurosurgery 57 (1991): 106-112.

Blanco, S., M. A. Lopez-Bote, and M. Desco. "Quality Assurance in Radiation Therapy: Systematic Evaluation of Errors During the Treatment Execution." Radiotherapy and Oncology 8 (1987): 256-261.

Drzymala, R. E., R. Mohan, L. Brewster, J. Chu, M. Goitein, W. Harms, and M. Urie. "DoseVolume Histograms." Int. J. Radiation Oncology Biol. Phys. 21 (1991): 71-78.

Flickinger, J. C., L. D. Lunsford, A. Wu, and A. Kalend. "Predicted Dose-Volume Isoeffect Curves for Stereotactic Radiosurgery with the 60Co Gamma Unit." Acta Oncologica 30 (1991): 363-367.

Flickinger, John C. "An Integrated Logistic Formula for Prediction of Complications from Radiosurgery." Int. J. Radiation Oncology Biol. Phys. 17 (1989): 879-885. 
Flickinger, John C., M. D., Ann Maitz, Andre Kalend, L. Dade Lunsford, M.D. and Andrew Wu. "Treatment Volume Shaping with Selective Beam Blocking Using the Leksell Gamma Unit." Int. J. Radiation Oncology Biol. Phys. 19 (1990) 783-789.

Flickinger, John C., M. D., L. Dade Lunsford, M.D., Andrew Wu, Ann Maitz, and Andre Kalend. "Treatment Planning for Gamma Knife Radiosurgery with Multiple Isocenters." Int. J. Radiation Oncology Biol. Phys. 18 (1990) 1495-1501.

Galloway Jr., Robert L., Robert J. Maciunas, and James W. Latimer. "The Accuracies of Four Stereotactic Frame Systems: An Independent Assessment." Biomedical Instrumentation \& Technology 25 (1991): 457

Glisch, Cheryl R., Carol A. Limberg, Susan Barber-Derus, Michael T. Gillin. "Clinical Application of a Record and Verify System in Radiation Oncology." Radiologic Technology: 251.

Hargrave, N. J., R. B. Huntley, and P. D. Allen. "Standards and Calibration Facilities of the Australian Radiation Laboratory for Ionizing Radiation Beams." Australiasian Pysical \& Engineering Sciences in Medicine 12 (1989): 92-99.

Houdek, Pavel V., James G. Schwade, Christopher F. Serago, Howard J. Landy, Vincent Pisciotta, Xiaodong Wu, Arnold M. Markoe, Alan A. Lewin, Andre A. Abitbol, Joanne L. Bujnoski, Evelyn S. Marienberg, Jeffrey A. Fielder, and Murray S. Ginsberg. "Computer Controlled Stereotaxic Radiotherapy System." Int. J. Radiation Oncology Biol. Phys. 22 (1991): 175-180.

International Organization for Standardization. ISO 9000: International Standards for Quality Management., 3rd edition. Geneva, Switzerland, 1993.
Jacky, J. and C. P. White. "Testing a 3D Radiation Therapy Planning Program." Int. J. Radiation Oncology Biol. Phys. 18 (1990): 253-261.

Kahn, Faiz M. The Physics of Radiation Therapy. Baltimore: Williams \& Wilkins, 1994.

Kelly, Patrick, M. D. Tumor Stereotaxis. Philadelphia: W. B. Saunders Company, 1991.

Kooy, Hanne M., Lucien A. Nedzi, M. D., Jay S. Loeffler, M. D., Eben Alexander III, M. D., Chee-Wai Cheng, Edward G. Mannarino, Edward J. Holupka, and Robert L. Siddon. "Treatment Planning for Stereotactic Radiosurgery of Intra-Cranial Lesions." Int. J. Radiation Oncology Biol. Phys. 21 (1991): 683-693.

Leksell, Lars, M.D. Stereotaxis and Radiosurgery: An Operative System. Illinois: Charles C. Thomas Publisher, 1971.

Leunens, G. J. Van Dam, A. Dutreix, and E. van der Schueren. "Quality Assurance in Radiotherapy by In Vivo Dosimetry." Radiotheraph and Oncology 17 (1990): 141151.

Lunsford, L. Dade, M.D. Stereotactic Radiosurgery Update. Proceedings of the International Stereotactic Radiosurgery Symposium held in Pittsburg, Pennsylvania, June 1991. New York: Elsevier, 1991.

Lunsford, L. Dade, M.D., J. C. Flickinger, M.D., Glenn Lindner, and Ann Maitz. "Stereotactic Radiosurgery of the Brain Using the First United States 201 Cobalt-60 Source Gamma Knife." Neurosurgery 24 (1989): 151.

Lunsford, L. Dade, M.D., Marc R. Mayberg and H. Richard Winn, eds. Neurosurgery Clinics of North America, Volume 3/Number 1. Philadelphia: Harcourt Brace Jovanovich, Inc., 1992. 
Lutz, Wendell, Ken. R. Winston, andNasser Maleki. "A System for Stereotactic Radiosurgery with a Linear Accelerator." Int. J. Radiation Oncology Biol. Phys. 14 (1988): 373-381.

Lyman, John T. and Anthony B. Wolbarst. "Optimization of Radiation Therapy, III: A Method of Assessing Complication Probabilities from Dose-Volume Histograms." Int. J. Radiation Oncology Biol. Phys. 13 (1987): 103-109.

Maitz, A.H., A. Wu, A. Kalend, J.C. Flickinger, L.D. Lunsford, D.S. Kondziolka, W. D. Bloomer. "Verification Criteria for Determining the Accuracy of the Dose Delivery System as Compared With the Treatment Planning System." In Stereotactic Radiosurgery Update, Proceedings of the International Stereotactic Radiosurgery Symposium, Pittsburgh, PA, June, 1991, L.D. Lunsford, ed., pp. 239-242, Elsevier, 1992.

Maitz, A.H., L. Dade Lunsford, M.D., A. Wu, Glenn Lindner and J. C. Flickinger M. D. Shielding Requirements On-Site Loading and Acceptance Testing of the Leksell Gamma Knife. New York: Pergamon Press, 1990.

Martinez, A. A., C. G. Horton, and R. F. Mould, eds. Brachytherapy: HDR and LDR. Proceedings of the Brachytherapy Meeting ' titled "Remote Afterloading: State of the Art," held in Dearborn, Michigan, 4-6 May 1989. Columbia, MD: Nucletron Corporation, 1990.

Masterson, M.E., G. Barest, C.S. Chui, K.P. Doppke, R.D. Epperson, W.B. Harms, K.E. Krippner, R. Mohan, E.D. Slessinger, M.R. Sontag, M.M. Urie, R.E. Wallace, J.W. Wong. "Institutional Experience in Verification of External Dose Calcualtions," Medical Physics, 21 (1991): 37-58.
Mattsson, O., H. Svensson, G. Wickman, S. R. Domen, J. S. Pruitt, and R. Loevinger. "Absorbed Dose in Water: Comparison of Several Methods Using a Liquid Ionizing Chamber." Acta Oncologica 29 (1990): 235.

McLaughlin, W. L. "Reference Dosimetry and Measurement Quality Assurance." Appl. Radiat. Isot. 40 (1989): 945-951.

Mijnheer, B. J., J. J. Battermann, and A. Wambersie. "What Degree of Accuracy is Required and can be Achieved in Photon and Neutron Therapy?" Radiotherapy and Oncology 8 (1987): 237-252.

Nedzi, Lucien, M. D., Hanne Kooy, Eben Alexander III, M. D., Rebecca S. Gelman, and Jay S. Loeffler, M. D. "Variables Associated with the Development of Complications from Radiosurgery of Intracranial Tumors." Int. J. Radiation Oncology Biol. Phys. 21 (1991): 591-599.

Phillips, Mark. H., Kenneth A. Frankel, John T. Lyman, Jacob I. Fabrikant, Richard P. Levy. "Comparison of Different Radiation Types and Irradiation Geometries in Stereotactic Radiosurgery." Int. J. Radiation Oncology Biol. Phys. 18 (1990): 211-220.

Photon Treatment Planning Collaborative Working Group. "State-of-the-Art of External Photon Beam Radiation Treatment Planning." Int. J. Radiation Oncology Biol. Phys. 21 (1991): 9-23.

"Protocol for the Dosimetry of X- and GammaRay Beams with Maximum Energies Between 0.6 and $50 \mathrm{MeV}$." Scientific Committee on Radiation Dosimetry of the American Association of Physicists in Medicine. Phys. Med. Biol. 16 (1971): 379-396.

"Radiation Protection." 1990 Recommendations of the International Commission on Radiological Protection, ICRP Publication 60; Annals of the ICRP, Vol. 21, No. 1-3, Pergamon Press, 1991. 
Redmond, Paul W. "Nuclear Regulatory Commission Report." Medical Dosimetry 13 (1988): 87-93.

Rogers, D. W. O. and C. K. Ross. "The Role of Humidity and Other Correction Factors in the AAPM TG-21 Dosimetry Protocol." Medical Physics15 (1988): 40.

Sadler, Larry R., Charles A. Jungreis, L. Dade Lunsford, and Matthew M. Trapanotto. "Angiographic Technique to PRecede Gamma Knife Radiosurgery for Intracranial Arteriovenous Malformations." AJNR 11 (1990): 1157-1161.

Seaver, D.A., and W.G. Stillwell. "Procedures for Using Expert Judgment to Estimate Human Error Probabilities in Nuclear Power Plant Operations." NUREG/CR-2743, Decision Science Consortium and Sandia National Laboratories, March 1983.

Shui, S.S., S. Tung, K. Hogstrom, J.W. Wong, R.L. Gerber, W.B. Harms, J.A. Purdy, R.K. Ten Haken, D.L. McShan, B.A. Fraass. "Verification Data for Electron Beam Dose Algorithms," Medical Physics, Vol. 19 (1992): 623-636.

Smith V., L. Verhey, E. Jones, and J. Lyman. "Consequences to the Patient in the Event of Hydraulic Unit Failure." Forthcoming in Stereotactic and Functional Neurosurgery, Vol. 61, Supplement 1, 1993.

Steiner, Ladislau, M. D., Christer Lundquist, M. D., David Forster, M. D., and Erik-Olof Backlund, M. D., eds. Radiosurgery: Baseline and Trends. New York: Raven Press, 1992.

Suntharalingam, N. and Karl-Axel Johansson. "Quality Assurance/Physics/Dosimetry." Int. J. Radiation Oncology Biol. Phys. 4 (1988): 521524.
Tsai, Jen-San, Beverly A. Buck, Goran K. Svensson, Eben Alexander III, Chee-Wai Cheng, Edward G. Mannarino, and Jay S. Loeffler. "Quality Assurance in Stereotactic Radiosurgery Using a Standard Linear Accelerator." Int. J. Radiation Oncology Biol. Phys. 21 (1991): 737-748.

Urie. M. M., M. Goitein, K. Doppke, J. G Kutcher, T. LoSasso, R. Mohan, J. E. Munzenrider, M. Sontag, J. W. Wong. "The Role of Uncertainty Analysis in Treatment Planning." Int. J. Radiation Oncology Biol. Phys. 21 (1991): 91-107.

"Use of Computers in External Beam Radiotherapy Procdures with High-Energy Photons and Electrons," International Commission on Radiation Units and Measurement (ICRU), Report No. 42, 1987.

Van Dyke, J., R. Barnett, J. Cyglar, P. Shragge. "Commissioning and Quality Assurance of Treatment Planning Computers." Int. J. Radiation Oncology Biol. Phys., 26 (1993): 261-273.

Wolbarst, Anthony B., Lee M. Chin, Goran K. Svensson. "Optimization of Radiation Therapy: Integral-Response of a Model Biological System." Int. J. Radiation Oncology Biol. Phys. 8 (1982): 1761-1769.

Wu, A. "Physics and Dosimetry of the Gamma Knife." In Neurosurgery Clinics of North America, Stereotactic Radiosurgery, L.D. Lunsford, ed., W.B. Saunders Company, 1992.

Wu, Andrew, G. Lindner, A. H. Maitz, A. M. Kalend, L. D. Lunsford, M. D., J. C. Flickinger, M. D., and W. D. Bloomer, M.D. "Physics of Gamma Knife Approach on Convergent Beams in Stereotactic Radiosurgery." Int. J. Radiation Oncology Biol. Phys. 18 (1990): 941-949. 


\section{APPENDIX A: \\ A REVIEW OF RELEVANT REGULATIONS, STANDARDS, AND GUIDELINES}


This appendix contains a summary of documents with regulations, standards, and guidelines concerning quality assurance and radiation safety that are relevant to the use of the Gamma Knife. Virtually none of the contents of these documents is specific to the Gamma Knife. The documents are from the regulatory or standard-setting organizations discussed in Section 2 of this report and are contained in the Bibliography.

Six quality assurance (QA) or safety areas were reviewed:

1.0 General information on standards or guidelines

2.0 General quality assurance information

3.0 Quality control

4.0 Service and maintenance

5.0 Computerized Treatment Planning System (CTPS)

6.0 General and risk-related information

This appendix includes a matrix comparing guidelines ordered by these QA topics and their subtopics. Each row of the matrix corresponds to a QA topic or subtopic, and each column refers to one of the reference organizations.

The matrix contains one column with sections referenced from 10 CFR Part 35 and associated with the appropriate QA topics. This permits a ready comparison of the NRC teletherapy regulations to those regulations, standards, and guidelines of the other regulatory or standard-setting organizations. 
Appendix A. Review of Relevant Regulations, Standards, and Guidelines

American Association of Physicists in Medicine (AAPM)

Doc. No.

AAPM 13
Document Title and Description

\section{Physical Aspects of $Q A$ in Radiation Therapy}

Calls for a QA program to be established for each radiation therapy facility depending upon the objectives and resources of the clinical services. This document discusses the physical tests and procedures to ensure credible assessment of treatment, and emphasizes radiation dose control to the target. It considers tolerances, measurements, simulation and external beam treatment equipment, and safety planning.

\section{Radiation Control and QA in Radiation Oncology, a Suggested Protocol}

This is based on the American Association of Physicists in Medicine Report No. 13, Physical Aspects of QA in Radiation Therapy. It outlines suggested procedures on various systems for measurements and monitoring of radiation safety. It also lists performance criteria for equipment.

\section{American College of Radiology (ACR)}

Doc. No.

$\bullet$

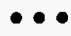

Document Title and Description

\section{American College of Radiology (ACR) Physical Aspects of $Q A$}

Describes the structure of physical aspects of a QA program to include QC of equipment used, treatment procedures, source therapy procedures and safety. A physics questionnaire to evaluate required standards for QA is listed in Appendix I.

\section{America College of Radiology (ACR) Standards for Radiation Oncology}

ACR recommends that facilities maintain basic monitoring and evaluation of $Q A$ in the areas of: (1) Appropriateness of examinations, (2) Radiation safety to patients and employees, (3) Handling acutely ill patients, (4) Nuclear medicine incidents and misadministration, (5) QC programs, and (6) Performance of personnel. It requires that the director of radiation oncology supervising the QA program be responsible for identifying problems and taking actions.

\section{American National Standards Institute (ANSI)}

Doc. No.

\section{ANSI}

N13.2-1969
Document Title and Description

\section{Guide for Administrative Practices in Radiation Monitoring}

This standard provides guidelines for the administrative practices of monitoring the exposure to ionizing radiation in facilities. Topics include managerial responsibilities, monitoring techniques, and assessments. 
American National Standards Institute (ANSI), cont.

Doc. No.

ANSI

N13.4-1971

N323-1978

ANSI

N449.1-1978
Document Title and Description

The Specification of Portable X-or Gamma-Radiation Survey Instrument

This specification describes requirements of performance and technical information about portable X- or Gamma-Radiation Survey devices.

\section{ANSI Radiation Protection Instrumentation Test and Calibration}

This standard provides methods and procedures for calibration and test of portable radiation protection instruments, but it can be applied to general protection devices. It considers alpha, beta, photon and neutron radiations only (no gamma). Definition of "standard" which includes national, secondary and laboratory standards are included. Other terms follow N1.1-1976 of the American National Standard Glossary of Terms in Nuclear Sciences and Technology.

\section{ANSI Procedures for Periodic Inspection of Cobalt-60 and Cesium-137} Teletherapy Equipment

This guideline, prepared by subcommittee N44.2, provides inspection procedures for cobalt-60 teletherapy devices. ANSI N449-1974 is referenced for tests and their frequencies for such equipment. Radiation safety requirements in ANSI N449-1974 are also recommended.

Food and Drug Administration (FDA)

Doc. No.

FDA 83-8218

FDA 87-4222

FDA 89-4165
Document Title and Description

\section{A Basic QA Program for Small Diagnostic Radiology Facilities}

This is an "all-in-one" guide that summarizes the information needed for a QA program for small facilities. This guide takes appropriate excerpts from previous FDA publications. There is no definition for "small" or "large" facility.

\section{An Introduction to Medical Device Regulations}

This a very simple, short and general description booklet on FDA regulations on medical devices.

\section{Regulatory Requirements for Medical Devices}

This has general descriptions of regulatory guidance on:

1. background information

2. definitions, classifications and characteristics

3. points of contact

4. process-tree for a device from design, manufacturing, pre-marketing, to maintenance and services 
Food and Drug Administration (FDA), cont.

Doc. No.

FDA 84-4191

FDA 91-4179

FDA Program 7382.010

FDA 90-4236

FDA Program 7382.830

FDA 88-4226
Document Title and Description

Medical Device GMP Guidance for FDA Investigators

This guidance provides interpretation of the GMP (FDA 91-4179) requirements and demonstrates the flexibility of the GMP in its application to manufacturing processes. It also provides cross references to sections of 21 CFR 820.

\section{Good Manufacturing Practice (GMP) for Medical Devices}

Subpart A states that the regulations in this part are intended for ALL finished devices for human use. Section 820.5 Quality Assurance Program requires the device manufacturer to prepare and implement a QA program to meet the guidelines of this part. Subpart B outlines the QA organization and QA personnel. Other subparts describe manufacturer's buildings, equipment, component controls, process controls, devices evaluations, and records.

\section{Medical Device Problem Reporting}

There are two problem reporting programs established by the Center for Devices and Radiological Health (CDRH). Voluntary reporting occurs through the Problem Reporting Program (PRP), while mandatory reporting is through the Medical Device Reporting (MDR) program. From what the FDA field investigator will analyze, this document implies that the contents of a problem report should include: any public hazards; identification of deficiencies in material, design or manufacturing; problem monitoring; trend analysis; training; and other data for compliance with $\mathrm{CDRH}$ program activities.

\section{Preproduction Quality Assurance Planning}

This document describes manufacturer's QA program for preproduction devices. It -provides guidance for a good design phase QA, and in Sections 4.2.1. \& 4.2.2, manufacturer's and service contractor's responsibilities.

\section{Inspection of Medical Device Manufacturers}

This program is to provide guidance to the FDA field inspectors for the enforcement of the requirements of the GMP regulations (21 CFR 820) when inspecting medical device manufacturer's facility.

\section{Medical Device Reporting $Q \& A$}

This report describes possible problems and how to solve them in writing FDA Medical Device Reporting (MDR) reports. MDR is an FDA mandatory reporting system that requires manufacturers and importers to report any accident caused by its device. 
Food and Drug Administration (FDA), cont.

Doc. No.

$\bullet \bullet \bullet$

FDA form 3322 Medical Device Report Form

This is a standardized FDA form used for the Manufacturer Medical Devices Reports required by $21 \mathrm{CFR} 803$. This form is not associated with the Safe Medical Devices Act of 1990 .

FDA form 3375 Medical Device Facility User Reporting

This is an interim guidance from FDA, stating the requirements of the Safe Medical Devices Act of 1990 (SMDA). It suggests user's approaches to the implementation of SMDA. It defines what, when, and where to report, and an unapproved form is attached; it is only voluntary to use such a form.

International Atomic Energy Association (IAEA)

Doc. No.

IAEA Safety

Series No. 9

IAEA Tech. Report No. 110
Document Title and Description

\section{Basic Safety Standards for Radiation Protection}

These standards provide guidance for the protection of personnel from undue risks of radiation exposure. It requires a facility to be registered and licensed, limits effective dose-equivalent exposure, and gives the annual limits on intake and derived air concentrations for various nuclides.

\section{Manual of Dosimetry in Radiotherapy}

This manual describes the necessary procedures for the selection of an external beam treatment plan, dose pattern, dosage level, and exposure time for achieving a good external beam treatment. It describes measurement instrument maintenance and calibrations, measurement of radiation output, quality, acceptance test, and protection survey. 


\section{International Atomic Energy Association (IAEA), cont.}

Doc. No.

IAEA Tech. Report No. 133

IAEA Tech. Report No. 150

Document Title and Description

\section{Handbook on Calibration of Radiation Protection Monitoring Instruments}

This handbook provides guidelines for establishing or operating calibration facilities for radiation monitoring instruments. It describes the techniques to be used, calibration facilities, errors and QC, and maintenance and repair of the instruments.

\section{Measurement of Short-Range Radiations}

This report describes the radiation measurement methods for alpha or beta emitting sources with maximum energy less than $200 \mathrm{keV}$ and X-rays less than $50 \mathrm{keV}$. It illustrates the method of dose calculation for alpha and beta radiation at various depths in tissue, and lists the criteria for selecting detection instruments.

Institute of Physical Sciences in Medicine (IPSM)/Hospital Physicists' Association (HPA)

Doc. No. Document Title and Description

\section{IPSM Report Radiation Protection in Radiotherapy} \#46

This report gives guidelines on radiation protection for different types of radiotherapy regarding administration, organization, training, rules, and records. The classifications and definitions may be different from those of the U.S. Three chapters, Chap. 2, External Beam Therapy, Chap. 3, Brachytherapy, and Chap. 5, Monitoring, are of particular interest.

\section{National Council on Radiation Protection and Measurements (NCRP)}

Doc. No. NCRP Report No. 91
Document Title and Description

Recommendations on Limits for Exposure to Ionizing Radiation

This report provides general recommendations for the exposure of radiation based on risk estimations, and supplies protection standards for external and internal exposures. It has a table of recommended exposure limits for various personnel under different situations. It also has an extensive list of NCRP publications, reports, and other references. 
Appendix A. Review of Relevant Regulations, Standards, and Guidelines

National Council on Radiation Protection and Measurements (NCRP), cont.

Doc. No.

NCRP Report

No. 105

NCRP Report

No. 102

NCRP Report

No. 49

NCRP Report

No. 69

NCRP Report

No. 57
Document Title and Description

Radiation Protection for Medical and Allied Health Personnel

Recommends that the primary responsibility for the Radiation Safety Committee (RSC) is to develop and maintain an effective radiation safety program for the medical facility. The primary function of the Radiation Safety Officer (RSO) is the supervision of the daily operation of a radiation safety program to ensure that individuals are protected from radiation.

All sealed nuclear medicine sources are required to be leak tested at periodic intervals (6 months maximum) to ensure detection of inadvertent escape of the radioactive materials.

Basic principles of radiation protection and specific application of these principles are also discussed in detail.

Medical X-Ray, Electron Beam and Gamma-Ray Protection for Energies up to 50 $\mathrm{MeV}$

This report provides guidance to physicians, device designers, manufacturers, service personnel, and radiation safety officers for radiation protection under various conditions.

Structural Shielding Design and Evaluation for Medical Use of X-Rays and Gamma Rays of Energies up to $10 \mathrm{MeV}$

This report is intended primarily for use in planning and designing new facilities and in remodeling existing facilities.

Dosimetry of X-Ray and Gamma-Ray Beams for Radiation Therapy in the Energy Range $10 \mathrm{keV}$ to $50 \mathrm{MeV}$

This report describes and discusses many procedures for the proper delivery of absorbed dose by radiation therapy machines, and the uncertainty in the delivery of absorbed dose. Chapter 2 discusses various principles of dosimetry. Sec. 2.3.6 says "national standardizing laboratories do not calibrate ionization chambers for photon energies higher than those of the gamma rays of cobalt-60." Chapters 3 and 4 give National and Secondary standards on calibration.

\section{Instrumentation and Monitoring Methods for Radiation Protection}

This report provides protection and monitoring guidelines to all workers or patients who may be exposed to radiation. It also provides procedures for the conduct of a radiation survey. Chapter 5 discusses the management of a radiation protection program, and Chapter 7 talks about basic principles of protection. Chapter 8 describes information for different categories of personnel. 
National Council on Radiation Protection and Measurements (NCRP), cont.

Doc. No.

NCRP Report

No. 71
Document Title and Description

Operational Radiation Safety-Training

This report supplements NCRP Report No. 59, Operational Radiation Safety Program. The report gives general guidance for the development of training in organizations. It emphasizes management's responsibility in identifying training requirements. 


\begin{tabular}{|c|c|c|c|c|c|c|c|c|}
\hline & 10 CFR 35 & AAPM & $\overline{A C R}$ & ANSI & FDA & IAEA & IPSM & NCRP \\
\hline $\begin{array}{l}1.0 \& 2.0 \\
\text { General Information }\end{array}$ & 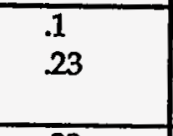 & & QA Guide & & $\begin{array}{l}87-4222 \\
89-4165 \\
83-8218 \\
\end{array}$ & & & 91 \\
\hline $\begin{array}{l}3.0 \\
\text { Quality Control }\end{array}$ & .32 & & & & & & & \\
\hline $\begin{array}{l}3.1 \\
\text { Device Review \& Acceptance Testing }\end{array}$ & & & $\begin{array}{l}\text { R.O. Stds. } \\
\text { QA Guide }\end{array}$ & & $\begin{array}{l}84-4191 \\
91-4179 \\
\end{array}$ & & & \\
\hline $\begin{array}{l}3.1 .1 \\
\text { Quality Assurance }\end{array}$ & .32 & 13 & R.O. Stds. & & $\begin{array}{l}83-8218 \\
84-4191\end{array}$ & & & \\
\hline $\begin{array}{l}3.2 \\
\text { Safety Review } \\
\end{array}$ & & 13 & & N449.1:5 & & 9:I & 46 & $\begin{array}{l}102.2 \\
105\end{array}$ \\
\hline $\begin{array}{l}3.2 .1 \\
\text { Treatment Rooms }\end{array}$ & .643 & & & & & & & 49 \\
\hline $\begin{array}{l}3.2 .2 \\
\text { Safety Instructions }\end{array}$ & .610 & & R.O.Stds. & & & & 46.3 & $\begin{array}{r}69.5 \\
105: 5 \\
\end{array}$ \\
\hline $\begin{array}{l}3.2 .3 \\
\text { Safety Precautions }\end{array}$ & .615 & & & & & & & \\
\hline $\begin{array}{l}3.2 .4 \\
\text { Survey Instruments }\end{array}$ & .620 & & QA Guide & $\begin{array}{l}\text { N13.4:3 } \\
\text { N323:4 }\end{array}$ & & & 46.5 & $\begin{array}{l}57.2,3,5 \\
105: 7\end{array}$ \\
\hline $\begin{array}{l}3.2 .5 \\
\text { Safety Checks }\end{array}$ & .636 & & QA Guide & & & & & \\
\hline $\begin{array}{l}3.2 .6 \\
\text { Radiation Surveys }\end{array}$ & .641 & & & $\mathrm{~N} 13.2: 4,5$ & & $\begin{array}{l}9: \mathrm{I}, \mathrm{V} \\
110.3\end{array}$ & & \begin{tabular}{|l}
105.2 \\
$57.2,3,5$ \\
69.2
\end{tabular} \\
\hline $\begin{array}{l}3.2 .7 \\
\text { Exposure Monitoring }\end{array}$ & .20 & & & $N 13.2: 4,5$ & 7382.010 & $\begin{array}{l}9: \mathrm{I}, \mathrm{V} \\
110.7 \\
150\end{array}$ & & $\begin{array}{l}57.2,3,5 \\
69 \\
91 \\
105.4 \\
\end{array}$ \\
\hline $\begin{array}{l}3.2 .8 \\
\text { Who Performs }\end{array}$ & .21 & & & & & & & 105.5 \\
\hline $\begin{array}{l}.3 \\
\text { Calibration \& Testing }\end{array}$ & .57 & 13 & & N13.4:5 & $84-4191$ & $\begin{array}{l}150.5 \\
133.2\end{array}$ & 46 & 91 \\
\hline $\begin{array}{l}3.3 .1 \\
\text { Survey Instrument }\end{array}$ & $\begin{array}{l}.51 \\
.620\end{array}$ & & & N13.4:3 & & & & \\
\hline $\begin{array}{l}\text { 3.3.2 } \\
\text { Dosimetry Equipment }\end{array}$ & .630 & & R.O.Stds. & & & $110.3,6$ & & 69 \\
\hline
\end{tabular}




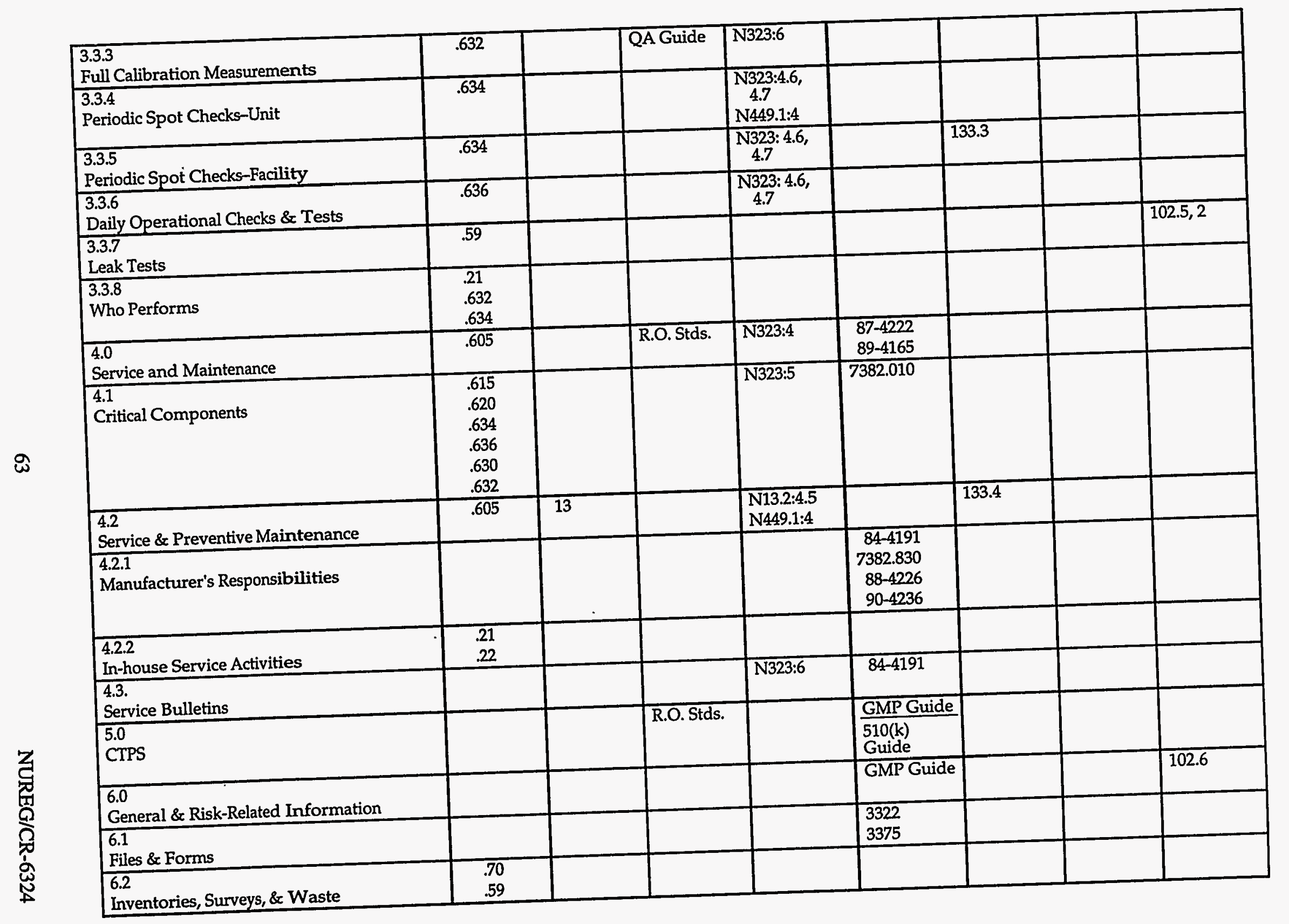




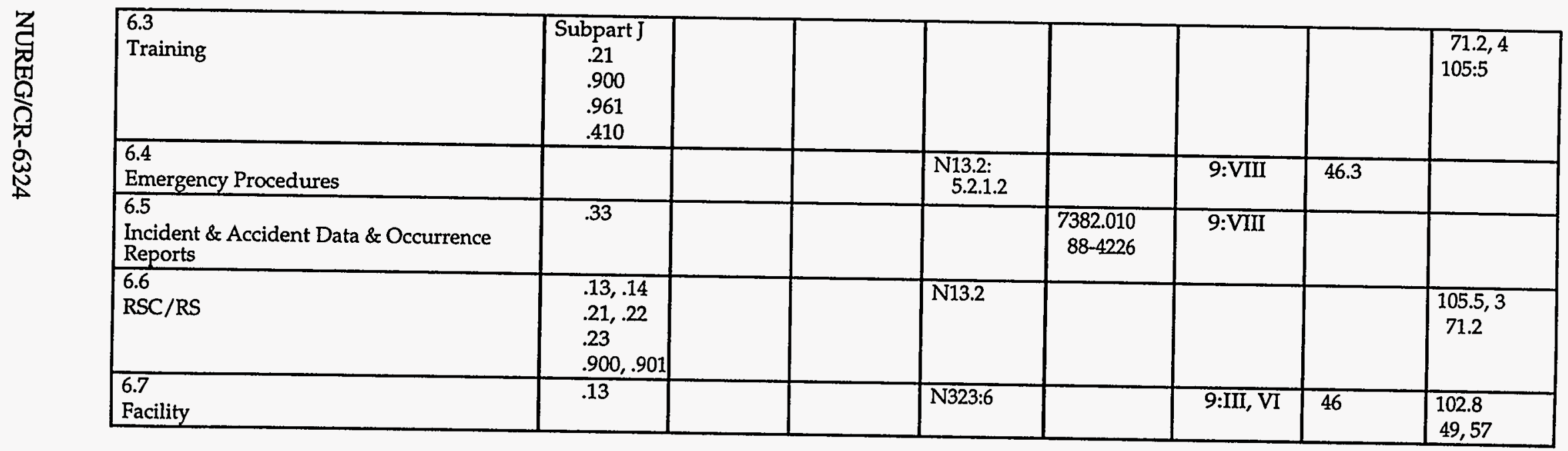


APPENDIX B:

FACILITIES AND EQUIPMENT 
Appendix B. Facilities and Equipment

This appendix contains a technical description and equipment specifications of the Gamma Knife system, as well as site planning criteria for Gamma Knife facilities. The contents of this appendix are adapted from materials provided by Elekta Instruments.

General Technical Description

1. Equipment Specifications-Leksell Gamma Unit

2. Physical Data

3. Technical Description and Specification of the Leksell Gamma Unit

3.1 Central Body

3.2 Collimating System

3.3 Radiation Unit Shielding

3.4 Helmets

3.5 Operating Table

3.6 Trolley

3.7 Helmet Hoist

3.8 Helmet Storage

3.9 Stereotactic Head Frame

4. Technical Description and Specification of Auxiliary Equipment

4.1 Control System

4.2 Control Panel

4.3 TV System

4.4 Audio Communication System

4.5 Hydraulic Equipment

5. Technical Description and Specification of Dose Planning System

6. Technical Description and Specification of Cobalt Supply

6.1 Sources

6.2 Radiation Protection

7. Service

8. Modifications 


\section{GENERAL TECHNICAL DESCRIPTION}

A general technical description of the gamma unit's main components is provided below:

RADIATION UNIT. The radiation unit contains 201 Cobalt- 60 sources located in a heavily shielded hemispherical central body. The beam from each individual source is collimated and converges precisely to the common focal point at the center of the spherical radiation unit. Thus, if a target of cerebral tissue is located at the focal point, the gamma radiation emitted by the sources creates a well-defined lesion. The absorbed dose in cerebral tissues surrounding the target volume is minimized due to the geometrical distribution of the sources in combination with the collimating system. The radiation unit is heavily shielded in order to provide adequate radiation protection for the patient and hospital staff.

The gamma unit is provided with four collimator helmets, with collimators of different sizes. Each helmet contains a set of collimators for identical gamma beams. By changing helmets, the size of a lesion can be varied. The configuration of the dose distribution can be further varied by plugging individual beam channels.

OPERATING TABLE. The operating table consists of a frame, a sliding cradle and a collimator helmet support. The sliding cradle, which rests inside the frame, constitutes the movable patient couch. The collimator helmet is fixed to the cradle by means of the helmet support. Hydraulic equipment installed as a separate unit, is used to move the sliding cradle into the treatment position in the radiation unit and to open and close the shielding door.

CONTROL PANEL. The control panel is located in an adjacent area separated from the treatment room. The gamma unit is operated and supervised from the control panel. The treatment time is measured and displayed by two independent timers which maintain treatment time, even in the event of a power failure. An interlock system prevents operation of the unit if technical faults are present. The patient is supervised on a $\mathrm{B} / \mathrm{W}$ TV monitor and an intercom system is used for communications between doctor and patient.

COMPUTER SYSTEM. A specially designed stereotactic planning software program and a Digital Equipment computer (Microvax II) are an integral part of the gamma unit. The program, KULA, is designed to calculate threedimensional dose distributions with high resolution. 


\section{EQUIPMENT SPECIFICATIONS-LEKSELL GAMMA UNIT:}

1) Radiation Unit including the charging of 201 encapsulated CO-60 sources with a total activity of 6000 Curie $+1-$ $10 \%$ at the time of charging of the Cobalt sources.

2) Collimator Helmets

- Collimator helmet with a final aperture of $4 \mathrm{~mm}$

- Collimator helmet with a final aperture of $8 \mathrm{~mm}$

- Collimator helmet with a final aperture of $14 \mathrm{~mm}$

- Collimator helmet with a final aperture of $18 \mathrm{~mm}$

3) 100 Plugs (for Collimator helmet)

4) Operating Table

- Operating table frame

- $\quad$ Sliding cradle

- Collimator helmet support

- Patient elbow rests

- Couch

5) Trolley

6) Helmet Hoist

7) Helmet Storage Table

8) Stereotactic Head Frame

- Stereotactic coordinate frame with 4 vertical posts

- 1 set of aluminum fixation pins

- 1 set of carbon fixation pins

- 1 set of glass fiber fixation pins

- CT Indicator with 3 indicator panels

- $\quad$ MR Indicator with 4 indicator panels

- X-Ray Indicator

9) Control Panel

10) TV System

- TV camera

- TV monitor mounted in the control panel

11) Audio Communication System

- Microphone

- Loudspeaker mounted in the control panel

12) Electric Box 
13) Hydraulic Equipment

- Hydraulic unit

- 2 cylinders mounted in the operating table frame for couch and shielding door

- 2 manual valves and 1 interlocking valve mounted in the operating table frame

14) Dose Planning System

Hardware

- Digital Equipment Micro Vax II computer

- Color Graphic terminal (GKS compatible), VT241

- Monochrome terminal (VT200 compatible), VT220

- Plotter (GKS compatible), LA210

- $\quad$ Printer, LVP166

Software

- "Kula" three-dimensional dose planning software

15) Cobalt Supply

- 201 encapsulated sources of Cobalt-60

\section{PHYSICAL DATA}

Overall Length

Overall Width

Overall Height

Total Weight, approximate

Total Co-60 activity at time of loading of radiation unit

Total Co-60 dose rate at the focal point at the time of

loading, approximate

Number of Co-60 sources

Mechanical Precision at Focal Point

Positioning Accuracy

Power Consumption, approximate

Power Supply

Internal Operating Voltage

Hydraulic Pressure

Nitrogen Pressure in Accumulator
$4,600 \mathrm{~mm}\left(15^{\prime} 1 "\right)$

$1,650 \mathrm{~mm}\left(5^{\prime} 5^{\prime \prime}\right)$

$1,725 \mathrm{~mm}\left(5^{\prime} 8^{\prime \prime}\right)$

$18,000 \mathrm{~kg}(40,000 \mathrm{lbs})$

6,000 Curie $+1-10 \%$

$300 \mathrm{rads} /$ minute

201

$+/-0.3 \mathrm{~mm}$

$+/-0.1 \mathrm{~mm}$

$3.0 \mathrm{~kW}$

$110 \mathrm{~V}, 60 \mathrm{~Hz}$

440V, 3-phase, $60 \mathrm{~Hz}$

$24 \mathrm{VDC}$ and $24 \mathrm{~V}, 60 \mathrm{~Hz}$

$60 \mathrm{Bar}$

$30 \mathrm{Bar}$ 


\section{TECHNICAL DESCRIPTION AND SPECIFICATIONS OF LGU}

\subsection{Central Body}

The Central Body is a half-spherical body made of spherolitic cast iron, which contains the machined channels for the collimating system and sources and attachments for helmets.

\subsection{Collimating System}

The central beam of the 201-beam array lies at a fixed angle of $55^{\circ}$ to the horizontal plane. The other beams are distributed in an arc of $+1-48^{\circ}$ from the central beam along the axis of the patient and treatment table and $+1-80^{\circ}$ along the transverse axis. No primary beam is directed at the shielding door opening and therefore only scattered radiation is emitted from the unit when the shielding door is open.

Each beam channel consists of a stationary collimator system located in the Radiation Unit and a final interchangeable collimator situated in the helmet. When the helmet is in the treatment position, the entire collimator system forms a conical channel with a circular cross-section. The shape of the channels is such that they diverge from the source towards the focus. The focus point is located at the center of the volume in the space where the axis of all beam channels intersect.

Each beam channel in the Central Body consists of a compound bushing containing a cavity for the encapsulated Cobalt- 60 source, a precollimator and a collimator.

The final collimator is placed in the helmet. The final collimator can be changed to a plug by use of a bayonet socket in the helmet.

The plugs are needed to optimize the relationship between the shape of the cerebral target and the isodose configuration. 100 plugs are included with the equipment.

The diameters of the four different collimator alternatives are 4,8,14, and $18 \mathrm{~mm}$. In cerebral tissue the resulting total spherical dose distributions, measured at the $50 \%$ isodose level, are approximately $5.4,10,18,22 \mathrm{~mm}$, respectively.

The drilling of the beam channels and the manufacturing of the compound bushings and final collimators is such tha the axis of each separate channel converges to the focus with a maximum tolerance of $+/-0.3 \mathrm{~mm}$.

\subsection{Shielding of Radiation Unit}

In order to allow hospital staff into the immediate vicinity of the gamma unit for extended periods of time, the Radiation Unit has been heavily shielded. It is assumed that the room in which the gamma unit is installed is separated from the rest of the treatment area.

The shield assembly of the Radiation Unit consists of the shielding base, the hemispherical shield, the shielding door, the sump plug, the linkage, the rails and the pivot bearings. The shield assembly encloses the Central Body with Co-60 sources, the collimating system, and a cavity into which the couch with helmet and patient is inserted during treatment.

The base, the hemispherical shield and the sump plug are made of cast iron. The Central Body is bolted to the base by four bolts.

The hemispherical shield fits over the Central Body. The base and the hemispherical shield are bolted together.

In order to reduce the amount of radiation emitted through the opening in the Radiation Unit, it is equipped with a shielding door which is closed when the equipment is not in use. The shielding door is made of cast steel, pivots and opens inward to admit the patient for radiosurgical treatment. The shielding door is operated by hydraulic force in both directions. In its open position, the shielding door rests on a rubber-tipped steel shock absorber. 
Appendix B. Facilities and Equipment

\section{$3.4 \quad$ Helmets}

The gamma unit is provided with four Collimator Helmets, the collimators of different apertures. Each helmet contains a set of collimators for identical gamma beams. Thus, by changing helmets, the size of the lesion can be varied. The configuration of the dose distribution can be further varied by plugging individual beam channels.

The Collimator Helmet is made of spherolitic cast iron. The 201 channels for the final collimators of plugs are drilled through the shell. There are two trunnions, one on the right side and one on the left side of the Collimator Helmet. They are used for orientation and fixation of the patient's head into the helmet.

The helmet has four pins at the upper side, which align the helmet correctly to the Central Body. Each pin has a conical part for centering and a cylindrical part for correct alignment. Both helmet and Central Body have precisionfinished surfaces for accurate contact. Two microswitches in the helmet verify correct contact.

At the underside of the helmet there are four guiding pins. When the helmet is placed on the helmet support, these guiding pins fit inside the flexible rubber mountings. A locking screw in each guiding pin secures the helmet to the helmet support.

All four helmets including the equipment are identical except for the cross-section of the final collimator apertures.

\subsection{Operating Table}

The Operating Table consists of a frame, a sliding cradle and a collimator helmet support. The sliding cradle, which rests inside the frame, constitutes the movable patient couch. The Collimator Helmet is fixed to the cradle by means of the helmet support. The movement of the sliding cradle into the treatment position in the Radiation Unit and the opening and closing of the shielding door are carried out by hydraulics.

The Collimator Helmets are locked onto the support and the patient's head is brought into the helmet where it is supported by two transverse fixation trunnions. The body of the patient rests on a resilient surface. At the start of the operation, the patient is automatically moved into the Radiation Unit.

The helmet support is equipped with flexible rubber mountings on which the helmet is fitted. On the helmet support is a limit switch for indicating closed position of the helmet back cover shield. A patient intercom microphone is fitted near the patient's head. At the rear end of the sliding cradle is a handle to be used when the sliding cradle is manually pulled out of the Radiation Unit. Patient elbow-rests of transparent acrylic plastic are fitted on each side of the sliding cradle.

The couch with the Collimator Helmet is supported on the Operating Table frame.

The base of the frame is made of steel sheet and the rails are made of stainless steel. The frame is attached to the Radiation Unit by means of screws and in the outer part supported by one leg, which has two screws for horizontal alignment when installing the unit. Hydraulic cylinders, linkages, cover belt, cable drag chain, valves, hydraulic piping, microswitches, electric cabling and inductive meters for maneuvering and position indication of shielding door and sliding cradle are housed in the frame.

The longitudinal top opening in the frame is covered by stainless steel sheets except for an opening of seven inches for moving the sliding cradle. This opening is closed by a cover belt.

\subsection{Trolley}

The Radiation Unit is mounted on a Trolley with rollers on which it can be moved into the desired position when installed or moved out for reloading.

When the gamma unit is installed in the correct position it is lifted and aligned horizontally on spacer plates, thus relieving the rollers of the weight of the gamma unit until the next reloading. 


\subsection{Helmet Hoist}

The Helmet Hoist is used for mounting the helmet on the support of the sliding cradle and for exchange of helmets including transport to and from the helmet storage table.

There are hoists to be used from either the left or right side of the gamma unit. The hoist is movable on free rollers.

\subsection{Helmet Storage Table}

Four helmets can be stored on the table.

The table and helmet supports are made of wood in order to avoid damaging the helmets.

\subsection{Stereotactic Head Frame}

Based on the Leksell Stereotactic System, this version of the Leksell Stereotactic Coordinate Frame has been developed specifically for radiosurgical operations in the Leksell Gamma Unit. It consists of a base ring with four vertical posts: two frontal and two occipital. Its design is coordinated with the Collimator Helmet design. It provides good freedom of mobility of the patient's head inside the Collimator Helmet and may thus be used throughout the entire operative procedure, starting with the preoperative MR, CT or X-ray examination and ending with the actual irradiation procedure.

The frame is supplied with aluminum and glass fiber fixation pins which are used for the preoperative examination and radiosurgical procedure.

\section{TECHNICAL DESCRIPTION AND EQUIPMENT SPECIFICATION OF AUXILIARY EQUIPMENT}

\subsection{Control System}

Electric components and wiring are located in the control panel, the electric box, the operating table and the hydraulic unit.

The Control Panel contains push buttons, pilot lamps, timers, TV and intercom systems.

The electric box contains relays, a transformer, rectifiers, a battery, power connections and terminals. The power supply to the complete electric system is connected to this electric box.

The Operating Table includes microswitches for helmets and intercom, microswitches for movements of the hydraulic cylinder, and a microswitch for the cover at the back of the helmet, cable drag chain and terminal box.

The hydraulic unit includes an electric motor, solenoids for hydraulic valves, a terminal box with printed circuit card, and sensors for hydraulic pressure, oil level, oil temperature and oil filter congestion.

At the treatment room door(s) is a microswitch for interlocking TREATMENT START and initiating TREATMENT STOP when the door(s) is open. In the treatment room is an emergency push-button with the same functions. Beside the treatment door(s) is a lamp indicating RADIATION ON.

The TV camera is placed in the longitudinal direction of the Operating Table facing the patient and the shielding door. 
Appendix B. Facilities and Equipment

\subsection{Control Panel}

The Control Panel is located in an adjacent area separate from the treatment room. The gamma unit is operated and supervised from the Control Panel. An interlock system prevents operation of the Unit if technical faults are present.

The Control Panel contains various push-buttons and pilot lamps in addition to pressure sensors connected to microswitches and other electronic components built into the Operating Table and helmet support. Tvo indenendent digital timers are mounted onto the Control Panel. An intercom system is used for communication with the patient, who is also observed with a TV system.

\subsection{TV System}

The TV system consists of a TV camera, a monitor mounted on the Control Panel. The camera zoom lens and focus can be adjusted with push-buttons on the Control Panel.

\subsection{Audio Communication System}

A microphone is mounted in the vicinity of the patient's head. This microphone is connected to the loudspeaker in the Control Panel. All patient speech or sounds are heard continuously at the control panel.

\subsection{Hydraulic Equipment}

Hydraulic components are located on the hydraulic unit in the hydraulic room just outside the treatment room. The two cylinders for couch and shielding door manipulation, two manual valves and one interlocking valve are located in the operating table frame.

\section{TECHNICAL DESCRIPTION AND SPECIFICATION DOSE PLANNING SYSTEM}

\subsection{Design Concept}

The KULA dose planning system has been designed and developed in collaboration between the neurological clinic at the Karolinska Hospital in Stockholm and the Uppsala University Data Center. The system is designed to meet the following basic requirements:

a) The system is an integrated part of stereotactic radiosurgery, i.e., target points, etc., are expressed in stereotactic coordinates, allowing the user to do all dose planning work in the most convenient way.

b) The system allows maximum flexibility when shaping dose distributions, i.e., it is possible to ${ }^{\circ}$ superimpose several isodose curves and display them.

c) The system is interactive, and guides the user in a short and effective dialogue. In addition, it is possible to obtain information on the questions posed by the system.

d) The user is able to make some modifications of the system, such as setting up color tables for plotting and translating the dialogue into language other than English, etc.

e) The system is able to run on a minicomputer under local control. 
Appendix B. Facilities and Equipment

\subsection{Hardware}

The KULA system requires the following hardware configuration which is supplied as part of the Leksell Gamma Unit:

1) DIGITAL EQUIPMENT MICRO VAX II computer running under VMS, version 4.2 or later

2) Color graphic terminal (GKS compatible), VT241

3) Monochrome terminal (VT200 compatible), VT220

4) Plotter (GKS compatible), LA210

5) Printer, LVPL16

Elekta is free to change the hardware specification due to technical development.

\section{TECHNICAL DESCRIPTION AND SPECIFICATION OF COBALT SUPPLY}

\subsection{Sources}

Each one of the 201 sources located in the Radiation Unit is composed of about 20 Co- 60 pellets $1 \mathrm{~mm}$ in diameter and $1 \mathrm{~mm}$ in height. The pellets are contained in double stainless steel capsules with welded closures. Sources are licensed and meet the ANSI standard N-542 for medical teletherapy sources.

As the time of loading the specific activity of the Co-60 is approximately $250 \mathrm{Ci} / \mathrm{g}$ and the total activity is 5,400 $6,600 \mathrm{Ci}$. The half-life of $\mathrm{Co}-60$ is 5.2 years.

\subsection{Radiation Protection}

The environmental requirement for the Unit is a clean but not sterile area with adequate light and ventilation. Poured concrete surrounding the treatment room is required to protect against scattered radiation from the Unit.

\section{SERVICE}

\subsection{Mechanical Hydraulic and Electrical Components}

Mechanical hydraulic and electrical components must be serviced on site. Service after the end of the warranty period is done by the Seller pursuant to the Repair Service Agreement.

\subsection{Spare Parts}

Only standard components are used for the hydraulic and electrical systems. Spare parts are supplied pursuant to the Repair Service Agreement.

\section{MODIFICATIONS}

ELEKTA INSTRUMENTS, INC. RESERVES THE RIGHT TO MAKE CHANGES TO THE PRODUCT SPECIFICATIONS AND EQUIPMENT COVERED THEREBY, AS LONG AS SUCH CHANGES DO NOT HAVE A MATERIALLY ADVERSE PRACTICAL IMPACT ON THE USE OF THE LEKSELL GAMMA UNIT FOR STEREOTACTIC RADIOSURGERY. 


\section{SITE PLANNING CRITERIA}


Appendix B. Facilities and Equipment

\section{LEKSELL STEREOTACTIC GAMMA UNIT SITE PLANNING CRITERIA}




\section{LEKSELLL STEREOTACTIC GAMMA UNIT}

1. Suite Design

2. The Functional Space Program

2.1 Patient Preparation Area

2.2 Control Area

2.3 Localization Room

2.4 Dosimetry Office and Computer Room

2.5 Hydraulic and Electrical Room

2.6 Gamma Unit Treatment Room

2.6A Structural Design

2.7 Hot Cell for Loading of Sources

3. Engineering Considerations

3.1 Mechanical Engineering

3.2 Electrical Engineering

4. Architectural Considerations

5. Site Layout (Example)

6. Loading Layout (Example) 


\section{LEKSELL STEREOTACTIC GAMMA UNIT}

This document is intended to serve as a guideline for architectural and engineering concerns relative to the configuration and location of a typical Gamma Knife Suite. It is not intended as a substitute for the services of qualified design professionals, but as a general description of the efficient design and construction of a functional facility.

\section{SUITE DESIGN}

The suite design for the Leksell Stereotactic Gamma Unit ("Gamma Knife") is controlled by a number of factors including:

1) The number and type of spaces necessary for the proper utilization of the Unit;

2) The specific requirements of the treatment room itself, including:

- its structural design

- its use as a temporary hot cell for installation of the radioactive sources;

3) The specific mechanical and electrical requirements necessary for the proper functioning of the suite.

Construction of a Gamma Knife Suite is no more cost intensive than an MRI facility or a linear accelerator installation. Unlike MRI and linear accelerator installations, the total square footage of a Gamma Knife is generally less because it is not so reliant on support activities. 1200-1500 square feet is a general area requirement for a Gamma Knife suite. Two specific considerations of the Gamma Knife suite which affect the costs are:

1) Logistics and timing requirements due to construction of the hot cell and the loading of the Unit on site.

2) Like the linear accelerator, it is concrete-intensive.

However, from the point of view of mechanical and electrical requirements, finishes, equipment, computers, and other aspects of health care construction, it is not highly sophisticated. 
Appendix B. Facilities and Equipment

\section{LEKSELL STEREOTACTIC GAMMA UNIT}

\section{THE FUNCTIONAL SPACE PROGRAM}

Refer to enclosed principal layout. The type of spaces required for proper utilization of the Gamma Knife includes:

\subsection{Patient Preparation Area (approximately.9' $\times 14^{\prime}$ )}

The Patient Preparation Area should be equipped to do all preparation of the patient before the treatment (such as frame fixation) and stabilization of the patient after treatment. The area should include all medical gas systems, counter and work area (with handwashing), IV tracks and proper lighting.

\subsection{Control Area (approximately $4^{3} \times 7^{\prime}$ )}

The Control Area functions as a nerve center. The area contains all controls, alarms, emergency shut-off unit and communication for the site.

\subsection{Localization Room (approximately $10^{\prime} \times 12^{\prime}$ )}

The Localization Room is an area for the neurosurgeon to review patient cases and, together with the physicist, plan target areas and dosages.

\subsection{Dosimetry Office and Computer Room (approximately 10' $\times 10^{\prime}$ )}

The Dosimetry Office and Computer Room is for the physicist to plan the dose rate and lesion configuration. The computer terminals, plotter and computer are housed in this room.

\subsection{The Hydraulic and Electrical Equipment Room (approximately $5^{3} \times 6.5^{\prime}$ )}

The Hydraulic and Electrical Equipment Room must be adjacent to the treatment room as hydraulic pipes will be connected to the Unit from the equipment in this room. This room also acts as a junction box for the control wiring necessary between the control station and the Gamma Unit itself. The hydraulic room must also be readily accessible from the control station in the event of an emergency requiring manual operation of the hydraulic unit.

\subsection{The Treatment Room (approximately $25^{\prime} \times 18^{\prime}$ [h. 10' finished])}

The Gamma Unit Treatment Room is the room within which the actual radiosurgical procedure takes place. The room contains the Gamma Knife Unit itself, and the helmet table. The room must have direct access from the control area. The entrance doors to the room must be outside the radiation cone and adjacent to the control station.

\subsection{The "Hot Cell" (8' $\times 10$ ' interior, 13' ceiling height)}

The "Hot Cell" is used to install the Co60 sources in the Gamma Unit. It must be of such design to shield the 6000 curies of Co60 and allow loading operations to take place. It will be used to load and reload the unit and if possible should be a permanent part of the facility. The design of the "Hot Cell" is very site specific and must be worked out with the Hospital's Radiation Physicist, Elekta and the Loading Contractor used by Elekta. 
Appendix B. Facilities and Equipment

\section{LEKSELL STEREOTACTIC GAMMA UNIT}

\subsection{Offices (As needed depending upon location in the hospital.) \\ 2.9 Structural Design of Gamma Unit Treatment Room and Hot Cell}

The Gamma Knife weighs approximately 20 tons and rests on the floor at five points. Four wheels on the central body chassis each support approximately 5 tons. The support leg on the sliding hydraulic table carries a nominal load of approximately 0.5 ton. The equipment foundation and floor slab must be designed to accommodate these loads.

The floor, walls and ceiling of the Treatment Room should be constructed of concrete to provide radiation shielding for the cobalt sources imbedded in the central body of the Gamma Knife. A reinforced floor slab should be considered for the room to facilitate equipment movement during "hot cell" operations. Wall thickness can vary depending on the geometry of the room, adjacent occupancies, final recommendations of the hospital radiation physicist, and the hot cell requirements. The ceiling thickness will vary depending on the same factors as the wall thicknesses.

The floor construction must include an 8 inch deep by 12 inch wide floor trench that runs from the support leg on Gamma Knife hydraulic table to the hydraulic equipment room.

A minimum clear finished height of 13 feet should be allowed between the floor and underside of the structural ceiling to permit cobalt loading operations in the temporary hot cell and the installation of a suspended ceiling to complete the interior finishes in the treatment room. The design of the structural ceiling and walls must include the openings, sleeves and embedments necessary for the temporary hot cell and any mechanical or electrical services required in the finished treatment room.

The design must not permit any straight-through penetrations of the shielding walls and ceiling. Where penetrations cannot be avoided, a double 90 degree offset should be embedded within the wall or ceiling. Large plugs and infill panels should incorporate a stepped-edge design detail.

The Radiation Unit is shipped fully assembled, weighs approximately $38,000 \mathrm{lbs}$., and is approximately 6 feet in diameter. The cobalt source shipping container is another large, heavy item that must be delivered to the site. The weight of the shipping container is $12,700 \mathrm{lbs}$.

The entire facility can be constructed of standard density concrete. High density concrete mixes can be used to minimize thicknesses and provide equivalent shielding where space limitations create a severe handicap, but construction costs may increase.

The entire structural design should be done in accordance with the applicable local, state or federal regulations. It may also be necessary to obtain geotechnical test data to ascertain the bearing capacity of the soils at and below the proposed site. 
Appendix B. Facilities and Equipment

\section{LEKSELL STEREOTACTIC GAMMA UNIT}

\subsection{A Hot Cell for Loading of Sources}

The Gamma Knife is planned to be loaded with cobalt 60 sources into the central body in a temporary hot cell constructed at the site. See loading layout. Erection of the temporary hot cell will generally include:

1) Installation of a Hot Cell serving as loading area close to the treatment room.

2) Installation of a Hot Cell viewing window.

3) Installation of a pair of remote operator arms in the same wall as the window.

4) Installation of temporary power for Hot Cell lighting and ventilation.

5) Installation of hoisting equipment which will be used to open the lid of the central body and cobalt source shipping cast during the loading operations.

Design details for the temporary hot cell are generally site specific and must be closely coordinated with the cobalt loading subcontractor during the layout and design phase of the project. Items to be considered during the design will include:

1) Wall sleeves for remote operator arms

2) Wall sleeve and infill panel for the temporary hot cell window

3) Embedment plates or beams for mounting the temporary hoisting equipment, and

4) Strategically located openings with concrete plugs for emergency access during the loading operation.

It is strongly recommended that the hospital and their design professionals work closely with Elekta Instruments and their cobalt loading subcontractor from the onset of the project to incorporate the requirements for on-site loading (reloading) into the design of the facility.

\subsection{B Optional Space}

1) Waiting Area

2) Office (Physician) 
Appendix B. Facilities and Equipment

\section{LEKSELL STEREOTACTIC GAMMA UNIT}

\section{ENGINEERING CONSIDERATIONS}

\subsection{Mechanical Engineering}

\section{HVAC SYSTEMS}

The entire Gamma Knife Suite should be air conditioned to maintain a design temperature range of $72-78$ degrees $F$ and a minimum of $30 \%$ relative humidity in the winter and a maximum of $55 \%$ relative humidity in the summer.

Special consideration of the temperature control in the Treatment Room is essential since the patient's movements can be restricted for an extended period of time depending on the exact length of the treatment and set-up time required. Remote temperature set point controls that are operable from the control panel should be considered.

The Treatment Room should be designed for a minimum of six (6) total air changes per hour with provisions for a minimum of one (1) outside air change per hour. Reheating of the supply air to the treatment room should be considered since the cooling load within the space is minimal (primarily lighting load). The Gamma Knife is operated hydraulically by remote equipment and, therefore, generates no heat within the Treatment Room.

Air conditioning requirements for the balance of the rooms in a typical Gamma Knife Suite are similar to other hospital ancillary spaces. HVAC systems serving patient areas must be designed to meet, or exceed, minimum code requirements for patient areas (viewing/control, dosimetry planning/computers) should be designed where the room cooling load requirements are used to determine the supply air quantities. The hydraulic equipment room does not need to be air conditioned, but it should be ventilated to prevent excessive heat build-up around the electronic control cabinet and the hydraulic unit.

\section{PLUMBING SYSTEMS}

The Gamma Knife Suite should have a handicapped accessible toilet room with handwashing facilities. Handwashing facilities should also be provided in the patient holding/preparation area. The Gamma Knife Unit itself requires no plumbing connections.

\section{MEDICAL GAS SYSTEMS}

Installation of an oxygen, vacuum and air outlet should be considered for the patient preparation area. Oxygen, vacuum, air, nitrous oxide and waste anesthetic gas disposal outlets should be considered for the treatment room in the event that a patient emergency condition arises. If the above gases are installed in the Suite, they should be isolated from the control piping systems by zone valves in the corridor outside of the Suite. 
Appendix B. Facilities and Equipment

\section{LEKSELL STEREOTACTIC GAMMA UNIT}

Medical gas outlets, if installed, should be located near the patient's head position in the patient preparation area and the treatment room. The outlets can be positioned to the patient's left or right, as required by the medical or anesthesiology staff.

\subsection{Electrical Engineering}

\section{POWER}

The Gamma Knife requires a 440 volt, 3 phase, 15 ampere power feeder (approximately $3 \mathrm{Kw}$ load) to the Gamma Knife electrical panel that is located in the hydraulic room. All of the Gamma Knife peripheral equipment (control unit, hydraulic unit, closed circuit television camera, infrared camera light, and control wiring for the door switch, control wiring for the warning light and control wiring for the emergency power off switches) are powered from the Gamma Knife electrical panel. The panel measures approximately $750 \mathrm{~mm} \times 1000 \mathrm{~mm} \times 200 \mathrm{~mm}$ and has a side-hinged front door. All of the cable and conduit connections are on the bottom of the panel.

Two (2) emergency power off switches should be installed in the treatment room at remote locations, preferably on the wall opposite the door and the wall at the foot end of the patient table, to stop the procedure once it is started while attending personnel are still in the room. Door switches should also be installed on the entrance door(s) to the Treatment Room to prevent a procedure from starting if the door(s) are in open position.

Normal emergency power is not required for the Gamma Knife since a loss of power automatically triggers the accumulator on the sliding hydraulic table to withdraw the patient and close the door on the central body. Emergency power is required within the Suite for the TV-system, remote radiation system, intercom system, exit lights and general lighting.

Dedicated circuits (110 volt, single phase) with common isolated ground or surge protection receptacles should be provided for the dose planning computer (DEC Micro Vax II) and the personal computer in the dosimetry room.

\section{LIGHTING}

Lighting in the treatment room should be designed to provide high general light levels (50 F.C.) maintained on the floor for maintenance and housekeeping, and be splitswitched or on dimmer controls to provide a subdued, relaxing atmosphere during the treatment procedure. Low brightness incandescent down lights or indirect perimeter lighting should be considered.

Indirect or other low glare type lighting should be used in the dosimetry planning, viewing and control areas since CRT's and television monitors will be used in these areas.

General overhead fluorescent lighting can be used in the patient preparation area, hydraulic room and computer room. 


\section{LEKSELL STEREOTACTIC GAMMA UNIT}

A "Radiation in Use" warning light should be located outside the door to the treatment room. The warning light should be powered independently through a relay that will be controlled from the Gamma Knife electrical panel.

\section{REMOTE RADIATION MONITORING (RRM)}

A remote area radiation sensor should be installed in the Treatment Room on the wall at the foot of the patient table. The monitor and alarm unit should be located at the control desk. The RRM system should be powered with normal/emergency power.

\section{RACEWAYS, CONDUITS AND PROVISION FOR COMPUTER HARDWARE}

Empty conduits or raceways should be provided between the dosimetry planning computer in the computer room and the peripheral equipment in the dose planning office. Two 2-inch conduits should be installed. Data cable conduits ( $3 / 4$ inch) should be installed for each piece of portable computer equipment and at each work station.

\section{PROVISIONS FOR TEMPORARY HOT CELL}

Two (2) temporary 220 volt, 1 phase, 20 ampere circuits should be provided. One of the circuits should be locally switched within the Gamma Knife Suite and terminate in three (3) duplex receptacles inside the temporary hot cell for equipment. The second circuit should terminate in two (2) duplex receptacles located near the hot cell window and remote operator arm control handles. This circuit will power remote operator arms that will be used during the loading process. Three (3) temporary 110 volt 1 phase circuits are necessary for lighting and cameras used within the hot cell, but switched at control arm location. In addition, a 440 volt, 3 phase, 20 amp circuit is necessary to power the hoist used to open and support the upper shield section of the Gamma Unit during loading procedures. 
Appendix B. Facilities and Equipment

\section{LEKSELL STEREOTACTIC GAMMA UNIT}

\section{ARCHITECTURAL CONSIDERATIONS}

As in many sophisticated treatment areas, the primary architectural problem is to minimize the high technology feeling and maximize a quiet, uncluttered, restful environment.

In plan, the uncluttered aspect of the suite can be heightened by the careful arrangement of the spaces to provide a clean and unobstructed traffic pattern both for the patient and professional staff. Separation of these patterns and minimizing crosstraffic problems is essential. The suite is not so large as to require a separate access and egress door for staff, but the viewing, dosimetry, and control functions should be placed to the rear of the suite to keep them out of the way of the patient entering or leaving the suite. The treatment room should allow for easy movement of the helmets. anesthesia functions should be located out of the traffic within the room.

There are two separate areas of consideration with respect to finishes. The staff area requires high task lighting and easily maintained finishes. Given that the patient area should be regarded as clean, all finishes should reflect the standard hospital applications of materials for clean suites. Seamless sheet vinyl flooring with an integral base is optional. Epoxy paint or stain resistant vinyl wall covering is optional for the walls, and monolithic plaster ceilings are optional. All casework can be plastic laminate finish. The emphasis in the patient area should be to avoid the institutional look of stainless steel and high gloss finishes without compromising the ability to keep the area clean.

If sheet vinyl flooring is used in the treatment room, the angle of maximum radioactivity output can be installed in the floor finish to alert the staff of the area of high radiation during patient treatment.

One source of concern is the finish on the trench cover. Equipment and heavy loads will be rolled over the trench cover regularly, and care should be taken in the detailing of the trench cover finish. Again, sheet vinyl fooring is an excellent cover material, in that it is monolithic, and can be incorporated into the overall treatment room floor finish.

In general, the finish requirements are not sophisticated or exotic, nor are they expensive. Careful thought on the maximizing of cleanliness and minimizing of the institutional environment is all that is needed. 

APPENDIX C: QUALITY CONTROL AND ASSURANCE 
This appendix has samples of licensees' quality assurance and control protocols collected by the LLNL team from various facilities during the QA assessment process. These model procedures were developed by each licensee based on input from the manufacturer and on examples from other facilities. The appendix is divided into a section on calibration and dosimetry and a section on QA/QC protocols. The dosimetry and calibration practices typically conformed to AAPM Task Group 21 protocol. The QA/QC protocols include several examples of daily, monthly, and annual checklists. 
CALIBRATION AND DOSIMETRY 


\section{GAMMA KNUTE DOSMMETRY}

\section{MEASUREMENT PROTOCOL}

Hospital:

Datc:

Total sounce activity $\mathrm{Ci} \mathrm{MBq}$, at date:

Name:

Ionization chamber PTW $233642 \mathrm{No}, 282$

Airpressure P.: $/ 0 / 9$ milibar

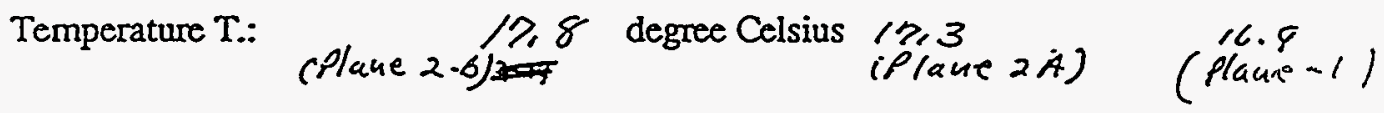

Warm up prosedure $>10$ minutes

Reading without exposure: $\begin{aligned} & 0.003 \\ & 0.002\end{aligned} \mathrm{nC} / \mathrm{min}$

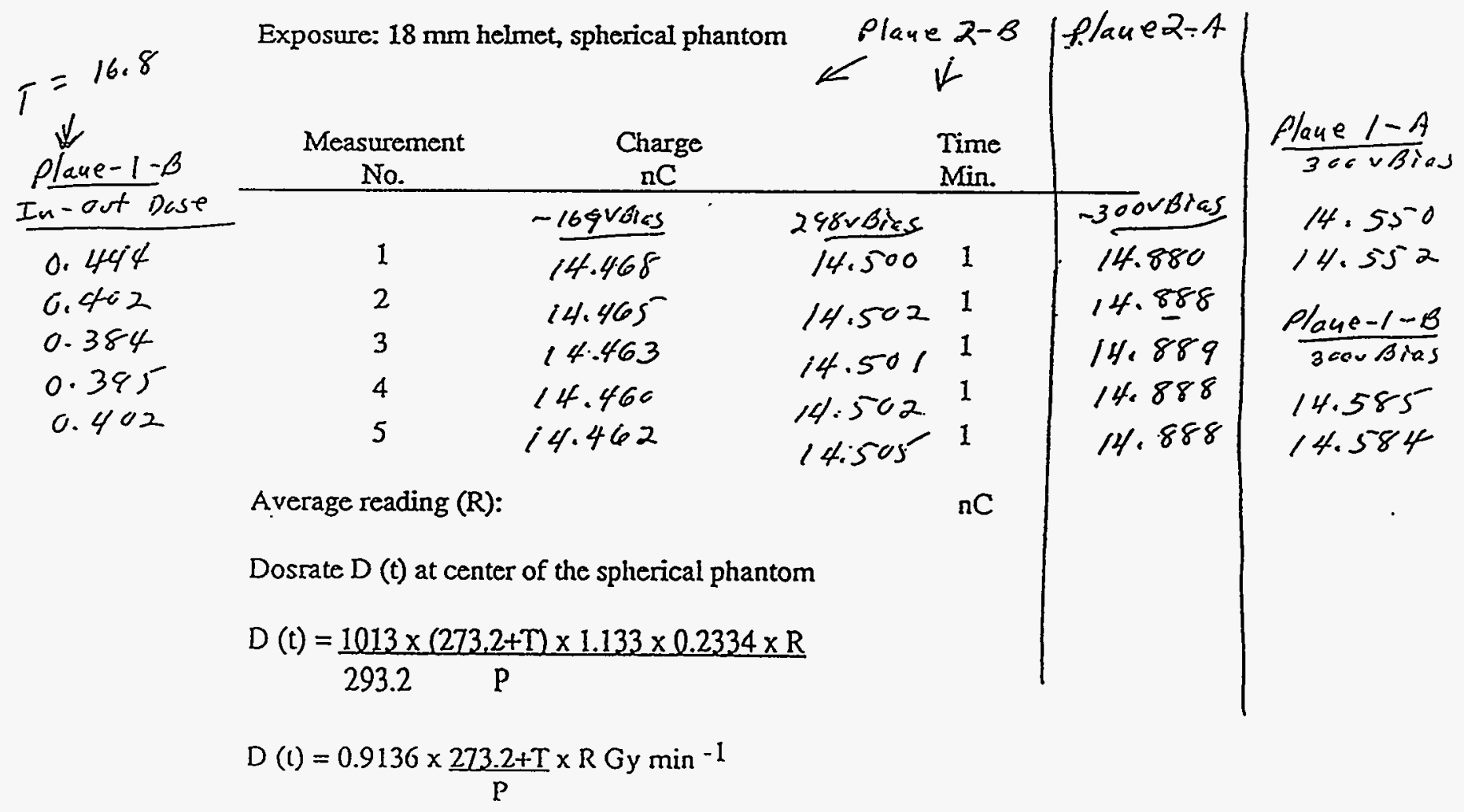


Worksheet (2) for calculating the dose to water at $d_{\text {max }}$ from photon boams

Nitulc: $\quad$ Date:

I. Radiation source: $C_{0}-60,6$ bemen Haife: Stated energy: $60-60,1.25 \mathrm{McV}$ Ionization ratio: Nominal accelerating potential: MV

(Sec. IV B) (Fig. 3)

2. Phantoon material (med): POLYSTYRENE SSD: 40

Collimator field size: $18 \mathrm{sam} \mathrm{cm}^{2} ;$ Depth of measurement: $\_8$

3.1. Dose to pliantom material per monitor unit [Eq. (9)]:

$$
D_{\text {mod }} / U=(\overline{M / U}) N_{\text {zus }}(\bar{L} / \rho)_{\text {alr }}^{\text {med }} P_{\text {wall }} P_{\text {lon }} P_{\text {sepl }}
$$

where $U$ refers to accelerator monitor units, or timie for a ${ }^{\circ} \mathrm{Co}$ unit.

3.2. The chamber emperature $T=\frac{22}{2} \mathrm{C}$ and pressure $P=760 \mathrm{~mm}$ at the time of measurement. The chamber signal $M$ is normalized to $22^{\circ} \mathrm{C}$ and 1 atmosphere using the factor:

$$
\frac{r+273^{\circ} \mathrm{C}}{295^{\circ} \mathrm{C}} \times \frac{760 \mathrm{mmHg}}{P}=1,00
$$

3.3. Mean chamber signal per monitor unit (at the higher collecting potential, and normalized $10 ? 22^{\circ} \mathrm{C}$ and $760 \mathrm{mmHg}$ )

$$
\begin{aligned}
&(\overline{M / U})=\longrightarrow \mathrm{C} / \text { monitor unit } \\
& \text { or }(\overline{M / U})=\longrightarrow \text { scale division/. } \\
& \text { monitor unit }
\end{aligned}
$$

3.4. Cavity-gas calibration factor: Chamber model: $P R-0.5 P$ Wall material: $C-552$

Inner diameter: $H \quad \mathrm{~mm}$ Wall thickness: $\frac{0.22}{N_{11}}=\frac{0.8667}{0.8624}$

3.5. Stopping-power ratio (Fig. 2, Table IV):

3.6. Wall correction factor [Eq. (io)]:

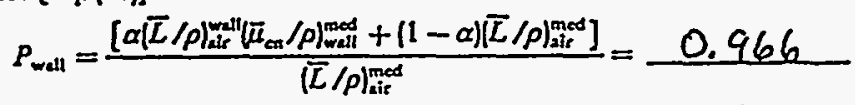

Fraction of ionization from chamber wall (Fig. 7):

$$
\begin{aligned}
\alpha & =\frac{0.92}{(1-\alpha)}=0.08
\end{aligned}
$$

If $\alpha>0.25$, enter $\alpha$ and $(1-\alpha)$.

If $\alpha<0.25$, enter $\alpha=0$ and proceed to 4 .

Stopping-power ratio (Fig. 2, Table IV):

$$
\overline{[L} / \rho)_{\text {sit }}^{\text {walt }}=1
$$

Energy-absorption coefficient ratio (Table.IX):

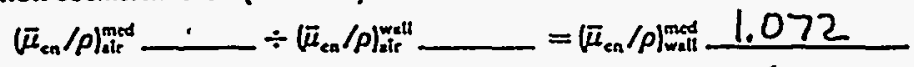

4. Ionization recombination correction (Sec. IV C and Fig. 4):

5. Replacement (gradient) correction (Fig. 5):

$$
\begin{aligned}
& P_{\text {ion }}=\frac{1}{0.995} \\
& P_{\text {sepl }}=0 .
\end{aligned}
$$

6. Dose to phantom material per monitor unit or per unit time, at point of measurement:

$$
D_{\text {nied }} / U=.9272 \quad G y / \text { monitor unit }
$$

7.1. Dose to water per monitor unit, at $d_{\text {max }}$ [Eq. (17)]:

$$
D_{\text {water }}\left(a t d_{\text {max }}\right) / U=\frac{\left(D_{\text {med }} / U\right) \times \operatorname{ESC} \times\left(\tilde{\mu}_{\text {en }} / \rho\right)_{\text {med }}^{\text {water }}}{P / 100}
$$

7.2. Correction for excess scatler from acrylic phantoms (Table XIV): ESC $=$

7.3. Encrgy-ibsorption cocflicicnt ratio/Table XII):

$$
\begin{aligned}
\left\langle\vec{u}_{\text {en }} /\left.p\right|_{\text {med }} ^{\text {waicer }}\right. & =\frac{1.036}{\rho}=\frac{100}{0.9606} \%
\end{aligned}
$$

7.4. Percent depth dose al deptli of measurement:

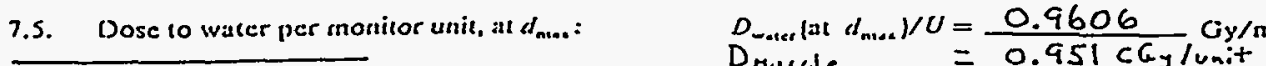

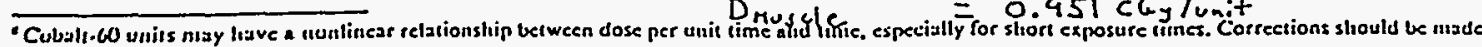
usine the tilethod or Orton and Siebert [Rer. 38).

Modlcal Pliyalce, Vot. 10, Ho, G. Hov/Ooc 1083 
Appendix C: Quality Control and Assurance

25 AAPM Protocol: Task Group 21: A Protocol lor absorbed dose from hlgh-energy beame

$$
G A M M A-K N I F E
$$

Worksheot (1) for calculating the cavlty-gas callbration factor $N_{\text {oas }}$

Namc:

_ Datc: _

The cavity gas calibration factor is obtained from Eq. (6):

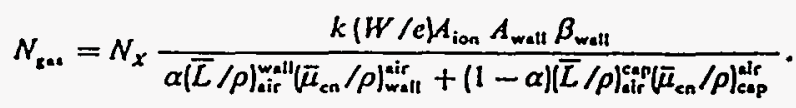

When chamber wall and buildup cap are of the same material, $\alpha=1.00$.

When chamber wall and buildup cap are of different materials, $\alpha$ is obtained from Fig. 1 .

1. (a) Chamber model and serial number: CAP INTEC PR-05P \#C11.076596

(b) Cavity inside diameter: 4

(c) Wall material and thickness: 0.22 _ $8 / \mathrm{cm}^{2} \quad 0.552$

(d) Buildup cap material and total wall plus cap thicleness: POLY $\mathrm{g} / \mathrm{cm}^{2}$

(c) Polarizing potential: $-3 / 2 \mathrm{~V}$

2. (a) Calibration laboratory and date: $K+S \quad 7|G| g \mid$

(b) Cobalt- 60 exposure calibration factor at $22^{\circ} \mathrm{C}$ and 1 atmosphere:

$$
\begin{aligned}
N_{x} & =\longrightarrow \text { R/C } \\
\text { or } N_{x} & =1,005 \quad \mathrm{R} / \text { scale division }
\end{aligned}
$$

3. (a) Charge per unit mass of air per unit exposure:

(b) Average energy per unit charge:

(c) Absorbed dose/collision fraction of kerma:

$$
\begin{aligned}
k & =2.58 \times 10^{-4} \mathrm{C} / \mathrm{kg} \mathrm{R} \\
W / e & =33.7 \mathrm{~J} / \mathrm{C} \\
\beta_{\text {well }} & =1.005
\end{aligned}
$$

4. (a) Ion-collection efficiency (obtained from NBS or ADCL, Sec. III D):

(b) Wall-correction factor (Tables II or III):

$A_{\text {ion }}=0.999$

(c) Fraction of ionization duc to electrons from chamber wall (Fig. 1):

$A_{\text {well }}=0.9905$

(d) Stopping-power ratio, wall/air (Table I):

$\alpha=0.92$

(c) Energy-absotption coefficient ratio, air/wall (Table I):

(I) Fraction of ionization due to electrons from buildup cap:

$\overline{[} / \rho)_{\text {air }}^{\text {wall }}=$ 1.00

$\left(\bar{\mu}_{\mathrm{cen}} / \rho\right)_{\text {wall }}^{\mathrm{ii}}=1.00$

(g) Stopping-power ratio, cap/air (Table l):

(h) Energy-absorption coefficient ratio, air/cap (Table I):

$$
(1-\alpha)=0.08
$$

$\overline{[L} / \rho)_{\text {ati }}^{\text {cep }}=\frac{1.112}{0.928}$

$\left(\bar{\mu}_{\text {en }} / p\right)_{\text {cap }}^{\text {sir }}=0.928$

5. Cavity-gas calibration factor at $22^{\circ} \mathrm{C}$ and 1 atmosphere:

$$
\begin{aligned}
& N_{\text {sat }}=-G y / C \\
& \text { or } N_{z a s}=0.8634 N_{x} \text { Gy/scale division } \\
& 0.8667 \text { red/scale division }
\end{aligned}
$$


CALIBRATION OF LEXSELL GAMMA UNIT

Date:

Temperature:

Pressure:

Calibrated by: Temperature/Pressure Factor:

\begin{tabular}{|c|c|c|c|c|c|c|c|c|c|c|}
\hline $\begin{array}{l}10 \\
1 !\end{array}$ & $\begin{array}{c}\text { Overlying } \\
\text { Thickness } \\
(\mathrm{cm})\end{array}$ & $\begin{array}{c}\text { Collimator } \\
\text { Size } \\
\text { (mo) }\end{array}$ & Chamber & $\begin{array}{l}\text { Measuring } \\
\text { Instrument }\end{array}$ & Scale & $\begin{array}{l}\text { Time } \\
\text { Set } \\
\text { (min) }\end{array}$ & $\begin{array}{l}\text { In-Out } \\
\text { Rdg. } \\
\text { (div) }\end{array}$ & $\begin{array}{c}\text { Readings } \\
\text { (Divisions) }\end{array}$ & $\begin{array}{l}\text { Avg Div. } \\
\text { Per Minute }\end{array}$ & Remarks \\
\hline & & & & & & & & & & \\
\hline & & & & & & & & & & \\
\hline & & & & & & & & & & \\
\hline & & & & & & & & & & \\
\hline & & & & & & & & & & \\
\hline & & & & & & & & & & \\
\hline
\end{tabular}
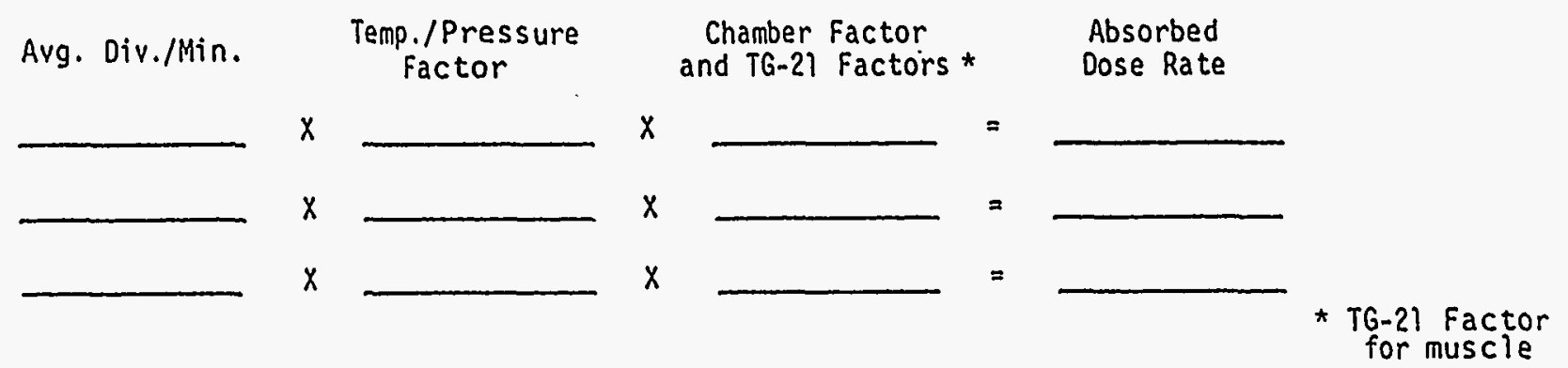

or interlock and warning lights

Timer accuracy

Checked by

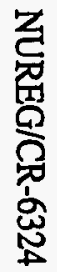

ites: 
Date:

Calibrated by:
Temperature: 24 Pressure: 758

Temperature/Pressure Factor: 1.009436

\begin{tabular}{|c|c|c|c|c|c|c|c|c|c|c|}
\hline $\begin{array}{l}\text { SAO } \\
\text { (ctil) }\end{array}$ & $\begin{array}{c}\text { Overlying } \\
\text { Thickness } \\
(\mathrm{cm})\end{array}$ & $\begin{array}{c}\text { Collimator } \\
\text { Size } \\
(\mathrm{mm}) \\
\end{array}$ & Chamber & $\begin{array}{l}\text { Measuring } \\
\text { Ins trument }\end{array}$ & Scale & $\begin{array}{c}\text { Time } \\
\text { Set } \\
(\min )\end{array}$ & $\begin{array}{c}\text { In-Out } \\
\text { Time } \\
\text { (min) }\end{array}$ & $\begin{array}{l}\text { Readings } \\
\text { (Divisions) }\end{array}$ & $\begin{array}{l}\text { Avg Div. } \\
\text { Per Minute }\end{array}$ & Remarks \\
\hline 40 & 8 & 18 & PROSP & CAPINILL-142. & EMA & $b$ & & 1642,1642 & & \\
\hline & & & & & & 5 & & 1370 & & \\
\hline & & & & & & 4 & & 1097 & & \\
\hline & & & & & & 3 & & 825 & & \\
\hline & & & & & & 2 & & 552 & & \\
\hline & & & & & & 1 & $9,9,9$ & $280,280,280$ & & \\
\hline
\end{tabular}

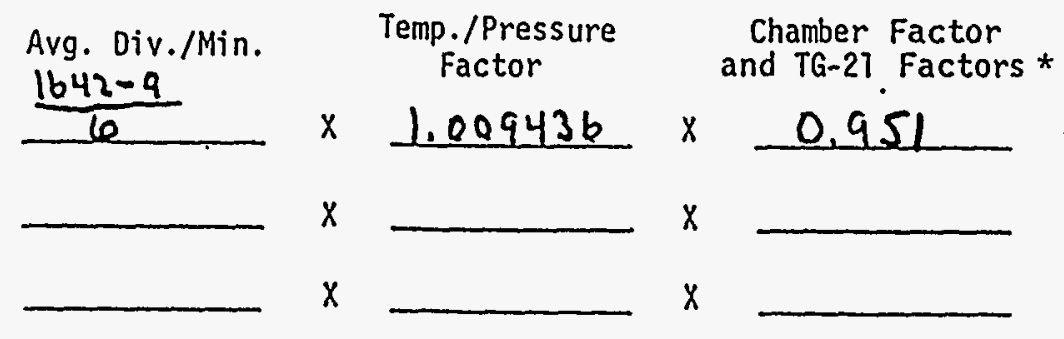

Absorbed

$=261.27 \mathrm{ral} / \mathrm{min}$

$6.00620 \mathrm{~min}$

* TG-21 Factor

for muscle

Door interlock and warning lights

Timer accuracy

Checked by

Notes: CQuCH + MORION SAFETY TIMER $=1.33$ min 


\section{QA/QC PROTOCOLS}




\section{DAILY QUALITY ASSURANCE CKECKLIST}

Parameters

1. Inspection of
A. Hydraulic Room
B. Console Area
C. Treatnent Room

2. With Kcy, Tum Unit Power ON;

Tum Video Monitors ON and Survey Meter ON; Verify that no one is present in Treatment Room
A. Lamp Test
$B$. Verification of Timer Accuracy

3. Safety Mechanisms
A. Treatment Start Button
B. Treatment Stop Button
C. Door Interlock
D. Emergency Interrupt
E. MicrophonelSpeaker

4. Check on console panel
A. Power On
$B$. Treatment YES
C. TreatmentNO
D. Radiation ON
E. Shield Open
F. Patient In
G. Patient Out
H. Zoom
I. Focus Camera (2)
J. Pump
$K$. Hydraulic Reserve
L. Warning
M. Door Open
N. Cover Open

5. Radiation beam monitor with battery back-up.

6. Portable radiation survey meter

7. Availability of Emergency Equipment
A. Long Állen Key
B. Crash Cart
C. Emergency Procedures

8. Set limer for 1 minute, initiate treatment

\section{Melhod}

Visual

Visual

Visual

\section{Visual}

Follow established procedure with NIST calibrated digital timer

\section{Activate and observe unit operate Activate and observe that treatment terminates. \\ Terminates "beam-on" when door is opened; beam remains off when ddor is closed. \\ Activate and verify couch stops. Audible Check}

\section{Visual \\ Visual \\ Visual \\ Visual \\ Visual \\ Visual \\ Visual \\ Visual \\ Visual \\ Visual \\ Visual \\ Visual \\ Visual \\ Visual}

Follow èstablished procedure.

Follow established procedure i.c. use check source.

Visual

Visual

Visual

Verify proper treatment cycle and completion 
GNMMA KNTFE

onxry guncity Assurnate

1. Visually Inspect Hydraulic Room, Console Nrea and Treatment Room

2. Turn Unit power on (with key)

Turn video Monitors ON, Survey Meter ON, Take Check Source

3. Enter Treatment Room, Place Check Source on Radiation Monitor

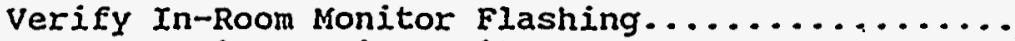

Inspect Unit, Verify Unit ok for Treatment

Open Cover at Rear of Helmet....... Helmet $m \pi$

4. Exit Treatment Room, Verify No one in Room

Verify Remote Radiation Monitor Flashing......... Set rimers to $1.0 \mathrm{~min}$ and Reset

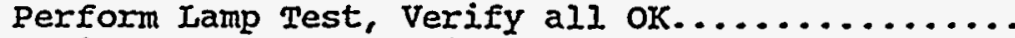

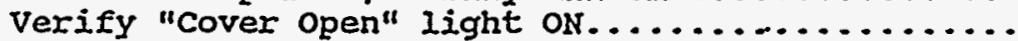

Attempt $\mathrm{Rx}$ start, Verify No Treatment..........

5. Enter Treatment Room

Close Cover at rear of Helmet, Verify Unit oK for Rx Remove Check Source

6. Exit Treatment Room, Verify No one in Room

Place check Source on Survey Meter

Verify Survey Meter Reading 1.2-2.0 mR/hr.......

Turn Survey heter OFF, Remove Check Source

7. Reset Timers ( 1.0 min), Initiate Treatment

With Couch in.Motion, Push Emergency Interrupt

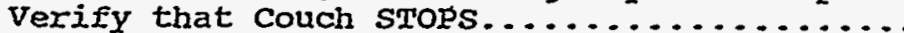

Release Emergency Interrupt, Continue Treatment During "Treatment YES", push Treatment stop Verify that Treatment terminates...........

open Room Door, Verify $R x$ CANNOT be Initiatea....

8. Reset Timers ( $1.0 \mathrm{~min})$, Initiate Treatment

Verify Proper Treatment cycle \& completion.......

9. Verify proper Function of (3) video Monitors..........

Verify proper function of Audio Communication (2-way) -

10. Run and Verify KULA Daily Q.A. Test Protocol

Time for each shot $=1.00 \mathrm{~min}$ for Dose:

Gy......

Date:

Tests performed By:

Comments : 
LEKSSELL GAMIMA UNIT

DAILY QUALIYY ASSURANCE CHECKLISI

Datc:

I. Inspection:

Time:
A. Hydraulic Room:
B. Console Area:
Yes
C. Treatment Room
Yes
Yes
No $\square$
No $\square$

Problems:

II. Lamp Test:

Non-Functioning lamps:

Yes $\square$ No

B. Verification of Timer Accuracy: Yes $\square$

No

(Set timer for 1.0 minute - verify accuracy with NIST calibrated Digital Timer) Inaccuracy/Deviation;

III. A. Safety Mechanisms: Functions Tested.

$\begin{array}{lcccc}\text { 1. Treatment Start Button } & \text { Yes } & & \text { No } & \square \\ \text { 2. Treatment Stop Button } & \text { Yes } & \text { No } & \square \\ \text { 3. Door Interlock } & \text { Yes } & \text { No } & \square \\ \text { 4. Emergency Interrupt } & \text { Yes } & & \text { No } & \square \\ \text { 5. Microphone/Speaker } & \text { Yes } & \text { No } & \square\end{array}$

Problems:

IV. Console Indicator Lights/Video Controls:

*Check each of the following functions on console panel: When applicable, set timer for 3 minutes and operate unit.

\begin{tabular}{llll} 
Power On & $\mathbf{L}$ & Focus Camera (2) & $\mathbf{Z}$ \\
Treatment (Yes) & $\square$ & Shield Closed & $\square$ \\
Treatment (No) & $\square$ & Pump & $\square$ \\
Radiation On & $\square$ & Hydraulic Reserve & $\square$ \\
Shield Open & $\square$ & Waming & $\square$ \\
Patient In & $\square$ & Door Open & $\square$ \\
Patient Out & $\square$ & Cover Open & $\square$ \\
Zoom & $\square$ & & \\
Problems: & & & \\
\hline
\end{tabular}

V. Primalert Radiation Monitor. Flashing (Exposed) Not Flashing (Not Exposed) Problems:
Yes
Yes $\square$ No $\square$

VI. Portable Survey Meter

Reading (mR/hr):

Problems:

$\square$ GM $\square$ Cutic Pie at door with check source

VII. Emergency Equipment:

Long Allen Key $\square$ Crash Cart $\square$ Emergency Procedures

Yai. Pruper Treatment Cycle: $\quad$ Yes $\square$. No $\square$ Problems:

Report all problems to

Radiotherapy Physicist (

) .

Checks performed by: 


\section{LEKSELL GAMMA UNIT \\ DAILY QUALITY ASSURANCE CHECKLIST}

Date:

I. Warm-Up Procedures:
A. Lamp Test:
Non-Functioning lamps:
no

B. Verification of Timer Accuracy:

(set timer for 1.0 minute - verify accuracy with NBS Digital Timer)

Inaccuracy/Deviation:

Time:

Yes

no

II. A. Safety Mechanisms: Functions Tested.

1. Treatment start Button

2. Treatment stop Button

3. Door Inter Lock

4. Emergency Interrupt

5. Microphone/Speaker

Problems:

Problems:

III. *Check each of the following functions on console panel: When applicable, set timer for 3 minutes and operate unit.

\section{Power on}

Treatment Yes Treatment No Radiation on Shield Open Patient In patient out zoom
Focus Camera (2) Shield Closed Pump Hydraulic Reserve warning Door Open Cover Open

IV. Primalert Radiation Detector Exposed Detector Not Exposed Monitor (A.C. Power)

Primalert Radiation Monitor (Battery Pack)

Cutie Pie Survey Meter (Standard Reading)

Cutie Pie survey Meter (Reading with check source)

Problems :

Report all problems to Radiological Physics Checks performed by: 


\section{DAILY QUALITY ASSURANCE GAMMA KNIFE}

1. Visually Inspeci Hydraulic Room, Consolo Area and Treatment Room

2. Tum Breaker on at Side of Relay Box and then Unit Power ON (with key) Turn Video Monitors ON, Survey Meter ON

3. Enter Treatment Room Inspect Unit, Verify Unit OK for Treatment

Open Cover at Rear of Helmet . . . . Helmet \#. . I $1 \mathrm{fm}^{\mathrm{mm}}$

4. Exit Treatment Room, Verify No One in Room

Set South Camera to Visualize Radiation Monitor. . . Set Timers to $1.0 \mathrm{~min}$ and Reset Perform Lamp Test, Verify all OK. . . . . . . . . Verify "Cover Open" light ON. Attempt Rx Start, Verify NO Treatment

5. Enter Treatment Room

Close Cover at rear of Helmet, Verify Unit OK for Rx

6. Exit Treatment Room, Verify No One in Room

Place Check Source on Survey Meter

Verify Survey Meter Reading 1.8-2.4 mR/hr (cover off) $/ . \mathrm{G}$

Turn Survey Meter OFF, Remove Check Source

7. Reset Timers ( $1.0 \mathrm{~min}$ ), Initiate Treatment

Verify that Radiation Monitor in room is flashing. . . . With Couch in Motion, Push Emergency Interrupt Verify that Couch STOPS.

Release Emergency Interrupt, Continue Treatment During "Treatment YES", Push Treatment Stop Verity that Treatment terminates. . . . . . . . After Shield Door closes, Verify that Radiation Monitor stops flashing. Open Room Door, Verify Rx CANNOT be Intiated.

8. Reset Timers (1.0 min ), Initiate Treatment

Verify Proper Treatment Cycle \& Completion . . . : .

9. Verify Proper Function of (3) Video Monitors . Verify Proper Function of Audio Communication (2-way)

10. Run and Verify KULA Daily Q.A. Test Protocol

Date: Tests Performed By:

Comments: 
Appendix C: Quality Control and Assurance

DAILY CIECKLIST FOR THE WEEK OF

Chore

SUN

MON

TUE

WED TIKUE FRI

SAT

Rádiation Monitor

Back up Power

Hand Held Monitor

Battery

Response

Emergency off

In Room

On Console

Hydraulic Switch

Cutoffs

Hydraulic Pressures

Door Interlock

Timer Terminates

Exposure

Visual and

Audio Systems

Helmet Microswitches

Lamp Test

Emergency Timing Circuit

Helmet Hoist

T.7itial.s

Notes 


\section{MONTHLY SPOT CHECK PROCEDURE}

The following text describes the procedures for the various items on the Monthly Spot Check report form.

1. Time since last Daily Q.A.

If the Daily Q.A. procedure has not been performed within the previous 10 days, due to clinical inactivity, this must be performed as part of the Monthly Spot Check.

\section{Beam Condition Indicators}

The Beam Condition Indicators should perform as indicated on the accompanying sheet. Any discrepancies should be noted and corrective.action pursued.

\section{Door Interlocks}

When the door to the treatment room is open, verify that the "Door Open" lamp on the control console is $\mathrm{ON}$. Confirm that the door interlock prohibits treatment if open, and that the Treatment Stop cycle is initiated if the door is opened during treatment.

\section{Emergency Off Buttons}

The two Emergency Off buttons are located at the left of the console area and in the treatment room adjacent to the Unit (on room entrance side). The test shall confirm that the Stop Treatment cycle is initiated when either Emergency Off button is depressed during treatment. Note that the in-room test requires that an individual remain in the treatment room for the initiation of treatment.

\section{Postings}

Confirm that the Notice To Employees, Emergency Procedures, and Safety Instructions are posted at the control console.

\section{Emergency Release Rod}

Confirm that the Emergency Release Rod is in its proper location, mounted on the wall immediately South of the unit. 


\section{Trunnions, Accuracy vs. X-frame test tool}

Mount the X-frame jig in the Helmet currently attached to the unit. Confirm that both sets of trunnions read within $0.2 \mathrm{~mm}$ of $100.0 \mathrm{~mm}$. Refer to previous Monthly Spot Checks and alternate this test over the four helmets.

\section{Helmet Inspection and Shim Test}

Each Helmet shall be carefully inspected to verify that all collimators are correct and properly rotated to prevent accidental displacement (important for posterior collimators).

Inspect the trunnion support assembly of each helmet for mechanical integrity.

Each Helmet shall be tested with and without $0.1 \mathrm{~mm}$ brass shims on the docking surface of the helmet. This test may alternately be performed with the helmet on the LGU, or by using the alignment ring and test circuit. Confirm normal operation without shims. Confirm that with shims in place the treatment cycle terminates within 2 sec of the normal Treatment Yes phase. If using alignment ring and test circuit, confirm proper operation with and without shims.

\section{Power Loss/Restart}

During Treatment YES phase, note readings on Timers and tum key OFF. Confthat Treatment Stop cycle is initiated and that couch is fully ejected. Activate leved in hydraulic room and confirm that shielding door closes fully twrder remaithing resenve pressure. Return lever in hydraulic room to normal position. Turn Key ON. Confirm that Timers correctly maintain readings that existed at the time of power loss. Confirm that treatment can be continued properly once reserve pressure has been established.

\section{Couch Motion Safety Timer}

To test that the timer is functional, one should initiate a procedure as normal, allowing the radiation door to open and the couch to begin its movement. One should then depress the "emergency interrupt". button, thereby halting the couch. This does not disrupt the timer, nor the signal lamp functions at the console. After approximately 2 minutes from treatment start, the "patient in" white light lamp will stop blinking and go out. The "patient out" white lamp will begin to blink indicating that the system has timed out and is attempting to abort the procedure. Releasing the "emergency interrupt" button at this time will allow the system to withdraw the couch and close the radiation door. If the "emergency interrupt" button is depressed before the couch begins its movement, the unit will open the radiation door, the timer will run its course and the unit will close the radiation door without the release of the "emergency interrupt" button. 
On the monthly spot check form record the time from "start treatment" to timeout, as described above.

11. Backup Battery-Radiation Monitor (required @6 months)

Disconnect in-room Radiation Monitor from line voltage supply. Conduct subsequent ionization measurements with monitor operating on battery backup. Confirm proper operation.

\section{Ionization Measurements}

Conduct ionization measurements with intrumentation and setup as noted. The phantom orientation is shown on the attached diagram. The Time Sets listed are arbitrary. However, alternate time sets must fulfill the requirements for testing Timer Error, Constancy, and Linearity. After determination of the temperature/pressure correction, calculate the dose delivered during each time set. Note that the final column of Dose Rate requires calculation of the Timer Error, dt, before its completion.

\section{Timer Accuracy}

For the $15 \mathrm{~min}$ time set, confirm the accuracy of the Timers at regular intervals against the wall clock or a watch. Demand overall agreement within $10 \mathrm{sec}$ (approx. 1\%) over 15 min period.

\section{Timer Error}

Using appropriate Dose values, calculate the Timer Error using the formalism given. Expect dt approximately $=0.03 \mathrm{~min}$. *

\section{Constancy}

Constancy is to be evaluated by considering the range of doses delivered in four separate irradiations with identical time sets. The constancy determined in this way is expected to be less than $2 \%$.

16. Linearity

Linearity is to be evaluated by considering the range of Dose Rates determined for different time sets. The linearity determined in this way is expected to be less than $2 \%$.

\section{Current Measurement of OUTPUT}

The value taken for the current measured Output is the Average Dose Rate determined in item 11. 
18. Last Full Calibration - Output Decayed to Today

Record data from the last full calibration of the Unit. A full calibration is required at least annually. Compare today's Output (average Dose Rate) determination vs. the Last Full Calibration dose rate decayed to today. The decay factor is determined using half-life of Co-60 $=5.263$ years.

Expect that the absolute value of the \% difference of today's output from the decayed calibration value should be less than $2 \%$.

\section{KULA - Dose Planning System - Treatment Time Determination}

A dose calculation shall be run on the KULA dose planning system for the following reference condition: $18 \mathrm{~mm}$ Helmet, unplugged, 100 Gy delivered to Center (Note, not Maximum) of $16 \mathrm{~cm}$ diameter spherical phantom. Print protocol for this calculation and attach 3rd page to this report. Complete the comparison of dose rates as indicated on Spot Check report form. Expect KULA dose rate to agree within $2 \%$ of the decayed calibration dose rate. "**

If determined value exceeds expected tolerance, the discrepancy should be confirmed or negated by additional measurements. If confirmed, additional documentation must accompany the report regarding the resolution of the discrepancy and/or the impact on subsequent clinical use of the Leksell Gamma Unit. 
Date:

Leksell Gamma Unit, Model U23016,

Co-60 sources, General Electric, Model AB Elekta 43047, s/n 1-201

JaN feb Mar apr maY JUN JUL aUg SEP OCT NOV DEC

1. Time since last Daily Q.A. : days (must be <10)

2. Beam Condition Indicators: ....OK? Y/N (see procedure diagram)

3. Door Interlocks: LT/RT. . . . .OK? Y/N door open - no Rx; Rx - door open - Rx term

4. Emergency OFF buttons: . . . . OK? $Y / N$ At Console, In Room; - Term Rx

5. Postings: ......... . OK? Y/N NRC, Emergency, Safety

6. Emergency Release Rod:. . . . .OK? Y/N

7. Trunnions: L1/R1, L2/R2. ... OK? Y/N $4 \mathrm{~mm}, 8 \mathrm{~mm}, 14 \mathrm{~mm}, 18 \mathrm{~mm}$

8. Inspect Helmets/Shim Test:. . . .OK? Y/N $4 \mathrm{~mm}, 8 \mathrm{~mm}, 14 \mathrm{~mm}, 18 \mathrm{~mm}$

9. Power Loss/Restart Rx Stop \& Timer Backup:. . . .OK? Y/N

10. Couch motion Safety Timer: . .OK? Y/N Time Start Rx to Timeout: $\sec (<120 s)$

11. "Radiation Monitor -

Battery Backup (@6 mos)... .OK? Y / N

Comments:

Instrumentation:

Keithley Electrometer, Model 35614 s/n 15182

Ion Chamber, Model IC10 s/n 754

(ADCL Calibration, Date: June - 1991)

Bias: $=100 \%$

Chamber at focus of $18 \mathrm{~mm} \mathrm{Helmet,} \mathrm{at} \mathrm{center} \mathrm{of} 16 \mathrm{~cm}$ diameter polystyrene phantom.

Electrometer: Coulomb scale. ECF=electrometer correction factor Temp: C. Pressure: $\mathrm{mm}, \mathrm{TP}=(273+\mathrm{T}) / 295^{*} 760 / \mathrm{P}=$

Dose to water $=$ RDG ${ }^{*}$ ECF $* \mathrm{TP} \cdot 2.171 \times 10^{10} \mathrm{cGy}=$ cGy 
Date:

DOSE RATE

12.Time Set RDG DOSE $\left\{R D G^{*}\right.$ \{Dose/(t+dt)\}

\begin{tabular}{|c|c|}
\hline (min) & \multirow[t]{2}{*}{$\left(10^{-8} \mathrm{C}\right)$} \\
\hline 1.0 & \\
\hline 1.0 & \\
\hline 1.0 & \\
\hline 1.0 & \\
\hline 4.0 & \\
\hline 10.0 & \\
\hline${ }^{*} 15.0$ & \\
\hline
\end{tabular}

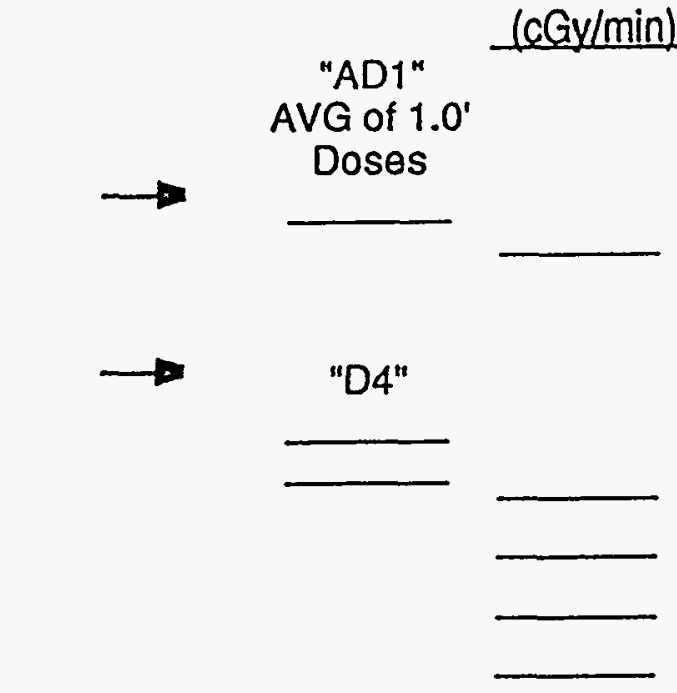

13. * For $15^{\prime}$ set, check Timers vs. wall clock or watch:. . OK? Y /N

14. Timer Error:. . . . dt $=\left(4^{*} A D 1-D 4\right) /(D 4-A D 1)=$ $\min \{<.05\}$

15. Constancy: Consider four $1.0^{\prime}$ Doses: $100 \%{ }^{*}(\operatorname{Max} / \mathrm{Min}-1)=$ $\%\{<2 \%\}$

16. Linearity: Consider DOSE RATE: . . 100\%* (Max/Min - 1) $=$ $\%\{<2 \%\}$

17. Output: . . . . . Avg. value of DOSE RATE $=$ cGy/min

18. Last Full Calibration: Date:

Timer Error: $\quad$ min, Calibration:

Days since last calibration:

Decay Factor: $\exp \left\{-0.0003602{ }^{\star} t\right.$ (days) $\}=$

Decayed Calibration . . . . . . . . . = cGy/min

$\%$ Difference, Today's Output vs. Decayed Cal. $=$ $\%\{<3 \%\}$

18. KULA: Time for 30 Gy Reference Treatment: $\min$

Kula Dose Rate: . . . . . . (3000cGy/time $)=$ cGy/min

$\%$ Difference, KULA Dose Rate vs. Decayed Cal. = $\%\{<2 \%\}$

Comments:

Performed By:

Medical Physicist: 


\title{
MONTHLY SPOT CHECK MEASUREMENTS REQUIRED
}

\author{
1. Timer constancy \\ 2. Timer linearity \\ 3. On-off error \\ 4. Stereotactic frames
}

5. Localization devices

6-12. Safety checks

13. Machine output in phantom with $18 \mathrm{~mm}$ Helmet

14. Alignment (using Leksell test tool)

15. Microswitch test (using. Leksell test tool) 
I.EKSLII. GANMA UNIT - MONTHLY SPOT CHLCK

$S=$ SAITSFACHORY $U=$ UNSATISHCIORY

1. T'inet Constancy

2. Timer Linearity

3. On-Off Error

4. Stereotactic Frames \& Acces.

5. Localization Devices (Trunnions)

6. Door Interlock

7. Helmet Switches/stops

8. Beam Condition Light

a. At Console

b. At Door (Radiation in-use light)

9. Viewing systems

a. T.V. Console

b. T.V. ifydraulic Room

c. T.V. Cabinet

10. Communication system

11. Emergency off Buttons

\begin{tabular}{c|l|l|l}
\hline a. on console & & & \\
\hline b. on side wall & & & \\
\hline c. on back wall & & &
\end{tabular}

\section{Room Monitor}

I 3. Machine Output

a. In Phantom with $18 \mathrm{~mm}$ Helmet

b. Measured Value

c. Anticipated Value

d. \& Difference

14. Alignment Check (using Leksell test tool)

15. Microswitch Test (using LekselI test tool)

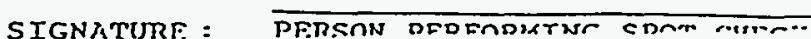


Appendix C: Quality Control and Assurance

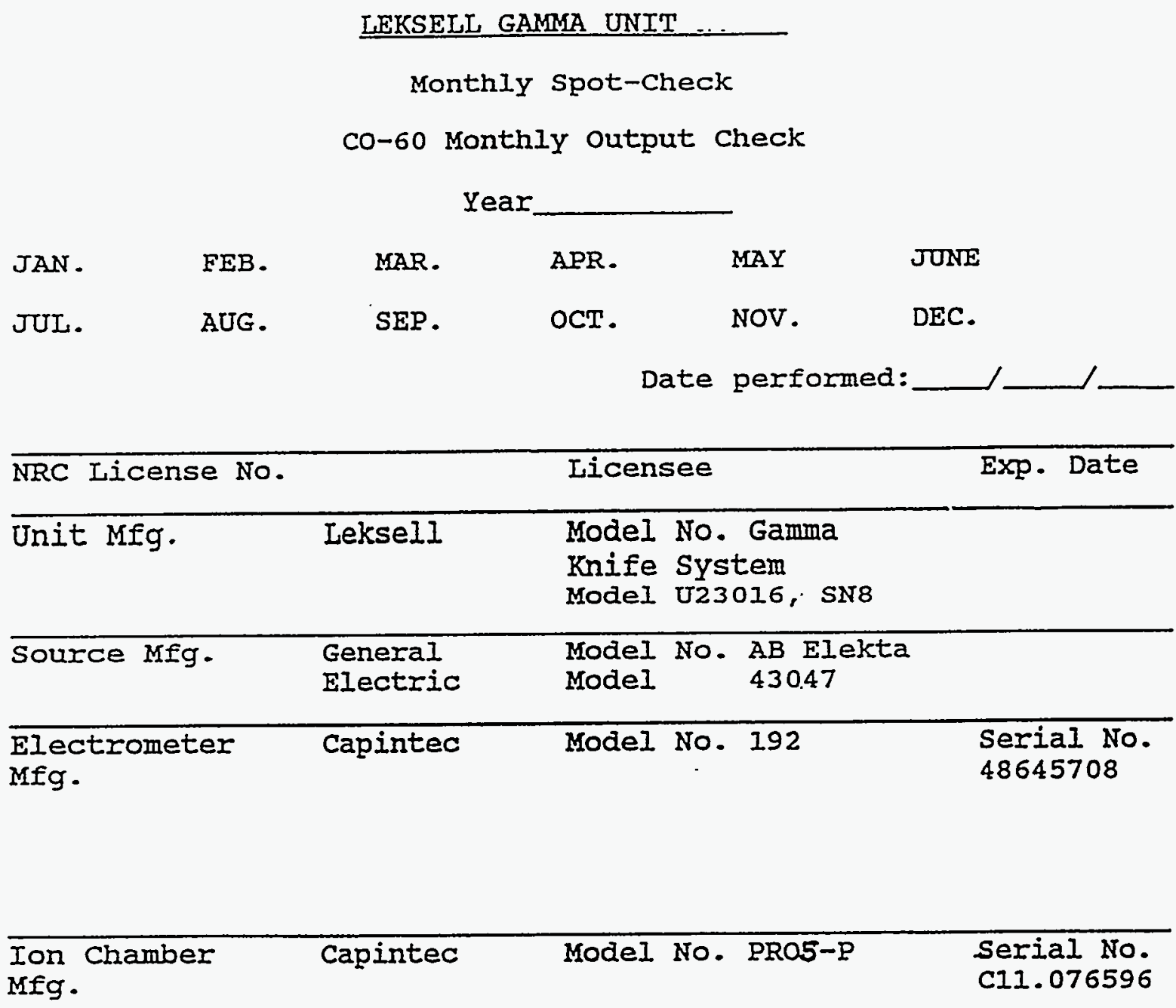

Last date of ADCL Calibration/Intercomparison/Comparison Month: Year: 


\begin{tabular}{|c|c|c|c|}
\hline 20 & $S$ & $\bar{U}$ & COMMENTS \\
\hline 1. Timer Constancy & & & \\
\hline 2. Timer Linearity & & & \\
\hline 3. On-off Error & & & \\
\hline 4. Stereotactic Frames \& Acces. & & & \\
\hline 5. Iocalization Devices (Trunnions) & & & \\
\hline 6. Door Interlock & & & \\
\hline 7. Helmet Switches/Stops & & & \\
\hline 8. Beam Condition Light & & & \\
\hline a. At Console & & & \\
\hline b. At Door (Radiation in-use light) & & & \\
\hline 9. Viewing systems & & & \\
\hline a. T.V. Console & & & \\
\hline b. T.V. Hydraulic Room & & & \\
\hline c. T.V. Cabinet & & & \\
\hline 10. Communication System & & & \\
\hline 11. Emergency off Buttons & & & \\
\hline a. On console & & & \\
\hline b. On side wall & & & \\
\hline c. on back wall & & & \\
\hline
\end{tabular}


Appendix C: Quality Control and Assurance

$$
-3-
$$

\begin{tabular}{|c|c|c|c|}
\hline 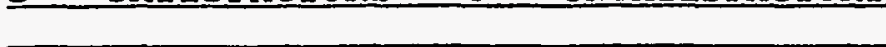 & $\mathrm{s}$ & 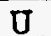 & COMMENTS \\
\hline 12. Room Monitor & & & \\
\hline a. On $\mathrm{A} / \mathrm{C}$ Iine & & & \\
\hline b. Emergency Line & & & \\
\hline c. Monitor Light at Console & & & \\
\hline 13. Emergency Instructions Posted & & & \\
\hline 14. NRC Postings & & & \\
\hline 15. Emergency-Release Rod & & & \\
\hline 16. Operational Survey Meter & & & \\
\hline 17. Machine output & & & \\
\hline a. In Phantom with 18 mm Helmet & & & \\
\hline b. Measured Value & & & \\
\hline c. Anticipated Value & & & \\
\hline d. $\%$ Difference & & & \\
\hline
\end{tabular}

SIGNATURE OF PERSON PERFORMING SPOT CHECK

SIGNATURE OF TEIETHERAPY PHYSICIST 
Monthly Spot Check

NRC

Leksell Gamna Unit Model \#

GE Sources Model \#

Date:

Performed by:
Capintec Electrometer Model 192 SN: Capintec Chamber Model PRO5P SN: ADCL Calibrated:

S U Comments

1. Timer Constancy

2. Timer Linearity

3. On-Off Error

4. Timer Termination of Exposure

5. Stereotactic Frames \& Acces.

6. Localization Devices (Trunnions)

7. Door Interlock

8. Helmet Micro Switches

9. Couch Movement Time; Emergency Timing Circuit

10. Beam Condition Light

a. At Console

b. At Door (Radiation in-use light)

11. Viewing systems

a. T.V. Console

b. T.V. Hydraulic Room

c. T.V. Gabinet

12. Communication System

13. Emergency off Buttons
a. On Console
b. On side wall
c. On back wall

14. Room Monitor
a. On $A / C$ line
b. Emergency Line (Annual Test)
c. Monitor Light at Console

15. Emergency Instructions Posted

16. Availability of Operating Instructions

17. NRC Postings

18. Emergency-Release Rod

19. Operational Survey Meter

20. Leak Test

21. Machine Output
a. In Phantom
b. Measured Value
c. Anticipated Value
d. Difference as of (d.)
e. Computer Output
$f$. \% difference

Double Checked by:

Date: 


\section{LEKSELL GAMMA UNIT}

\section{FULL ANNUAL CALIBRATION}

The Leksell Gamma Unit is provided with four different helmets, with collimator sizes of $4,8,14$, and $18 \mathrm{~mm}$ diameter. The treatment planning system (KULA) provided by ELEKTA, Inc. requires only the output of the $18 \mathrm{~mm}$ collimator to be entered into the software of the treatment planning system. This is the output in Grays per minute at a SAD of $400 \mathrm{~mm}$ and at a depth of $80 \mathrm{~mm}$ in a water equivalent phantom. To determine the radiation output we use a Keithley Model 616 Digital Electrometer coupled to a Capintec PR-05P mini-chamber.

This chamber has a $0.07 \mathrm{ml}$ active volume and an outside diameter of 6.4 $\mathrm{mm}$. Since the $100 \%$ isodose diameter for the $4 \mathrm{~mm}, 8 \mathrm{~mm}$, and $14 \mathrm{~mm}$ collimators are much less than the outside diameter of the PR-05P minichamber it is physically impossible to measure the output directly for these three collimators with an ionization chamber. The output for these three collimators can be calculated by using the collimator factors supplied by the manufacturer of the Leksell Gamma Unit which are incorporated into the provided software. The collimator factors as determined by ELEKTA are as follows:

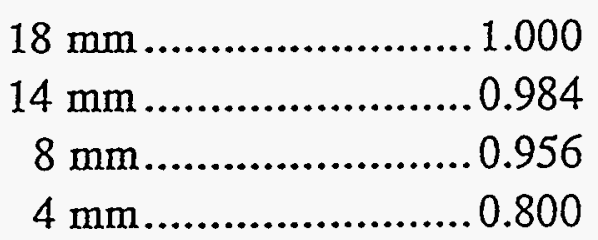

An indirect method using film, TLD's, or diodes is used to verify the collimator factors for the four different sizes. If the results agree within \pm $5 \%$ of the values supplied by ELEKTA, then no change is made in the treatment planning system's software. If the results differ by more than 5\% from ELEKTA'svalues, then ELEKTA will be contacted and a resolution of the differences made. 
To verify the linearity of the Leksell Gamma Unit timer output, measurements are made with an ion chamber with the $18 \mathrm{~mm}$ helmet for a number of different periods of time. Linear regression analysis is performed with time assigned to the $\mathrm{x}$-axis and the ion chamber reading assigned to the $y$-axis. The correlation coefficient should be 0.999 or better if the timer is linear. The linear regression analysis provides the $x$ intercept which is a measure of the on-off error. The on-off error is a result of the time required for the patient to move into and out of the treatment position. This results in a small absorbed dose, approximately $0.1 \mathrm{~Gy}$, to the patient which is referred to as the "transport dose", and is determined by calculation of the $y$ intercept of the linear regression analysis. 


\section{FULL CALIBRATION MEASUREMENTS REQUIRED}

\section{Parameter}

1. Timer Constancy

2. Timer Linearity

3. On-Off Error

4. Machine output in phantom with $18 \mathrm{~mm}$ Helmet

5. Spatial Absorbed Dose

Distribution
a. X Axis
b. Y Axis
c. $\mathrm{Z}$ Axis

6. Radiological Determination of Focal Point
a. X Axis
b. Y Axis
c. Z Axis

7. Determination of Collimator Factors
a. $4 \mathrm{~mm}$ Helmet
b. $8 \mathrm{~mm}$ Helmet
c. $14 \mathrm{~mm}$ Helmet

\section{Method}

NIST calibrated timer

Ion Chamber

Ion Chamber

Ion Chamber

Film

Film

Film, TLD's or Diodes

\section{Specifications}

$\pm 0.1 \mathrm{~min}$.

Correlation

Coefficient of 0.9999

$\pm 0.01 \mathrm{~min}$.

$\pm 3 \%$

$\pm 1 \mathrm{~mm}$ on $50 \%$ line

$\pm 0.3 \mathrm{~mm}$

$\pm 5 \%$ 
LEKSELL GAMMA UNIT

Annual Calibration

Date Performed:

\begin{tabular}{|c|c|c|c|}
\hline NRC License & $\# 45-00034-30$ & Licensee-Univ. of VA & $\begin{array}{ll}\text { Exp. } & \text { Date } \\
\text { July } & 31,1993\end{array}$ \\
\hline Unit Mfg. & Leksell & $\begin{array}{l}\text { Model No. Gamma } \\
\text { Knife System } \\
\text { Model U23016, SN8 }\end{array}$ & \\
\hline $\begin{array}{l}\text { Source } \\
\text { Mfg. }\end{array}$ & $\begin{array}{l}\text { General } \\
\text { Electric }\end{array}$ & $\begin{array}{l}\text { Model No. AB Elekta } \\
\text { Model }\end{array}$ & \\
\hline Electrometer & Capintec & Model No. 192 & $\begin{array}{l}\text { Serial No. } \\
48645708\end{array}$ \\
\hline $\begin{array}{l}\text { Ion } \\
\text { Chamber }\end{array}$ & Capintec & Model No. PRO5-P & $\begin{array}{l}\text { Serial No. } \\
\text { C11.076596 }\end{array}$ \\
\hline
\end{tabular}

Last date of ADCI Calibration: 
Appendix C: Quality Control and Assurance

$S=$ SATISFACTORY $U$ = UNSATISFACTORY

$S \quad U$ COMMENTS

i. Timer Constancy

2. Timer Linearity

3. On-off Error

4 Stereotactic Frames \& Acces.

5. Localization Devices (Trunnions)

6. Door Interionk

7. Helmet Switches/stops

8. Beam Condition Light

........ At console

$\ldots \ldots \ldots \ldots \ldots \ldots \ldots \ldots \ldots \ldots \ldots \ldots$

b. At Door (Radiation in-use Iight)

9. Viewing stations

......................

a. T.V. Console

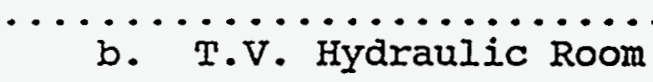

.................... Cabinet

io. Communication system

ii. E. Emergency off Buttons

........ on Console

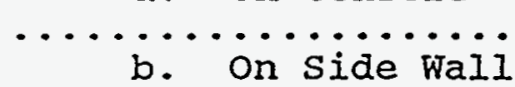

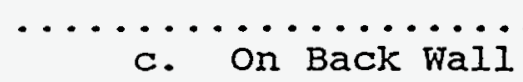

i2. Room Monitor

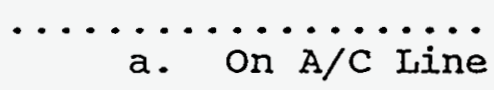

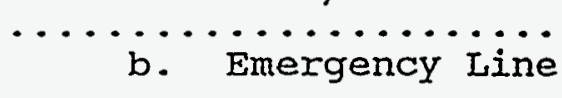

......... Monitor Light at Console

13 Emergency Instructions Posted

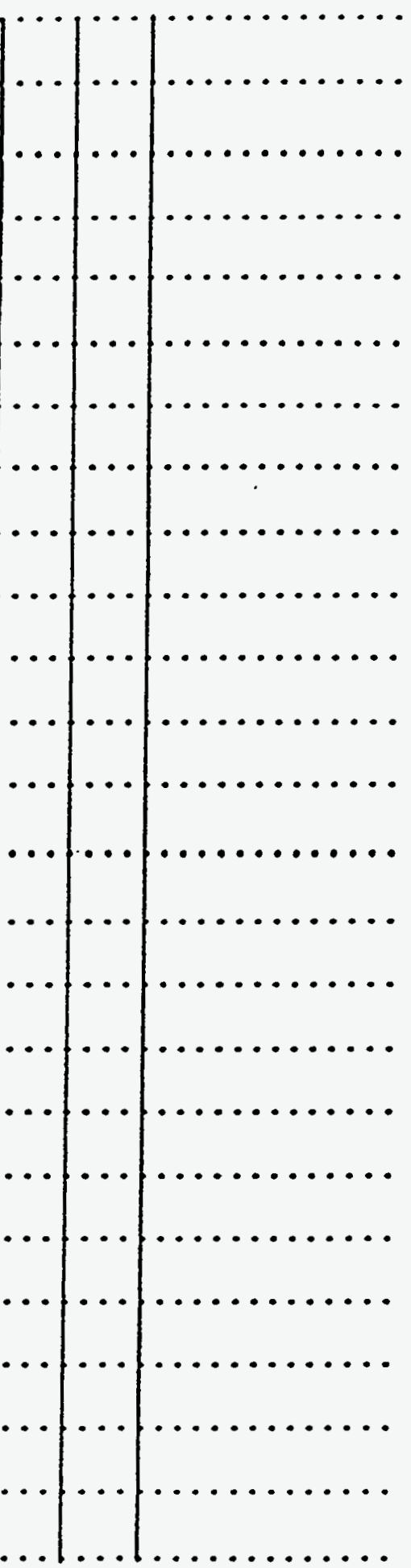


$S=$ SATISFACTORY U = UNSATISFACTORY

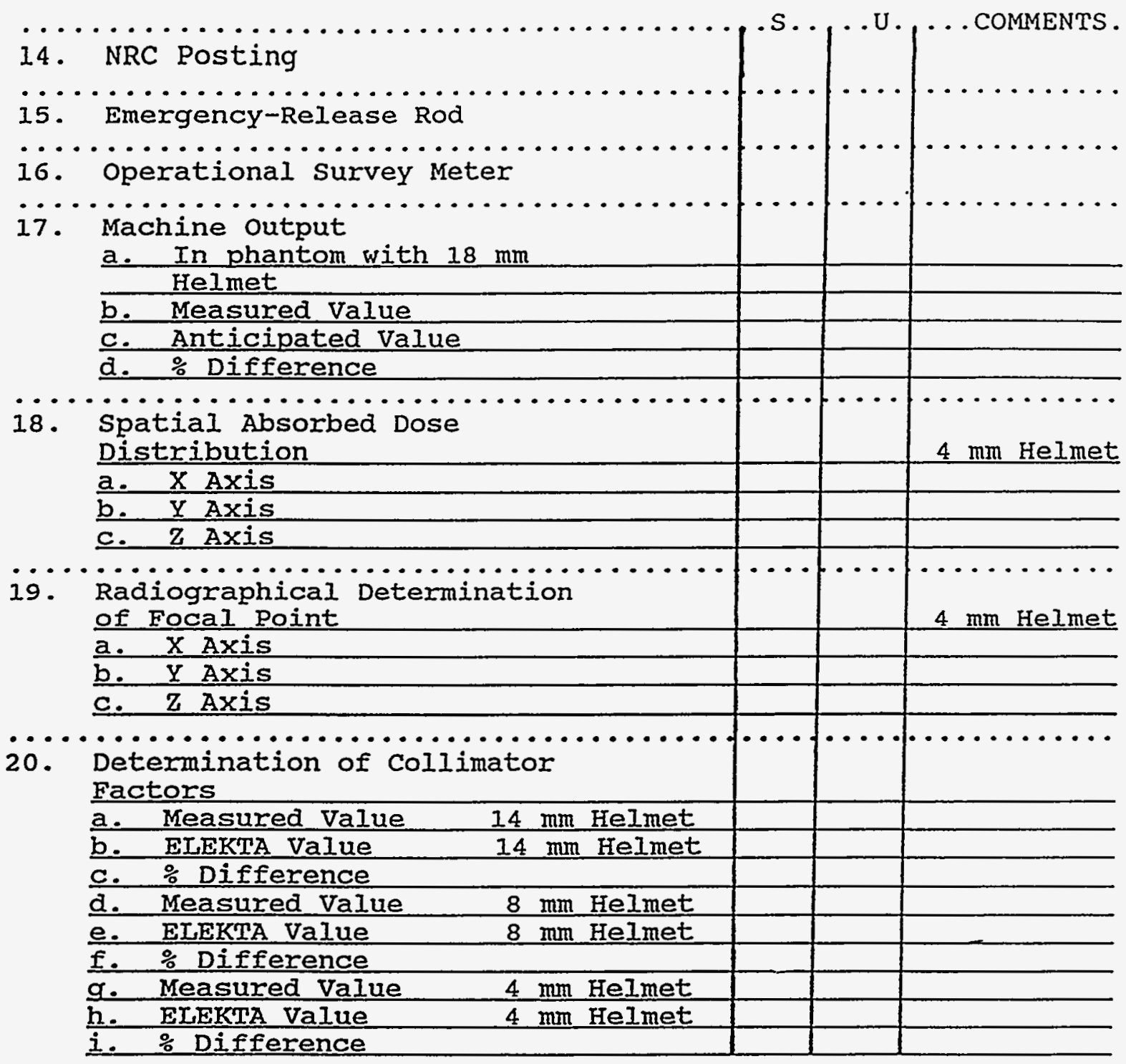



APPENDIX D:

EXAMPLES OF WRITTEN EMERGENCY PROCEDURES 
Appendix D: Examples of Written Emergency Procedures

This appendix includes three representative Gamma Knife facility emergency procedures acquired during the quality assurance assessment process. 
1. If power failure occurs during irradiation, the couch will automatically be removed out of radiation unit. The shielding door is then to be closed by manually shifting the sHIELDING DOOR CLOSURE lever on the hydraulic unit in the hydraulic room. Closing of the shielding door is prevented by an interlock until the couch is fully removed. After closure of the shielding door, entry. to the treatment room is allowed.

2. If hydraulic pump failure occurs during treatment, there is enough reserve pressure to complete the treatment and stop-treatment cycle. If reserve pressure is not enough, the operator shall enter the hydraulic room and reestablish pressure with the hand pump. If the hydraulic failure is due to an electrical failure which affects the couch microswitches, the operator must also shift the SHIELDING DOOR CLOSURE lever on the hydraulic unit after the patient couch has exited and before the shielding door can be closed by means of the hand pump. Assuming continued power to the control panel, however, the main controls will give information about status of the unit during hand pumping.

3. If there is not sufficient reserve pressure, the stop-treatment cycle is automatically initiated. The pressure level at which point the hydraulic pump is activated during the treatment cycle is sufficient to complete the stop-treatment cycle. In the event reserve pressure is not sufficient at any time during the treatment cycle and the pump fails to restore sufficient hydraulic reserve pressure within one minute, the stop-treatment cycle is automatically initiated.

4. If the hydraulic system fails and it is not possible to withdraw the couch and to close the shielding door with hand pumping, manual removal of patient can be effected by the following means:

a) Enter treatment room.

b) PuIl out handle at foot end of couch.

c) Two persons have to retract the couch to the outermost position by manual force.

d) Remove patient from helmet fixation trunnions and bring him out of high level radiation area.

e) After removal of patient from the treatment room, close the treatment room door and secure the room. 
f) The radiologist or physicist in charge shall immediately report to and request assistance from the radiation safety officer. All persons present inside the treatment room shall be under control of the radiation safety officer.

g) Contact Elekta Instruments for repair assistance.

5. If the couch gets stuck in the radiation unit and it is not possible to withdraw it with hydraulic hand pumping or manual retraction, patient must be brought out manually from high level radiation area by the following means:

a) Loosen the bolt locking one or both head fixation trunnions with the special long Alien key.

b) Push out the loosened head fixation trunnion. Patient's head will then be released from fixation.

c) Remove patient from high level radiation area.

d) After removal of the patient from the treatment room, close the treatment door and secure the room.

e) The radiologist or physicist in charge shall immediately report to and request assistance from the radiation safety officer. All persons present inside the treatment room shall be under supervision of the radiation safety officer.

E) Contact Elekta Instruments for repair assistance.

6. Any repair requiring personriel to enter the treatment room while the shielding door is open shall be performed under the direct supervision of Elekta Instruments in consultation with the University of Virginia radiation safety officer.

IMPORTANT PHONE NUMBERS:

Elekta (Atlanta Office)

Radiation Safety office

Business

Home

Radiological physics 
1. If gOFER FAILURE occurs during irradiation, the couch wiIl automatically be withdrawn from the unit. The shielding door is then to be closed by manually shifting the SHIELDING DOOR CLOSURE lever on the hydraulic unit in the hydraulic room. closing of the shielding door is prevented by an interlock until the couch is fully removed. After closure of the shielding door, entry to the treatment room is allowed.

2. If HYDRAULIC PUMP FAILURE occurs during treatment, there is enough reserve pressure to complete the treatment and stop-treatment cycle. If regerve pressure is not enough, the operator shall enter the hydraulic room and re-establish pressure with the hand pump. If the hydraulic failure is due to an eleptrical failure. which affects the couch microswitches, the operator must also shift the SHIBLDING DOOR CLOSURE lever on the hydraulic unit after the patient couch has exited and before the shielding door can be closed by means of the hand pump. Assuming continued power to the control panel, however, the main controls will give information about status of the unit during hand pumping.

3. If there is not sufficient reserve pressure, the stop-treatment cycle is automatically initiated. The pressure level at which point the hydraulic pump is activated during the treatment cycle is sufficient to complete the stop-treatment cycle. In the event reserve pressure is not sufficient at any time during the treatment cycle and the pump fails to restore sufficient hydraulic reserve pressure within one minute, the stop-treatment cycle is automatically initiated.

4. If the hydraulic system fails and it is not possible to withdraw the couch and to close the shielding door with hand pumping, MANUAI REMOVAI OF PATIENT can be effected by the following means:

a) Enter the treatment room;

b) Rull out handle at foot end of couch;

c) Two persons have to retract the couch to the outermost position by manual force;

d) Remove patient from helmet fixation trunrions and bring him out of high level radiation area;

e) After removal of patient from the treatment room, close the treatment room door and secure the room;

f) Immediately report to and request assistance from the radiation safety officer;

g) Contact Elekta Instruments for repair assistance. 
ENERGENCY PROCEDURES (COntinued) LEKSELL GHMHA UNIT Page: 2

5. If the couch gets stuck in the radiation unit and it is not possible to withdraw it with hydraulic hand pumping or manual retraction, patient must be brought out manually from high level radiation area by the following means:
a) Loosen the bolt locking one or both head fixation trunnions with the special long Allen key (hanging on the treatment room wall);
b) Push out the loosened head.fixation trunnion. Patient's head will then be released from fixation;
c) Remove patient from high level radiation area;
d) After removal of the patient from the treatment room, close the treatment door and secure the room;
e) Immediately report to and request assistance from the radiation f) Contact Elekta Instruments for repair assistance.

6. Treatment may be terminated and the couch withdrawn at any time by hitting the TREATMENT STOP button on the control console or any of the 3 RED EMERGENCY STOP buttons located in the treatment room ( 2 buttons) and next to the control console ( 1 button). Motion of the couch may be completely stopped by hitting the EMERGENCY INTERRUPT button on the control console. The couch remains motionless until this button is hit again to relase.

7. The FLASHING YELIOF STROBE IIGHT is a warning that the patient couch has not fully retracted from the unit within approximately 90 secorids from treatment stop. In this case take action immediately to remove the patient.

8. Any repair requiring personnel to enter the treatment room while the shielding door is open shall be performed under the direct supervision of Elekta Instruments in consultation with the Hospital of the Good Samaritan radiation safety officer.

IMPORTANT PEONE NUMBERS

Elekta (Atlanta)

Radiation safety officer:

Consulting Medical Physicist: 


\section{EMERGENCY PROCEDURES}

A. Power fallure during treatment (reserve hydraulic pressure available) -couch is automatically removed from unit -authorized person closes shielding door on unit manually by shifting a "door - closure" lever on the hydraulic unit -if the power failure is momentary, treatment can be restarted, do NOT reset timers -if extended power failure, remove patient from fixation, call Radiation Oncology Physics.

\section{B. Hydraulic pump failure during irradiation}

i. full reserve pressure - continue treatment

ii. Low reserve pressure - authorized person shall initiate "stop-treatment" cycle -if there is also electrical failure, shift the "door closure" lever after the couch has exited the unit

-if the shielding door does not close completely, establish pressure with hand pump in hydraulic room

iii. minimal reserve pressure - "stop-treatment" cycle begins automatically

iv. no reserve pressure -

two individuals must manually remove the patient by the following means:

-enter treatment room

-pull out handle at foot end of couch

-retract couch with manual force

-remove patient from helmet fixation trunnions

-remove patient from room

-close door, secure area

-call Radiation Oncology Physics

v. no reserve pressure - couch stuck in unit

-enter treatment room

-loosen bolt locking one or both head fixation trunnions with the special long Allen key

-push out the loosened head fixation trunnion. Patients head is now released from fixation.

-remove patient from room

-close door, secure area

-call Radiation Oncology Physics and Radiation Safety

C. Radiation Monitor Alarms Other Than During Treatment Cycle

- immediately inspect status of shielding door.

i. if door is OPEN, remove all individuals

ii. call Radiation Oncology Physics and Radiation Safety

iii. if door is CLOSED, use survey meter to measure radiation level at location of room monitor (normal: $<0.1 \mathrm{mR} / \mathrm{h}$ ) and in front of shielding door at rear of helmet (normal: $<20 \mathrm{mR} / \mathrm{h}$ ). If measured radiation levels exceed expected values, remove all individuals from room, secure area, contact Radiation Oncology Physics and Radiation Safety. If measured levels are normal, suspect malfunction of radiation monitor. Contact Radiation Oncology Physics. 
Appendix D: Examples of Written Emergency Procedures

\section{SAFETY INSTRUCTIONS}

\section{OPERATION}

A. Before initiating treatment a visual inspection of the treatment room shall confirm that no one other than the patient is in the treatment room.

B. If the Emergency Interrupt is employed to stop couch motion and the patient must be attended to while the shielding door is open, those individuals entering the room shall limit their exposure by attention to the demarkation of the scatter radiation cone and minimizing time in the room, consistent with patient care.

C. If the couch motion has been stopped with the Emergency Interrupt and the treatment room entered, or if a door interlock interruption occurs, the operator shall confirm that no one other than the patient is in the treatment room before continuing treatment.

D. If treatment is stopped, manually or by power failure, the treatment times (elapsed and remaining) are preserved on the timers. If treatment is restarted, the timers are not to be reset.

E. Report immediately any abnormal unit operation to Radiation Oncology Physics.

Radiation Encolegy Physics 
APPENDIX E:

SAMPLE FACILITY TRAINING PROGRAM 
EXEIBIT VII

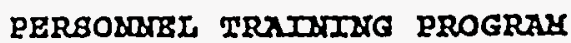

1. Schedule for Training

Training will be provided by: personnel from the Division of Radiological physics:

a. Before an employee assumes duties with or in the immediate vicinity of radioactive materials,

b. Annually as refresher training for all employees, and

c. Whenever a significant change occurs in duties, regulations, or the terms of the NRC Iicense.

2. Description of the Training Program

Training will be sufficient to ensure that:

a. Individuals who work in or frequent restricted areas are instructed in the items specified in $\$ 19.12$ of 10CFR Part 19, and

b. Individuals whose duties may require work in the immediate vicinity of radioactive materials are informed about radiation hazards and appropriate precautions.

3. Content of the Training Program

The program of instruction will include:

a. Pertinent terms and conditions of the NRC license, including procedures developed as a prerequisite for obtaining the license and commitments incorporated into the license by condition.

b. Appropriate response to emergencies or unsafe conditions, including participation by appropriate staff in "dry runs" of emergency procedures conducted as a part of the 
Inttial and annual refresher training.

c. Areas where radioactive material is used or stored.

d. Potential hazards associated with fadioactive material.

e. Radiological safety procedures appropriate to the duties of the employee.

f. Pertinent NRC regulations.

g. The obligation of all personnel to report unsafe conditions to the radiation safety officer.

h. The right of all personnel to be informed of radiation exposure and bioassay results.

i. The locations where the Iicensee has posted or made available notices, copies of regulations, and copies of pertinent licenses and license conditions (including applications and applicable correspondence) as required by 10CFR Part 19.

4. Records that Document Training

Records of initial and refresher training will be maintained by the Division of Radiological Physics until the NRC terminates the teletherapy license and will include:

a. The name of the individual who conducted the training,

b. The names of the individuals who received the training,

c. The dates and duration of the training session, and

d. Iist of the topics covered. 


\begin{tabular}{|c|c|}
\hline $\begin{array}{l}\text { U.S. NUCLEAR REGULATORY COMMISSION } \\
\text { BIBLIOGRAPHIC DATA SHEET } \\
\text { (See instructions on the reverse) }\end{array}$ & $\begin{array}{l}\text { 1. REPORT NUMBER } \\
\text { (Auslgnod by MRR. Add Vol, Supp., Rev., } \\
\text { and Addondum Numbers, , at any.) } \\
\text { NUREG/CR-6324 } \\
\text { UCRL-ID-120056 }\end{array}$ \\
\hline \multirow[t]{4}{*}{$\begin{array}{l}\text { 2. TITLE AND SUBTITLE } \\
\text { Quality Assurance for Gamma Knives }\end{array}$} & \\
\hline & 3. DATE REPORT PUBLISHED \\
\hline & \multirow{2}{*}{\begin{tabular}{|l|r|} 
MONTH & YEAR \\
September & 1995 \\
4. FIN OR GRANT NUMBER \\
L1938
\end{tabular}} \\
\hline & \\
\hline \multirow[t]{2}{*}{$\begin{array}{l}\text { 5. AUTHOR(S) } \\
\text { E. D. Jones, W. W. Banks, L. E. Fischer }\end{array}$} & $\begin{array}{l}\text { 6. TYPE OF REPORT } \\
\text { Technical }\end{array}$ \\
\hline & 7. PERIOD COVERED (Inclusive Dates) \\
\hline \multicolumn{2}{|c|}{$\begin{array}{l}\text { 8. PERFORMING ORGANIZATION - NAME AND ADDRESS (If NRC, provide DWision, Office or Region, U.S. Nuclear Regulatory Commission, and malling address; if contractor, provide } \\
\text { neme and melling gddressil }\end{array}$} \\
\hline \multicolumn{2}{|c|}{$\begin{array}{l}\text { Lawrence Livermore National Laboratory } \\
7000 \text { East Avenue } \\
\text { Livermore, CA } 94550\end{array}$} \\
\hline \multicolumn{2}{|c|}{$\begin{array}{l}\text { 8. SPONSOING ORGANIZATION - NAME AND ADDRESS IIINRC, ivpe "Same as above"; if contractor, provide NRC Division, Office or Reglon, U.S. Nuclear Regulatory Commission, } \\
\text { Division of Industrial and Medical Nuclear Safety } \\
\text { Office of Nuclear Material Safety and Safeguards } \\
\text { U.S. Nuclear Regulatory Commission } \\
\text { Washington, DC 20555-0001 }\end{array}$} \\
\hline \multicolumn{2}{|l|}{ 10. SUPPLEMENTARY NOTES } \\
\hline \multicolumn{2}{|c|}{$\begin{array}{l}\text { 11. ABSTRACT (200word or was) } \\
\text { This report describes and summarizes the results of a quality assurance (QÄ) } \\
\text { study of the Gamma Knife, a nuclear medical device used for the gamma } \\
\text { irradiation of intracranial lesions. The study's focus was on the physical } \\
\text { aspects of QA and did not address issues that are essentially medical, such as } \\
\text { patient selection or prescription of dose. A risk-based QA assessment } \\
\text { approach was used. In this report, sample programs for quality control and } \\
\text { assurance are included. The use of the Gamma Knife was found to conform to } \\
\text { existing standards and guidelines concerning radiation safety and quality } \\
\text { control of external beam therapies (shielding, safety reviews, radiation } \\
\text { surveys, interlock systems, exposure monitoring, good medical physics } \\
\text { practices, etc.) and to be compliant with NRC teletherapy regulations. There } \\
\text { are, however, current practices for the Gamma Knife not covered by existing, } \\
\text { formalized regulations, standards, or guidelines. These practices have been } \\
\text { adopted by Gamma Knife users and continue to be developed with further } \\
\text { experience. Some of these have appeared in publications or presentations and } \\
\text { are slowly finding their way into recommendations of professional } \\
\text { organizations. }\end{array}$} \\
\hline \multicolumn{2}{|l|}{ 12. KEY WORDS/DESCRIPTORS (LList words or phresess that will ass/st resoenchers in locating the report.) } \\
\hline \multirow[t]{3}{*}{$\begin{array}{ll}\text { quality assurance } & \text { quality management } \\
\text { regulation } & \text { standards } \\
\text { Gamma Knife } & \text { radiation therapy } \\
\text { nuclear medicine } & \text { medical } \\
\text { quality control } & \end{array}$} & $\begin{array}{l}\text { Unl imited } \\
\text { 14. SECURITY CLASSIFICATION } \\
\text { (This Pagel } \\
\text { Uncl assified } \\
\text { (This Repon) }\end{array}$ \\
\hline & \begin{tabular}{|l} 
Unclassified \\
15. NUMBER OF PAGES
\end{tabular} \\
\hline & 16. PRICE \\
\hline
\end{tabular}

